$$
\begin{gathered}
\text { UNIVERSIDADE DE BRASÍLIA } \\
\text { FACULDADE DE EDUCAÇÃO FÍSICA } \\
\text { PROGRAMA DE PÓS-GRADUAÇÃO STRICTO-SENSU EM } \\
\text { EDUCAÇÃO FíSICA }
\end{gathered}
$$

Efeito do treinamento neuromuscular na modulação do padrão de recrutamento reflexo elétrico evocado de unidades motoras em escolares praticantes de basquetebol

Gabriela Sartório Barbosa

Brasília

2016 


\title{
Efeito do treinamento neuromuscular na modulação do padrão de recrutamento reflexo elétrico evocado em escolares praticantes de basquetebol
}

GABRIELA SARTÓRIO BARBOSA

\begin{abstract}
Dissertação apresentada à Faculdade de Educação Física da Universidade de Brasília, como requisito para obtenção do grau de Mestre em Educação Física.
\end{abstract}

ORIENTADOR: PROF. DR. RINALDO ANDRÉ MEZZARANE

AUTORIZO A REPRODUÇÃO E DIVULGAÇÃO TOTAL OU PARCIAL DESTE TRABALHO, POR QUALQUER MEIO CONVENCIONAL OU ELETRÔNICO, PARA FINS DE ESTUDO E PESQUISA DESDE QUE CITADA A FONTE. 
Catalogado na publicação

Serviço de Biblioteca e Documentação

Faculdade de Educação Física da Universidade de Brasília

Ficha catalográfica elaborada automaticamente, com os dados fornecidos pelo(a) autor(a)

SG118p

Sartório Barbosa, Gabriela

Padrão de recrutamento de unidades motoras e mecanismos de modulação reflexa em escolares praticantes de basquetebol submetidos a um programa de treinamento proprioceptivo / Gabriela Sartório Barbosa; orientador Rinaldo André Mezzarane. -Brasilia, 2016. $143 \mathrm{p}$.

Dissertação (Mestrado - Mestrado em Educação Física) -- Universidade de Brasilia, 2016.

1. Plasticidade neuronal. 2. Reflexo H. 3. Ganho de recrutamento de unidades motoras. 4. Treinamento proprioceptivo. 5. inibição pré-sináptica. I. André Mezzarane, Rinaldo, orient. II. Título. 
Efeito do treinamento neuromuscular na modulação do padrão de recrutamento reflexo elétrico evocado em escolares praticantes de basquetebol

Gabriela Sartório Barbosa

\section{BANCA EXAMINADORA}

Prof. Dr. Rinaldo André Mezzarane

Prof $^{\mathrm{a}}$. Dra ${ }^{\mathrm{a}}$. Luciana Hagstrom Bex

Prof. Dr. Emerson Fachin Martins

Prof. Dr. Marcelino Monteiro de Andrade

Dissertação defendida e aprovada em:

2016. 


\section{SUMÁRIO}

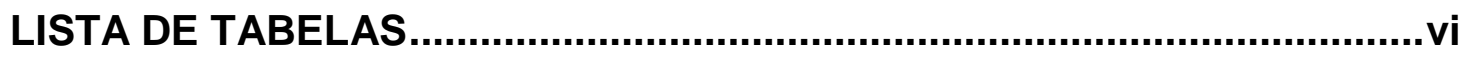

LISTA DE FIGURAS .........................................................................ii

LISTA DE SIGLAS, ABREVIAÇÕES E SÍMBOLOS ..................................

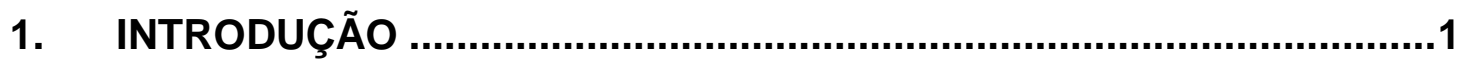

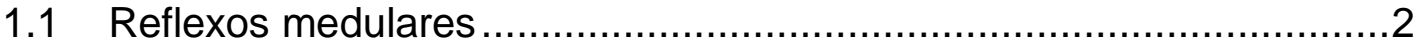

1.2 Impacto do treinamento neuromuscular no basquetebol......................4

1.3 Adaptações de jovens praticantes de basquetebol ao treinamento .....6

2. TÉCNICAS EMPREGADAS EM ESTUDOS NEUROFISIOLÓGICOS ...7

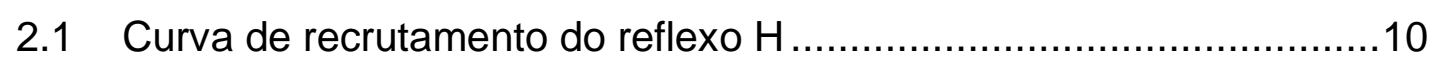

2.1.1 Parâmetros extraídos da curva de recrutamento ..........................16

2.2 O reflexo $\mathrm{H}$ e o estudo da inibição pré-sináptica.................................20

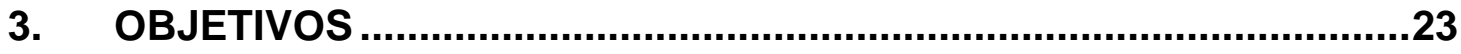

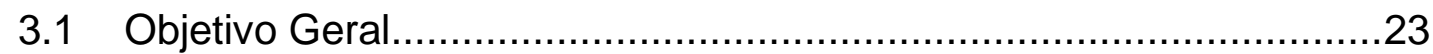

3.2 Objetivos Específicos ...............................................................24

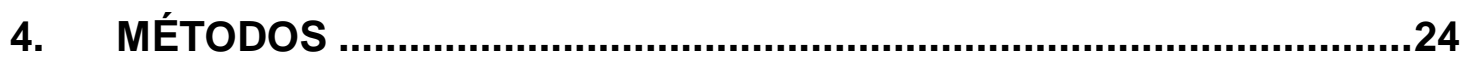

4.1 Coleta de dados ................................. Erro! Indicador não definido.

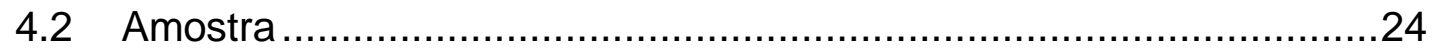

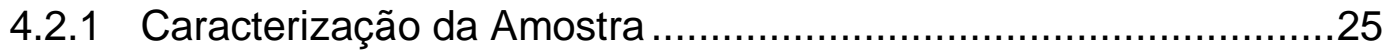

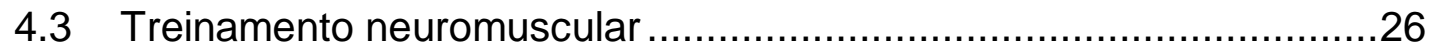

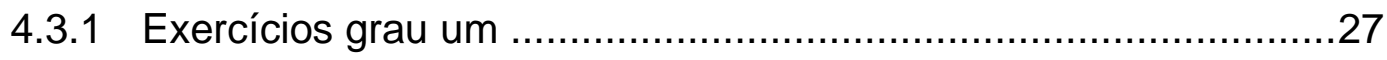

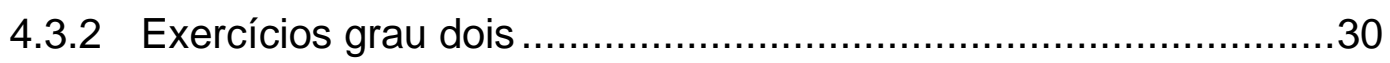

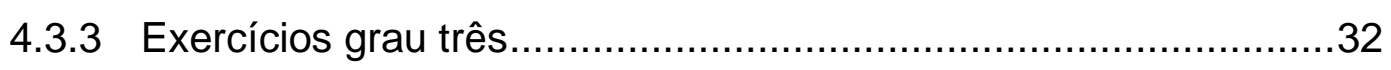

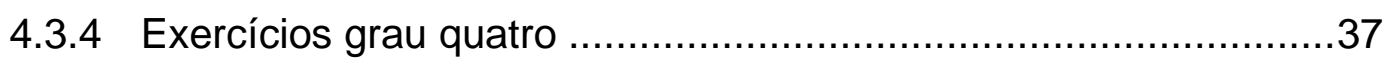

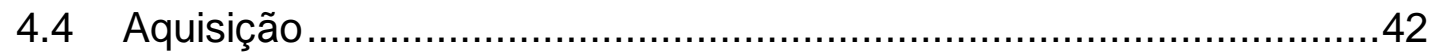

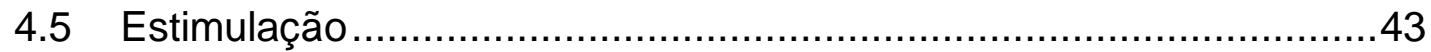

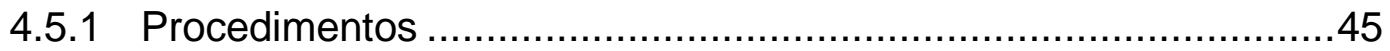

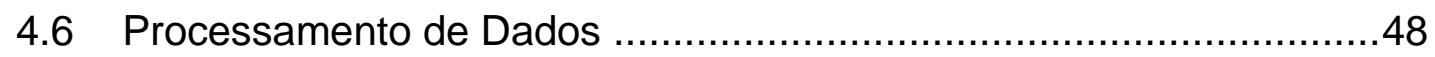

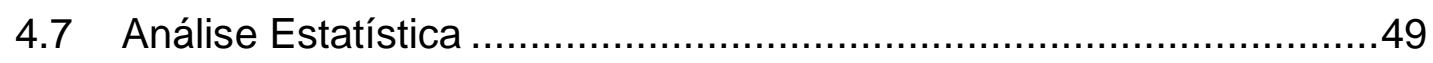

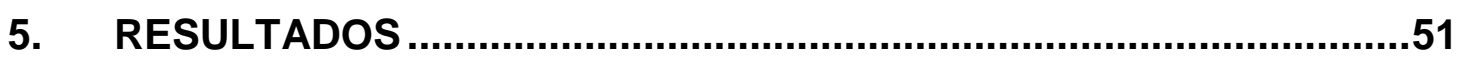

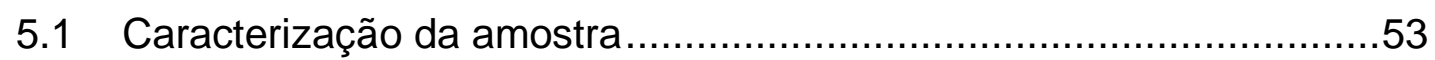

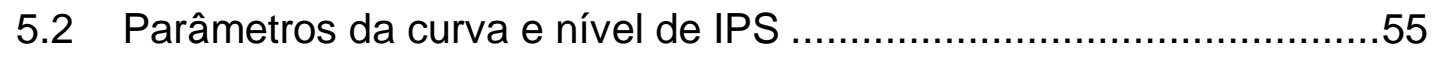

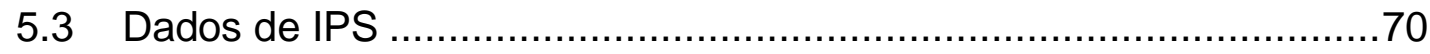

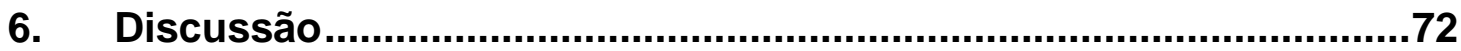


6.1 Efeitos do treinamento neuromuscular ...................................73

6.1.1 Especificidades do treinamento neuromuscular .......................77

6.2 Aspectos da modalidade Basquetebol .......................................78

6.3 Análise da plasticidade neuronal após treinamento de equilíbrio por meio da CR e medidas de inibição reflexa ............................................... 80

6.4 Aspectos metodológicos ..................................................... 84

6.4.1 Idade maturacional e plasticidade neuronal ............................84

6.4.2 Análise estatística ...........................................................88

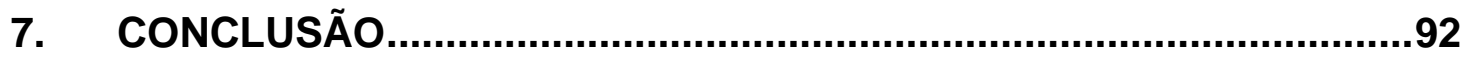

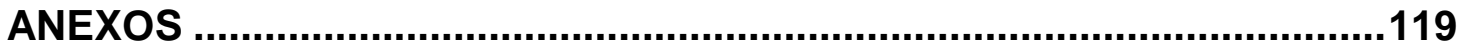

Anexo I - Termo de Assentimento Livre e Esclaredido ............................119

Anexo II - TERMO DE CONSENTIMENTO E LIVRE ESCLARECIMENTO

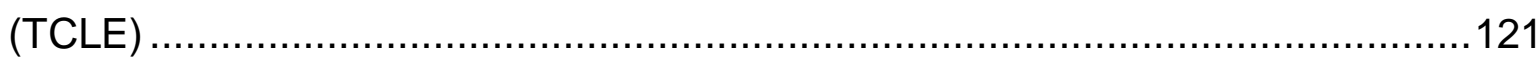

Anexo III - Parecer aprovado - Plataforma Brasil .............................. 124

Anexo IV - Questionário de Caracterização da Amostra ..........................126

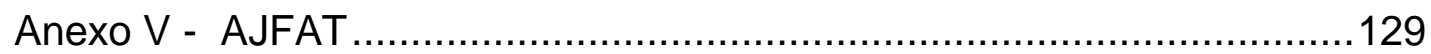

Anexo VI - IPAQ VERSÃO CURTA …............................................ 133

Anexo VII - Questionário adaptado do estudo de Bonetti e Coelho ...........136 


\section{LISTA DE TABELAS}

Tabela 1 - Resumo dos exercícios do Grau 1 de dificuldade. ........................30

Tabela 2 - Resumo dos exercícios do Grau 2 de dificuldade. ........................32

Tabela 3 - Resumo dos exercícios do Grau 3 de dificuldade. .........................36

Tabela 4 - Resumo dos exercícios do Grau 4 de dificuldade. .......................42

Tabela 5 - Descrição dos sujeitos analisados. ..............................................55

Tabela 6 - Valores $p$ do teste de normalidade Shapiro-Wilk..........................56

Tabela 7 - Valores $p$ do teste de normalidade Shapiro-Wilk para dados independentes de uma medida (diferença pós-pré). ..........................................58

Tabela 8 - Valores de significância para os dados de medidas repetidas. .....59

Tabela 9 - Valores de significância para os dados independentes.................63 


\section{LISTA DE FIGURAS}

Figura 1.1 - Esquema mostrando o reflexo de estiramento...............................

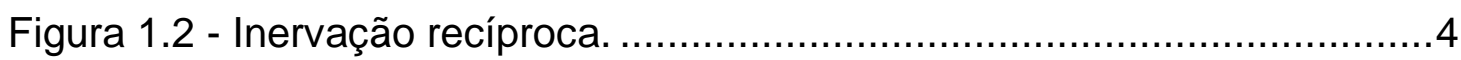

Figura 2.1 - Esquema ilustrando a técnica utilizada para a obtenção do reflexo H.

Figura 2.2 - Recrutamento das UMs em resposta ao aumento progressivo da intensidade de estímulo.

Figura 2.3 - Ativação das fibras sensoriais e motoras responsáveis pela geração do reflexo $\mathrm{H}$ e da onda $\mathrm{M}$. .13

Figura 2.4 - Curvas de recrutamento obtidas do músculo soleus...................15

Figura 2.5 - Ajuste sigmoidal do reflexo $\mathrm{H}$............................................18

Figura 2.6 - llustração mostrando o mecanismo de inibitição pré-sinaptica....21

Figura 2.7 - Representação de influências descendentes e periféricas na IPS.

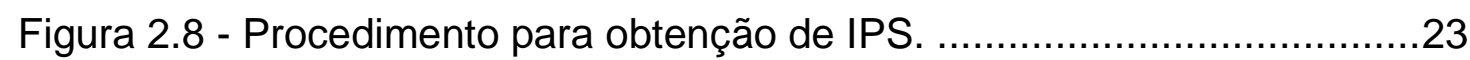

Figura 4.1 - Primeira etapa do exercício dois do Grau 1 .............................28

Figura 4.2 - Segunda etapa do exercício dois do Grau 1 . ..........................28

Figura 4.3 - Exercícios três e quatro do Grau 1............................................29

Figura 4.4 - Resumo dos exercícios do Grau 1 de dificuldade. .....................29

Figura 4.5 - Primeira e segunda etapa do exercício um do Grau 2. ..............31

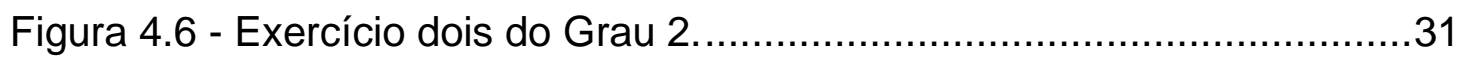

Figura 4.7 - Resumo dos exercícios do Grau 2 de dificuldade. .....................32

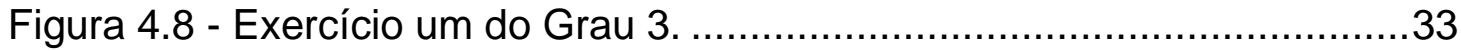

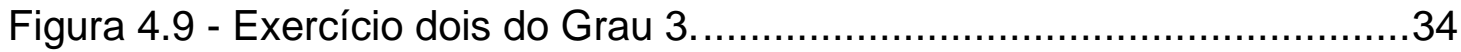

Figura 4.10 - Exercícios 3 e 4 do grau três. ...............................................34

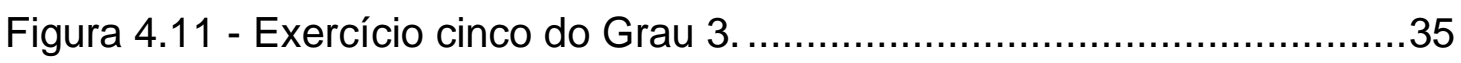

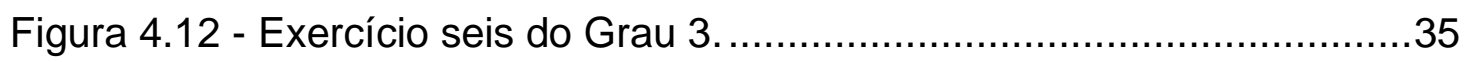

Figura 4.13 - Resumo dos exercícios do Grau 3 de dificuldade...................36

Figura 4.14 - Exercício um do Grau 4 ....................................................

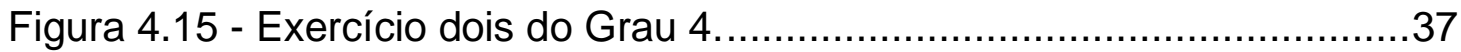

Figura 4.16 - Exercício três do Grau 4.................................................38

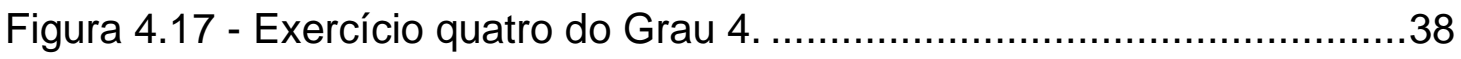

Figura 4.18 - Exercício cinco do Grau 4.................................................39 
Figura 4.19 - Exercício seis do Grau 4.................................................. 40

Figura 4.20 - Exercício sete do Grau 4. .................................................40

Figura 4.21 - Exercício oito do Grau 4. ...................................................... 41

Figura 4.22 - Exercício nove do Grau 4 ....................................................41

Figura 4.23 - Resumo dos exercícios do Grau 4 de dificuldade. ....................42

Figura 4.24 - Modelo dos eletrodos de superfície. ......................................43

Figura 4.25 - Equipamento Nihon-Kohden do Laboratório de Processamento de Sinas Biológicos e Controle Motor da Faculdade de Educação Fìsica da Universidade de Brasília (UnB).

Figura 4.26 - Controle individual de coletas de dados diagramado para cada sujeito.

Figura 4.27 - Estrutura para fixação dos pés. .46

Figura 4.28 - Trigger desenvolvido em Arduino Uno com respectivo algoritmo.

Figura 5.1 - Média e desvio padrão das variáveis com Tamanho do Efeito intermediário.

Figura 5.2 - Média e desvio padrão das variáveis que apresentam interação entre grupo e momento.

Figura 5.3 - Curva de recrutamento do reflexo $\mathrm{H}$ (azul) e da onda $\mathrm{M}$ (vermelho).

Figura 5.4 - Sinais eletromiográficos mostrando as ondas $\mathrm{M}$ e os reflexos $\mathrm{H}$ de um sujeito do GC. Estão superimpostos 50 sinais evocados com diferentes intensidades de estímulo e cores.

Figura 5.5 - Os mesmos dados apresentados na Figura 5.4 com os valores de amplitude e corrente normalizados pela onda Mmax e pela corrente necessária para se obter $50 \%$ da onda Mmax, respectivamente. As retas verticais em magenta indicam os limites para o ajuste sigmoide.

Figura 5.6 - Novamente, os mesmos valores de amplitude, agora com os ajustes sigmoidais na alça ascendente do reflexo $\mathrm{H}$ (em magenta) e na curva de recrutamento da onda $M$ (em verde). As retas de regressão (para fornecer $O$ parâmetro slope) estão indicadas com linhas pontilhadas.

Figura 5.7 - Detalhe da região demarcada com um retangulo preto na Figura 5.6 .

Figura 5.8 - Exemplo de ajuste sigmoidal pré e pós-intervenção da alça ascendente da curva de recrutamento do reflexo $\mathrm{H}$ de um dos sujeitos do GC........68 
Figura 5.9 - Detalhe ampliado da Figura 5.8 mostrando o H@th (losango amarelo), H@50 (losango preto) e H@100 (losango azul).... 69

Figura 5.10 - Exemplo de ajuste sigmoidal pré e pós-intervenção da alça ascendente da curva de recrutamento do reflexo $\mathrm{H}$ de um do GE. .70

Figura 5.11 - Detalhe ampliado da Figura 5.10 mostrando o H@th (losango azul), H@50 (losango verde) e H@100 (losango amarelo). .70

Figura 5.12 - Registros de EMG mostrando reflexo $\mathrm{H}$, onda $\mathrm{M}$ e artefato de estímulo. .71 


\section{LISTA DE SIGLAS, ABREVIAÇÕES E SÍMBOLOS}

$\begin{array}{ll}\text { AJFAT } & \text { Questionário - Ankle Joint Functional Assessment Tool } \\ \text { ANOVA } & \text { Análise de variância } \\ \text { CEMEIT } & \text { Centro de Ensino Médio da Escola Industrial de Taguatinga } \\ \text { CID } & \text { Centro de Iniciação Desportiva } \\ \text { CMAP } & \text { Potenciais de ação musculares compostos } \\ \text { CR } & \text { Curva de recrutamento } \\ \text { C-T } & \text { Paradigma condicionante- teste } \\ \text { Diff } & \text { Diferença entre as variáveis } \\ \text { EMG } & \text { Eletromiografia } \\ \text { FF } & \text { MNs que inervam fibras musculares tipo llb de contração rápida } \\ \text { e fadigáveis } & \\ \text { FNP } & \text { Facilitação neuromuscular proprioceptiva } \\ \text { FR } & \text { MNs que inervam fibras musculares tipo lla de contração rápida } \\ \text { e resistentes a fadiga } \\ \text { Hmax } & \text { Resposta reflexa máxima } \\ \text { IMC } & \text { Indicie de Massa corporal } \\ \text { IPAQ } & \text { Questionário Internacional de Atividade Física } \\ \text { IPS } & \text { Inibição Pré-Sináptica } \\ \text { IR } & \text { Inibição Recíproca } \\ \text { Mmax } & \text { Resposta motora máxima } \\ \text { MI } & \text { Membros inferiores. } \\ \text { MN } & \text { Moto Neurônios Espinhais } \\ \text { PA } & \text { Potencial de ação } \\ \text { Pool } & \text { Conjunto de Moto neurônios } \\ \text { S } & \text { MNs que inervam fibras musculares tipo I de contração lenta } \\ \text { SNC } & \text { Sistema Nervoso Central } \\ \text { SO } & \text { Músculo Sóleos } \\ \text { TA } & \text { Músculo Tibial Anterior } \\ \text { TALE } & \text { Termo de assentimento livre esclarecido } \\ \text { TCLE } & \text { Termo de consentimento livre esclarecido } \\ \text { UM } & \text { Unidades Motoras } \\ \text { la } & \text { Fibras aferentes intrafusais } \\ \text { Ila } & \text { Fibras musculares inervadas por motoneurônios tipo FR } \\ \text { IIb } & \text { Fibras musculares inervadas por motoneurônios tipo FF } \\ & \end{array}$




\section{RESUMO}

Introdução: A excitabilidade da via reflexa pode ser alterada em virtude de adaptações resultantes do treinamento neuromuscular. O objetivo do presente trabalho foi avaliar o efeito do treinamento neuromuscular na modulação do padrão de recrutamento reflexo evocado eletricamente, em escolares praticantes de basquetebol. Métodos: Ensaio clínico clássico randomizado e controlado com amostra recrutada por conveniência em centro de iniciação desportiva. A amostra foi constituída por 29 escolares saudáveis ( 14 anos) praticantes de basquetebol, divididos aleatoriamente em dois grupos: grupo experimental (GE: $n=14$ ) e grupo controle (GC: $n=15)$. As alterações nos padrões de recrutamento de unidades motoras (UM) foram observadas a partir da curva de recrutamento (CR) do reflexo $\mathrm{H}$. O grau de inibição pré-sináptica (IPS) foi avaliado pelo paradigma condicionanteteste (C-T). O treino neuromuscular teve duração de 8 semanas. A análise estatística dos dados estudados foi realizada por meio do software livre R. O efeito do treinamento neuromuscular sobre as variáveis foi verificado através de uma ANOVA mista com 2 fatores e medidas repetidas e ANOVA não paramétrica de 2 fatores e medidas repetidas, considerando a intervenção como efeito entreindivíduos e entre os momento (pré e pós-intervenção) como efeito intra-indivíduo. A comparação entre os grupos com dados de medidas únicas foi feita pelo teste t não pareado ou pelo teste $U$ de Mann-Whitney, a depender da normalidade dos dados. Além das análises baseadas no teste de hipóteses, o tamanho do efeito foi calculado para dados de distribuição normal ( $d$ de Cohen) e não normal (delta de Cliff). A normalidade foi verificada pelo teste de Shapiro-Wilk. Resultados: A variável SlopeH (delta Cliff=0,469) aumentou no GE indicando que houve diminuição na variabilidade dos limiares de ativação dos motoneurônios, logo um aumento no ganho reflexo de recrutamento de UM após o treinamento. A variável H@th (delta Cliff=0,367) aumentou no GE indicando alterações na relação estímulo-resposta reflexa das unidades motoras menores após o treino. A variável Mmax não sofreu alteração, mas a SlopeM $(\delta=0,357 ; P=0,035)$ reduziu para o $G$. Isso pode ser consequência de alterações nas características de recrutamento dos axônios motores para estímulo elétrico externo. Apesar da literatura sugerir aumento da IPS em resposta ao treinamento neuromuscular, o Grau IPS não foi alterado no presente estudo. O Percentual de Gordura (\%G), diminuiu significativamente $(p=0,030)$, porém o tamanho do efeito foi muito pequeno $(\delta=-0,240)$. Conclusão: Os dados 
eletrofisiológicos sugerem que o treino neuromuscular induziu plasticidade na excitabilidade reflexa medular, refletida no aumento do ganho de recrutamento de UM e maior efetividade da relação estímulo-resposta das UM menores. Logo, o treinamento facilitou a resposta do sistema neuromuscular para movimentos que utilizem fibras do tipo $\mathrm{S}$, resistentes à fadiga.

Palavras-chaves: plasticidade neuronal, reflexo $\mathrm{H}$, ganho de recrutamento de unidades motoras, treinamento neuromuscular, medula espinhal, inibição présináptica, basquetebol. 


\section{ABSTRACT}

Introduction: The excitability of reflex pathway changes according to adjustments resulting from the balance training. The aim of this study was to evaluate the effect of a balance training program on the pattern of recruitment of motor units andas well as the excitability of the modulatory mechanisms of spinal reflexes in school basketball players during rest. Method: A sample of 29 healthy young ( 14 years) basketball players was randomly divided into 2 groups: experimental group (EG: $n=14$ ) and control group (CG: $n=15$ ). Patterns of $M U$ recruitment and the level of the PSI (evaluated through the C-T paradigm) were evaluated before and after the intervention. Statistical analyzes were performed by the freeware "R". The effect of balance training on the variables was verified by a mixed ANOVA and nonparametric ANOVA, both with 2 factors and repeated measures and considering the intervention effect as between subjects and the time as within subjects. The comparison between groups was made by unpaired t test or $U$ Mann-Whitney test, depending on the normality of the data. Besides the conventional hypothesis testing, the effect size was calculated for normal (d Cohen) and not normal (delta Cliff) distribution data. Normality was verified by the Shapiro-Wilk test. Results: The SlopeH variable increased in GE (delta $\mathrm{Cliff}=0.469$ ) indicating a decrease in the variability of membrane thresholds for $\mathrm{MN}$ activation, hence, an increased recruitment gain of UM after training. The variable H@th increased in GE (delta Cliff $=0.367$ ) indicating changes in stimulus-response relationship, i.e., the same relative low intensity current released in the pre training condition produced a greater amplitude response in the post training condition. The variable Mmax did not change, but the Slope $M$ reduced to $G C$ (Cliff= $0.357 ; P=0.035$ ). This may result from changes in recruitment characteristics of motor axons for external stimulus. Although the literature indicates increased PSI after a training protocol, the level of PSI in the present study did not change. Conclusion: The proprioceptive training induced plasticity in the spinal cord: decrease in the variability of MNs membrane potentials, increase in MU gain recruitment and more effective relationship stimulus-response in the threshold for the smaller MU.

Key words: neuronal plasticity, spinal cord, $\mathrm{H}$ reflex, recruitment gain of motor units, proprioceptive training, presynaptic inhibition, basketball. 


\section{INTRODUÇÃO}

O reflexo de estiramento é fundamental para o controle do tônus muscular em diferentes contextos motores, garantindo eficiência na execução dos movimentos e protegendo estruturas como músculos e articulações contra potenciais lesões. A excitabilidade da via reflexa pode ser alterada por meio de treinamento. Vários estudos têm demonstrado que regimes de treinamento que submetem o indivíduo a condições que desafiam a estabilidade postural diminuem a incidência de lesões articulares durante a prática esportiva. Contudo, os mecanismos neurofisiológicos responsáveis por estas adaptações ainda são pouco conhecidos.

Neste projeto, pretende-se estudar os efeitos do treinamento neuromuscular sobre uma via inibitória que controla o ganho da via do reflexo de estiramento (a inibição pré-sináptica). Além do interesse em mecanismos de modulação reflexa, um objetivo adicional é investigar o padrão de recrutamento reflexo das unidades motoras (que consiste no conjunto constituído pelo motoneurônio e as fibras musculares que este inerva) por meio de alterações na intensidade de um estímulo externo (que consiste na ativação elétrica das aferentes do fuso neuromuscular).

Apesar de ser um recrutamento artificial (não fisiológico) as informações obtidas por este procedimento experimental podem ser úteis para enriquecer o entendimento da neurofisiologia do controle motor e suas adaptações à diferentes condições e/ou intervenções (como o treinamento neuromuscular, por exemplo).

O interesse neste tipo de intervenção é a alegação de uma alteração no ganho na estabilidade corporal obtida após o treinamento (ZECH et al., 2010), especialmente para a musculatura em torno da articulação do tornozelo. Esta alteração aumenta a eficiência da integração sensóriomotora, resultando em um controle motor mais preciso em diferentes contextos motores. Desta forma, medidas reflexas de um músculo postural (soleus), como as atualmente propostas (curva de recrutamento do reflexo H), são altamente recomendáveis na avaliação das possíveis alterações da resposta desencadeada por vias proprioceptivas e processos neuronais decorrentes do treinamento. 


\subsection{Reflexos medulares}

Os reflexos medulares, além de participarem na proteção contra estímulos nocivos do ambiente, cumprem outras funções. Os circuitos neuronais envolvidos nestas vias reflexas participam no controle e na coordenação de movimentos voluntários, e também na manutenção da estabilidade corpórea. Isto justifica o alto contingente de fibras provenientes dos centros superiores que fazem contato com os diferentes elementos medulares (interneurônios, motoneurônios e terminais sensoriais). $O$ fato de haver influências suprasegmentares (tratos descendentes), segmentares (interneurônios proprioespinhais) e periféricas (aferentes cutâneas, musculares e articulares) sobre os neurônios da medula, reforça o importante papel desta última na integração de sinais provenientes de diferentes fontes, contrastando com a noção equivocada de que a medula é apenas uma "via de passagem" de informação proveniente dos centros superiores (MEZZARANE et al., 2013).

O reflexo de estiramento, por exemplo, tem basicamente a função de resistir ao alongamento muscular promovendo uma tensão basal no músculo. Essa tensão, ou estado parcial de contração constante dos músculos durante o repouso, é conhecida como tônus muscular e, além de manter o comprimento do músculo em um valor desejável, estabiliza a articulação durante a execução de diferentes tarefas motoras. Contudo a via do reflexo de estiramento não é restrita ou dedicada à apenas uma função. Seu papel no controle motor é de grande importância na execução coordenada dos movimentos.

O reflexo de estiramento é essencial para que as ações entre músculos agonistas e antagonistas ocorram de forma coordenada (Figura 1.1). A inervação recíproca entre músculos agonistas e antagonistas permite um controle local em torno da articulação (Figura 1.2). Contudo, o padrão de conectividade dos neurônios interpostos nesta via não determina apenas uma ação específica, ou seja, ativação do agonista e inibição do antagonista. Dependendo da tarefa a ser executada, esta relação entre os músculos (ou grupos musculares) pode mudar, graças a mecanismos medulares controlados por estruturas suprassegmentares. 


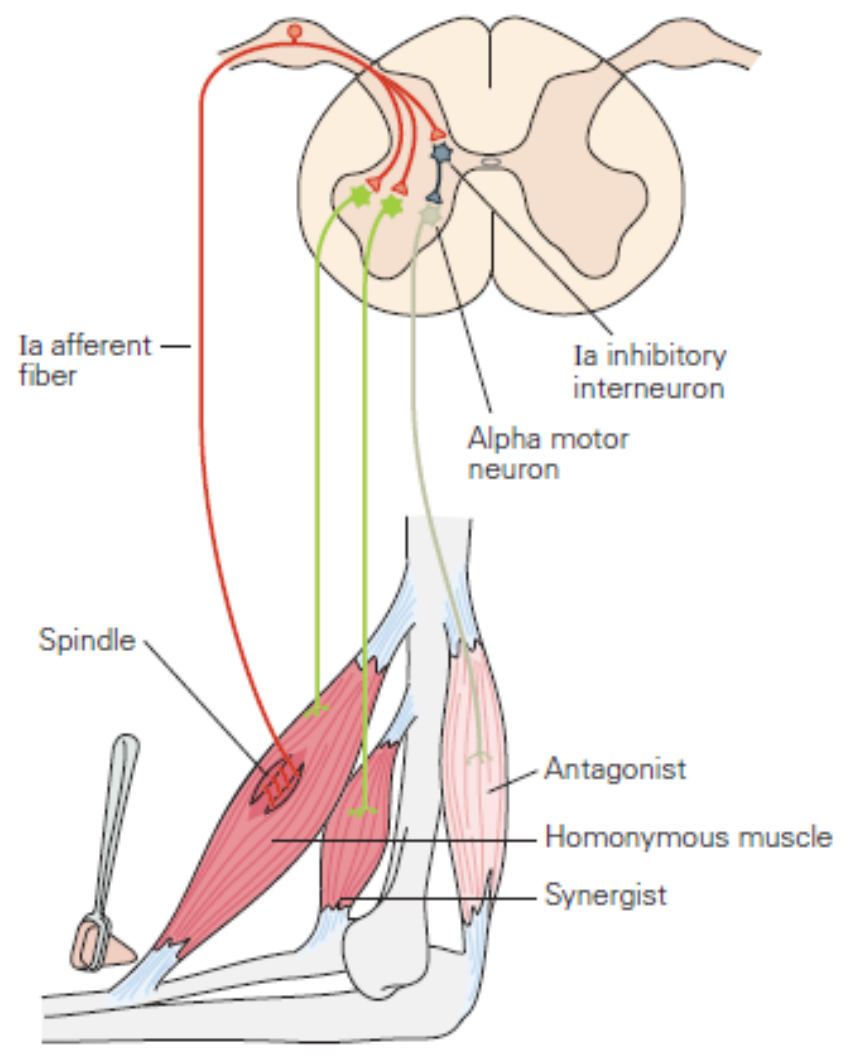

Figura 1.1 - Esquema mostrando o reflexo de estiramento.

Esquema mostrando o reflexo de estiramento com os neurônios sensoriais (fibras la), motoneurônios alfa e interneurônio inibitório (la) com suas conexões e músculos inervados. Esses neurônios sensoriais fazem conexões excitatórias monosinápticas com (1) os neurônios motores alfa no corno anterior da medula espinhal, que por sua vez inervam o mesmo músculo (homônimo), e com (2) os neurônios do circuito local, fazendo conexões inibitórias com os neurônios motores alfa que inervam músculos antagonistas (heterônimos). Conhecido como inervação recíproca, esse arranjo resulta em contração rápida do músculo estirado e relaxamento do simultâneo músculo antagonista (KANDEL et al., 2013). 


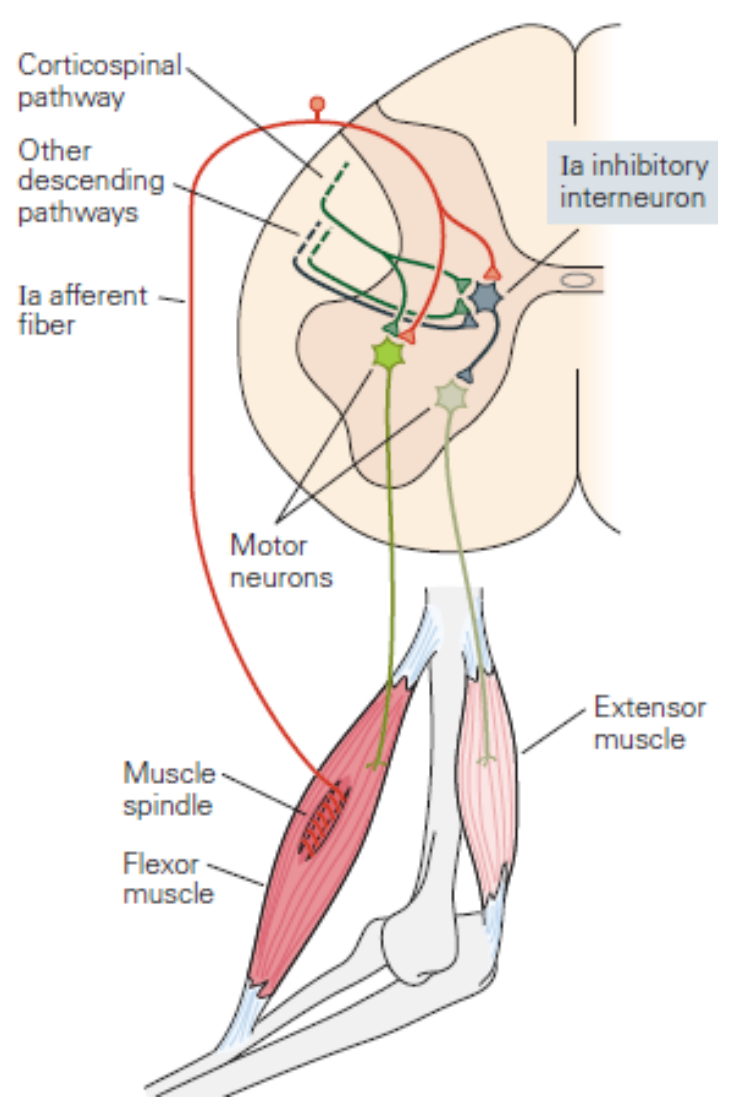

Figura 1.2 - Inervação recíproca.

A inervação recíproca está representada pela conexão feita pelo neurônio sensorial (fibras la) junto aos motoneurônios da musculatura agonista e aos interneurônios inibitórios la, cuja a função é inibir os motoneurônios alfa que inervam a musculatura antagonista (KANDEL et al.,2013).

Este fato evidencia a versatilidade dos circuitos medulares em controlar ações motoras diversas envolvidas em movimentos rítmicos e/ou voluntários.

Para melhor entender o papel do reflexo de estiramento é preciso avaliar os mecanismos que regulam sua excitabilidade. Estes mecanismos podem ter o seu funcionamento alterado em virtude de adaptações resultantes do treinamento neuromuscular, ainda pouco exploradas na literatura.

\subsection{Impacto do treinamento neuromuscular no basquetebol}

Para John, Powell e Barber-Foss (1999), treinamentos neuromusculares proprioceptivos (FNP) têm como objetivo melhorar o controle neuromuscular, aumentando assim a estabilidade articular funcional. Além disso, esses treinamentos podem reduzir o tempo da resposta muscular 
dos atletas e, possivelmente, alterar mecanismos de ativação muscular em diferentes demandas.

O basquetebol é um esporte bem difundido mundialmente (SILVA et al.,2007) com aproximadamente 300 milhões de praticantes (MELLO \& PARADA, 2002). Esse esporte é caracterizado por movimentos básicos como saltos, aterrissagens, corrida, aceleração, desaceleração, mudanças de direção e pivoteios, que fazem o basquetebol potencialmente lesivo (CHENG et al.,2000). A alta incidência de lesões em diferentes regiões corporais, sendo a região lombar e as articulações dos membros inferiores as mais comprometidas (BACKX et al.,1991), surge como consequência da frequência desses movimentos aliada ao contato físico entre jogadores característico da prática (ACQUESTA et al., 2007). Estas lesões são também associadas ao desequilíbrio físico e biomecânico, como desalinhamentos posturais (GANTUS \& ASSUMPÇÃO, 2002; PASTRE et al., 2007). Segundo De Rose et al. (2006), a ausência de um programa preventivo para a estabilidade articular também é uma das causas de lesões. Foi verificado que o basquetebol é uma modalidade esportiva cuja maior carga de trabalho aparece nos membros inferiores dos praticantes. Entre as lesões mais frequentes dos membros inferiores prevalecem as lesões nas articulações de tornozelo e joelho (MEEUWISSE et al.,2013), sendo o entorse do tornozelo por inversão a mais comum (MCKAY et al.,2001; FU et al.,2005).

Sugere-se, portanto, que os treinos neuromusculares possam aumentar a eficiência na resposta do sistema somatosensorial auxiliando na manutenção do equilíbrio (GAUCHARD et al.,1999). Willems et al. (2005) comentam que a manutenção ineficiente do equilíbrio postural está associada ao risco de entorse do tornozelo em inversão. Desta forma, exercícios neuromusculares deveriam ser incluídos nos treinamentos de diversas modalidades esportivas, inclusive no basquetebol.

Melhoras funcionais são amplamente discutidas em associação às adaptações nos mecanismos de controle neuromuscular (como a propriocepção) resultantes de exercícios de equilíbrio (ZECH et al., 2010). Uma melhora na propriocepção, e, consequentemente, no controle neuromuscular do indivíduo lesado minimiza o risco de reincidência da lesão, restaurando a consciência sinestésica (LEPHART et al., 2002). 
Neste contexto, técnicas eletrofisiológicas permitem avaliar, por exemplo, o padrão de recrutamento de unidades motoras (UMs) de músculos posturais, com vistas a elucidar o papel de mecanismos medulares atuantes no controle da ativação muscular. Estudos que utilizam essas técnicas contribuem para o melhor entendimento da neurofisiologia da medula espinhal, especificamente, para descrever os mecanismos envolvidos na plasticidade neuronal, fornecendo elementos para caracterizar as adaptações da integração sensório-motora pós-treinamento.

\subsection{Adaptações de jovens praticantes de basquetebol ao treinamento}

A prática de atividade física é fundamental na adolescência por ser um período marcado por diversas mudanças corporais. As fases de desenvolvimento que englobam a pré-adolescência e a adolescência caracterizam-se por apresentarem diversas adaptações e ajustes posturais. Essas mudanças são decorrentes do processo de crescimento e podem ser influenciadas pelo treinamento esportivo (GUIMARÃES \& SACCO, 2007). O estudo longitudinal de associação entre desempenho motor e maturação biológica demonstrou que quanto menor a idade ou nível maturacional, maior é o desempenho em equilíbrio ao comparar crianças e adolescentes entre oito e 16 anos (FREITAS et al. 2003).

Devido à imaturidade das estruturas musculoesqueléticas, jogadores adolescentes de basquetebol federados podem gerar compensações biomecânicas, pois estão sujeitos às altas exigências físicas. Apesar de serem adaptáveis no início, as compensações posturais podem se tornar permanentes e predispor esses jovens atletas à lesões (GUEDES \& JOÃO, 2014). Além disso, as exigências de treinamentos repetitivos e intensos em esportes de alto rendimento geram hipertrofia muscular e redução da flexibilidade, o que pode gerar um desequilíbrio na coordenação das musculaturas agonista e antagonista, provocando dores e lesões (KLEINPAUL, MANN \& DOS SANTOS, 2010), caso um trabalho de alongamento e flexibilidade não seja realizado

Estudos sobre a aquisição e desenvolvimento de habilidades motoras e sua relação com adaptações neurofisiológicas são ainda escassos em crianças e adolescentes. Kawaishi \& Kazuhisa (2015) sugerem que a 
capacidade para modular a excitabilidade do reflexo de estiramento monossináptico em resposta a uma mudança de postura é um fator significativo para o equilíbrio dinâmico. Segundo Myklebust (1990), embora o mecanismo do reflexo miotático seja bem conhecido, a utilidade desta resposta reflexa na identificação de mecanismos de controle postural e de movimento permanece indefinida.

Ao comparar o controle do equilíbrio estático e dinâmico entre modalidades esportivas, Bressel et al. (2007) verificaram que os praticantes de basquete escolar possuem menor equilíbrio estático do que os praticantes de ginástica. Os jogadores de basquete do ensino médio que apresentaram desequilíbrio durante 0 teste estrela apresentaram fatores de risco para lesões nos membros inferiores (PLISKY,2006). Mcguine et al. (2006) propõem o programa de treinamento de equilíbrio aos atletas de basquetebol escolar, afim de reduzir a incidência de entorse de tornozelo e os custos com despesas médicas. Uma explicação para a prevalência de lesão no tornozelo nesta população seria a grande oscilação postural desses jogadores verificada durante teste de equilíbrio em posição uni podal (WANG et al., 2006). A sugestão proposta pelos autores seria um treino de equilíbrio antes da sessão de treino de basquete.

Para distinguir se as mudanças no equilíbrio são geradas pelas adaptações ao treinamento ou a diferenças maturacionais do indivíduo, testes de maturação biológica precisam ser aplicados. Existem atualmente testes realizados de forma direta (Tanner- Whitehouse Mark II) (FREITAS et al., 2003) ou indireta (prancha de Tanner) (PINTO JR, de SOUSA e GAYA, 2012), e parte das inferências relacionadas às aptidões físicas partem de testes funcionais acessíveis, como Eurofit. Porém, há necessidade de medidas de avaliação direta mais específicas para cada aptidão explorada e justificada. As inferências relacionadas às mudanças fisiológicas neuronais podem partir de análises fisiológicas diversas, como 0 padrão de recrutamento de unidades motoras (UM) e o nível de excitabilidade reflexa.

\section{TÉCNICAS EMPREGADAS EM ESTUDOS NEUROFISIOLÓGICOS}


Muitas técnicas foram desenvolvidas nas últimas cinco décadas visando aperfeiçoar o estudo do sistema motor humano, como a eletromiografia, a estimulação transcortical e os potenciais evocados. Particularmente, a reflexologia tem sido de grande utilidade, pois envolve técnicas não invasivas (como o reflexo $\mathrm{H}$ ) para estudar a circuitaria da medula espinhal humana. Por meio destas técnicas, é possível estudar a interação entre os diferentes elementos medulares e fazer um paralelo com os resultados obtidos em animais (HULTBORN \& NIELSEN, 2007; MEZZARANE et al., 2012).

O reflexo $\mathrm{H}$, designação dada por Magladery \& Mcdougal (1950) em homenagem a Paul Hoffmann (quem primeiro o descreveu em 1918), é um homólogo do reflexo de estiramento muscular. Porém, é evocado eletricamente. Este sinal mioelétrico é extensivamente utilizado em estudos da neurofisiologia da medula espinhal em humanos, pois torna possível a avaliação do grau de excitabilidade da via do reflexo de estiramento. Adicionalmente, permite o estudo de vias inibitórias da medula como as de Inibição Recíproca (IR) e Inibição Pré-Sináptica (IPS), ambas intermediadas por diferentes tipos de interneurônios (glicinérgicos e GABAérgicos, respectivamente), abrindo também a possibilidade de realizar estudos farmacológicos para fins clínicos.

A técnica do reflexo $\mathrm{H}$ possibilita um estudo não invasivo da interação mútua entre os elementos medulares no repouso, durante a execução de tarefas (marcha, manutenção da postura ortostática, execução de um movimento voluntário, etc) ou sob condicionamento por diferentes estímulos externos (elétricos, mecânicos, perturbações na postura, entre outros) (PIERROT-DESEILLIGNY \& BURKE, 2012). É também uma ferramenta útil para a clínica neurológica, pois permite a avaliação do estado dos circuitos neuronais em pacientes com lesões medulares ou outras neuropatias.

$\mathrm{O}$ reflexo $\mathrm{H}$ pode ser obtido em um dado músculo pela estimulação elétrica do nervo periférico que o inerva, disparando de maneira seletiva as aferentes sensoriais la, que se originam nos fusos neuromusculares e que fazem sinapse com os motoneurônios ( $\mathrm{MN \alpha}$ ) na medula (Figura 2.1). Os potenciais de ação (PA) gerados nos $\mathrm{MN \alpha}$ se propagam pelos axônios 
eferentes até o músculo, provocando a despolarização das fibras musculares via junções neuromusculares, com o consequente disparo de PA nas fibras musculares. As correntes geradas por estes PA causam pequenas ondas de potenciais captados à distância por eletrodos de eletromiografia de superfície localizados sobre o músculo. O reflexo $\mathrm{H}$ é, portanto, um potencial de ação composto muscular (ou CMAP, do inglês, Compound Muscle Action Potential) captado à distância, ou seja, é a soma dos potenciais de várias unidades motoras (MUPs) que são disparadas ao mesmo tempo, diferente do padrão de interferência do eletromiograma (EMG) que é caracterizado pelo disparo assíncrono de várias unidades motoras em resposta à ativação voluntária.

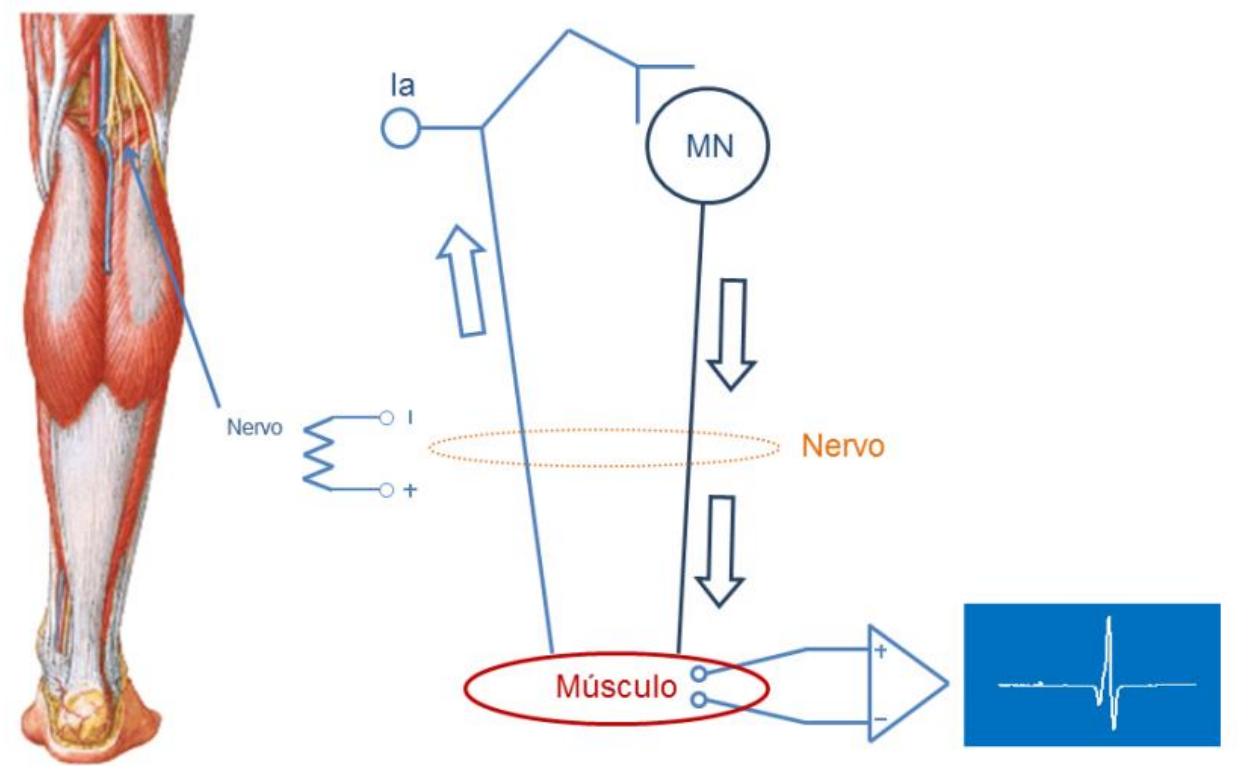

Figura 2.1 - Esquema ilustrando a técnica utilizada para a obtenção do reflexo $\mathrm{H}$.

O nervo periférico está representado pela esfera laranja pontilhada. A estimulação elétrica externa, que dispara de maneira seletiva as fibras aferentes sensociais la, está representa pelo símbolo de diferença de potencial em azul claro. As setas azuis claras representam os potenciais de ação de origem reflexa que seguem para a medula pelos axônios sensoriais (aferentes). As setas azuis escuras representam os potenciais de ação que seguem para o músculo pelos axônios motores (eferentes) dos motoneurônios alfa. $O$ triângulo azul claro representa eletrodos de eletromiografia de superfície posicionados sobre o músculo estudado (esfera vermelha). A amplitude reflexa, formada pelo potencial de ação composto 
muscular, está representada pelo registro eletromiográfico branco sobre o fundo azul (osciloscópio).

A amplitude do reflexo $\mathrm{H}$ do músculo soleus é a principal variável a ser estudada no presente trabalho. Esse músculo foi escolhido, pois tem um papel importante na manutenção da postura ortostática. Além disso, o fácil acesso ao nervo tibial torna o músculo soleus um dos mais investigados em pesquisas que utilizam a técnica do reflexo $\mathrm{H}$.

\subsection{Curva de recrutamento do reflexo $\mathrm{H}$}

As aferentes la ativadas pelo estímulo elétrico geram potenciais excitatórios pós-sinápticos (PEPS) que terão maior amplitude nos MNs $\alpha$ menores (que constituem as unidades motoras mais lentas, com maior resistência de membrana e menor velocidade de condução) e menor amplitude nos $\mathrm{MN \alpha}$ maiores (unidades motoras mais rápidas, com menor resistência de membrana e maior velocidade de condução). Como cada aferente la faz contato com todos os $\mathrm{MN \alpha}$ (doravante referidos apenas como $\mathrm{MN}$ ) que constituem o núcleo motor do músculo homônimo (e com alguns MN de músculos sinergistas), ocorre uma somação espaço-temporal de PEPS em todos os MN do pool (núcleo motor). Para estímulos de baixa intensidade os MN maiores não irão disparar, mas os seus potenciais de membrana estarão mais próximos do potencial limiar de disparo de PA, devido ao PEPS gerado pelas aferentes, ou seja foram facilitados.

O aumento na intensidade do estímulo elétrico irá aumentar o número de aferentes ativadas provocando o disparo de um número maior de MN na medula, o que causa um aumento na amplitude da resposta $\mathrm{H}$ (um número maior de fibras musculares despolariza contribuindo para o aumento na amplitude do CMAP) (Figura 2.2). Esta ordem de recrutamento para entradas sinápticas, dos MN menores para os maiores é conhecida como o princípio do tamanho (HENNEMAN \& MENDELL, 1982). É importante ressaltar que este mesmo princípio é aplicado para a maioria das entradas sinápticas sobre os MN de diferentes origens (periférica, segmentar ou descendente) e tipo (inibitórias ou excitatórias). 

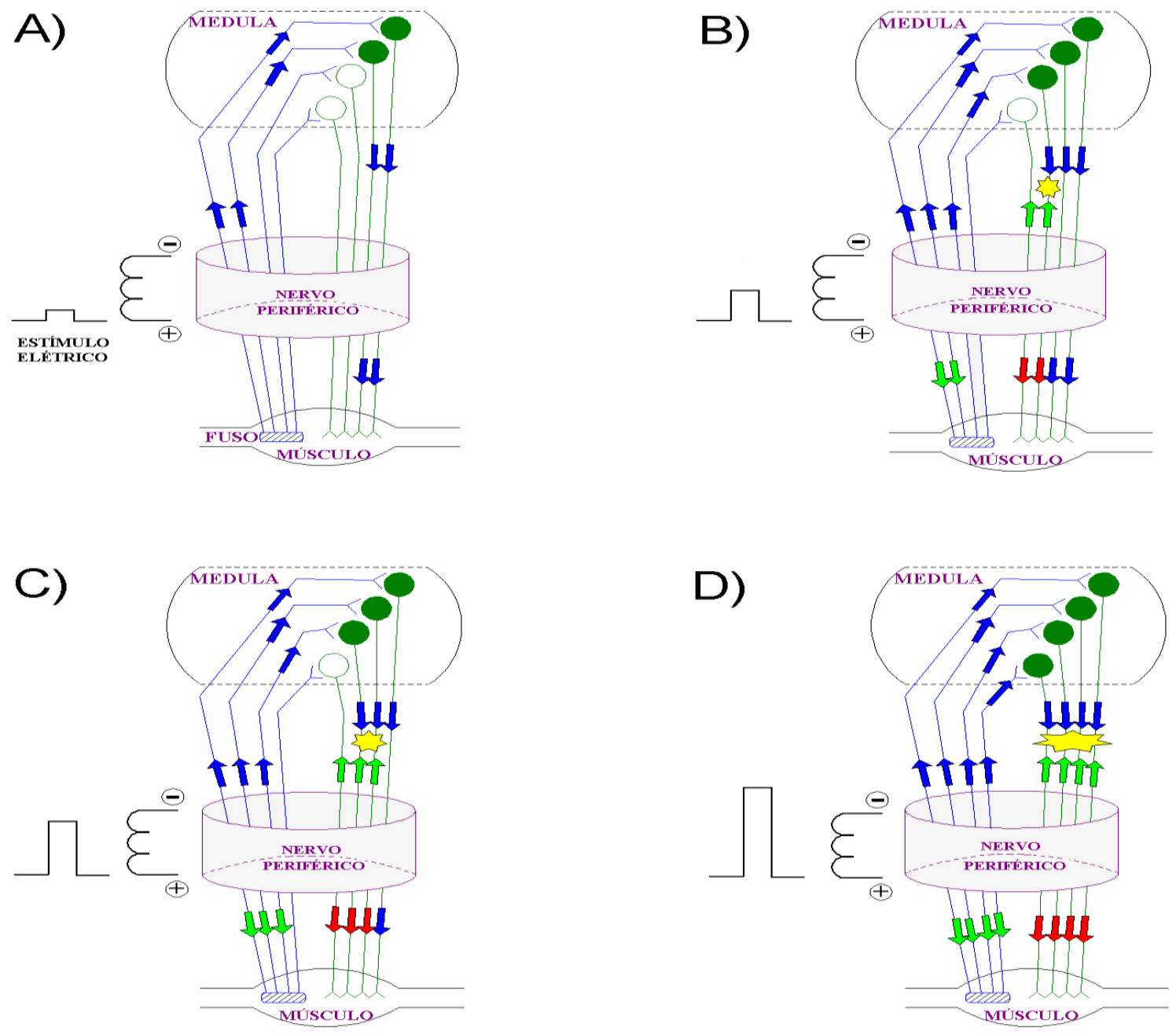

Figura 2.2 - Recrutamento das UMs em resposta ao aumento progressivo da intensidade de estímulo.

Representação esquemática do recrutamento das UMs em resposta ao aumento progressivo da intensidade de estímulo. A propagação de potenciais de ação é bidirecional para estímulo elétrico de um ms. As setas azuis indicam os potenciais de origem reflexa que seguem no sentido fisiológico (ortodrômico) para a medula, que irão gerar o reflexo $\mathrm{H}$. As setas verdes indicam os potenciais que seguem pelas aferentes e eferentes no sentido antidrômico (para o músculo). Os potenciais que seguem no sentido ortodrômico pelos axônios eferentes (motores) para o músculo são representados pelas setas vermelhas, e irão gerar a onda $\mathrm{M}$. Os potenciais de ação evocados pelo estímulo elétrico nos axônios motores também seguem para a medula (sentido antidrômico) representados pelas setas verdes. Esses potenciais colidem com os potenciais de origem reflexa (setas azuis) nos axônios eferentes causando a aniquilação mútua de potenciais de ação (estrela amarela). Em A) quando a intensidade de estímulo é baixa as UM menores (círculos a cheios) são recrutadas, de acordo com o princípio de tamanho, e nenhuma colisão é observada. Neste ponto, apenas o reflexo $\mathrm{H}$ (sem onda-M) está presente no EMG; Em B) quando há um aumento da intensidade de estimulação elétrica, um pequeno número de axônios motores dispara potenciais de ação que se propagam antidromicamente e que provocam o aniquilamento. Neste ponto, o reflexo $\mathrm{H}$ é acompanhado por uma onda $\mathrm{M}$ no EMG. Essa onda $\mathrm{M}$ tem uma latência mais curta do que o reflexo $\mathrm{H}$, pois é uma resposta direta, ou seja, que não viaja para a medula espinhal e de volta para 
o músculo (setas vermelhas alcançam o músculo antes das azuis). Em C) A intensidade do estímulo é maior e a colisão ocorre em um número maior de axônios eferentes em comparação à situação $B$. Neste ponto, a amplitude de reflexo $\mathrm{H}$ menor que a onda M. Em D) a intensidade é supramáxima e recruta $100 \%$ das fibras sensoriais e motoras induzindo 100\% de aniquilação (MEZZARANE et al., 2013)..

É importante ressaltar que a Figura 2.2 apresenta uma forma esquemática do recrutamento das fibras sensoriais e motoras. Obviamente, o quadro geral é muito mais complexo do que o esquema apresentado. Por exemplo, os círculos desenhados representam não um, mas uma população de MN de um determinado tamanho médio. Ademais, cada aferente muscular faz sinapse com todos os MN do pool aumentando a complexidade dos efeitos. De qualquer forma, a Figura 2.2 visa esclarecer de maneira geral os efeitos causados pela variação na intensidade de estímulo sobre o nervo periférico.

Os PAs dos MNs, cujos PEPS ultrapassam o limiar de disparo, seguem pelos respectivos axônios para o músculo com o qual se conectam por meio de junções neuromusculares. Com a liberação do neurotransmissor acetilcolina pelos terminais dos axônios dos $\mathrm{MN}$, as fibras musculares são despolarizadas além do limiar, cada uma disparando um PA. A soma de todos esses PA gera um CMAP captado na superfície do músculo que é denominado de reflexo $\mathrm{H}$, que provoca uma contração muscular fásica.

Com o aumento da intensidade de estímulo a amplitude do reflexo $\mathrm{H}$ aumenta gradualmente até um patamar. Nesta ocasião, observa-se 0 surgimento de uma onda com latência menor, a onda $M$, que também é um CMAP (Figura 2.1). A latência para o surgimento da onda $M$ é menor, pois os PAs são gerados nos axônios eferentes numa região do nervo próxima ao eletrodo de estimulação e seguem diretamente para o músculo (condição antidrômica - Figuras 2.2 e 2.3). 

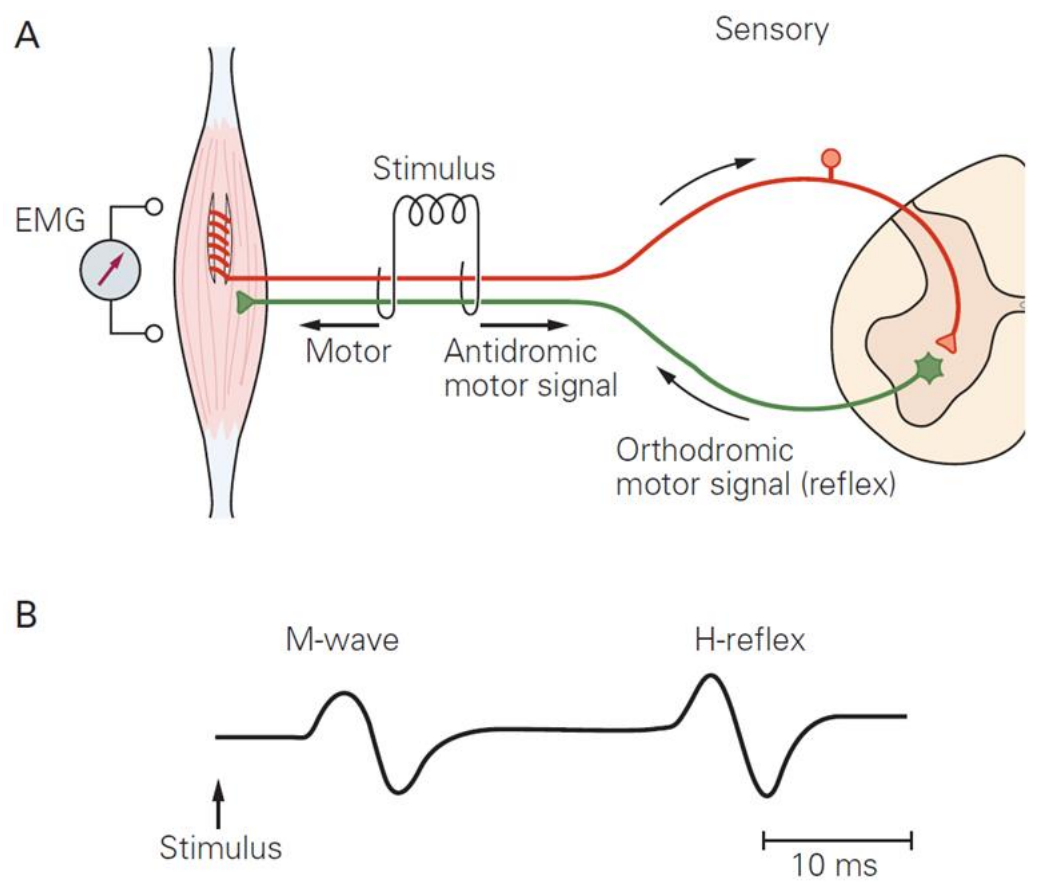

Figura 2.3 - Ativação das fibras sensoriais e motoras responsáveis pela geração do reflexo $\mathrm{H}$ e da onda $\mathrm{M}$.

Axônio vermelho: Fibras sensoriais ou aferentes. Axônio verde: Fibras motoras ou eferentes. Setas preta: Potenciais de ação. A Figura A, llustra os potenciais de ação do sentindo antidrômio (seta preta no sentido da medula localizada na fibra eferente) se colidindo com os de sentido ortodrômico (seta preta no sentindo do músculo). A figura B mostra o resitro de eletromiografia em função do tempo, respectivamente: Seta preta representa o artefato de estímulo aplicado ao nervo misto; a onda $\mathrm{M}$ ( $M$-wave) ou resposta motora direta; e reflexo $\mathrm{H}$ (H-reflex) (KANDEL, 2013).

Uma explicação fisiológica para esses eventos é apresentada a seguir: Para estímulos externos (estimulação elétrica transcutânea) os axônios de maior diâmetro são ativados para as menores intensidades de estímulo, e posteriormente os de diâmetro intermediário seguidos dos de diâmetro menor. Esta ordem de recrutamento vale para as fibras sensoriais (aferentes) e motoras (eferentes). Como as fibras aferentes (principalmente as aferentes do tipo la oriundas do fuso neuromuscular) apresentam em média diâmetros maiores e, consequentemente, maior velocidade de condução, estas são recrutadas antes das fibras eferentes. Cumpre-se ressaltar que esta ordem de recrutamento "inversa" (das maiores para as menores) tem sido observada com experimentos em animais (ERLANGER \& GASSER, 1937). 
Em humanos ainda não existe nenhuma evidência direta. Contudo, essa suposição (ordem de recrutamento "inversa") ajuda a explicar os eventos esquematizados na Figura 2.2.

Ao estimular eletricamente o nervo misto periférico, são gerados PAs que seguem em ambas as direções no axônio, para a medula e para o músculo (Figura 2.2). Os PAs que se propagam para o músculo pelos axônios eferentes seguem no sentido ortodrômico, ou seja, sentido fisiológico (Figura 2.2, setas vermelhas e setas azuis). Existem também os PAs que seguem no sentido antidrômico (sentido não fisiológico), que se propagam para a medula pelas fibras eferentes e no sentido do músculo pelas fibras aferentes (setas verdes da Figura 2.2).

Quando as fibras eferentes começam a ser recrutadas (quando se alcança uma determinada intensidade de estimulação, conhecida como limiar motor ou "Motor Threshold", MT), tem início um fenômeno conhecido como colisão ou aniquilação, que consiste na colisão dos PA antidrômicos originados nas fibras eferentes (motoras), com os PA ortodrômicos de origem reflexa, que são mutuamente extintos devido aos seus respectivos períodos refratários (Figura 2.2, estrelas amarelas). Esta colisão ocorre nas fibras eferentes, pois a velocidade de condução das fibras aferentes de maior diâmetro é um pouco maior que a das fibras eferentes, dando tempo suficiente para haver a transmissão sináptica (la-MN) antes dos PAs antidrômicos (Figura 2.3) das eferentes, gerados pelo estímulo elétrico, alcançarem o corpo celular dos MNs.

À medida que a intensidade do estímulo aumenta, um número maior axônios motores (e sensoriais) passam a ser recrutados aumentando o número de eferentes que sofrem colisão, isto contribui para a diminuição da resposta $\mathrm{H}$. Quanto maior o número de eferentes que sofrem colisão, menor será a amplitude da onda $H$ (menor quantidade de fibras musculares despolarizadas). Por outro lado, a resposta direta (de origem não reflexa) tende a aumentar, pois não existe colisão na região distal do axônio (referente ao ponto de aplicação do estímulo). Isto induz um aumento monotônico na amplitude da onda $M$ até um máximo, quando todos os axônios eferentes forem recrutados pelo estímulo elétrico. 
Deste modo, aplicando-se uma intensidade de estímulo supramáxima sobre o nervo periférico, na qual $100 \%$ das fibras motoras são ativadas diretamente pelo estímulo, não se observa a presença da onda $\mathrm{H}$ (devido à colisão que ocorre em $100 \%$ dos axônios eferentes), e a onda M máxima (Mmáx) é evocada. Esses efeitos podem ser observados claramente na curva de recrutamento do reflexo $\mathrm{H}$ (Figura 2.4).

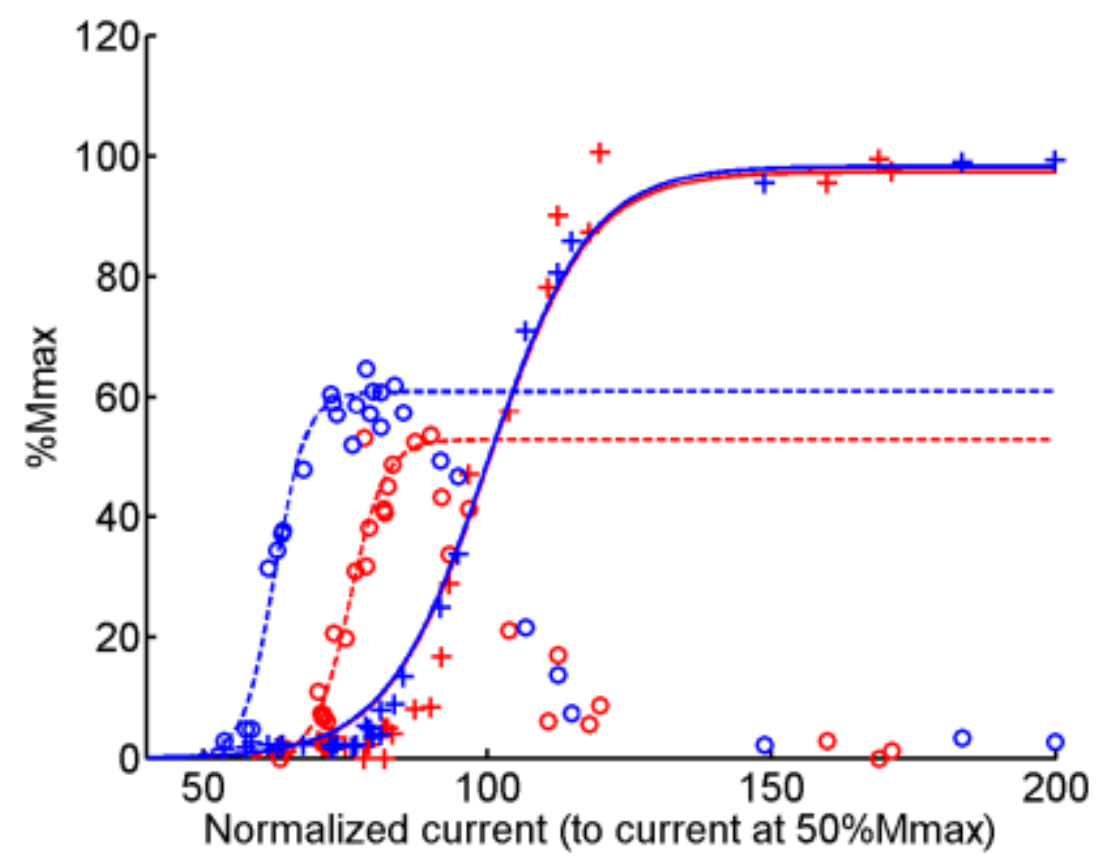

Figura 2.4 - Curvas de recrutamento obtidas do músculo soleus

Curvas de recrutamento obtidas do músculo soleus de um sujeito em repouso (azul) e durante o movimento rítmico dos braços (vermelho). Círculos e cruzes representam, respectivamente, as amplitudes pico-a-pico do reflexo $\mathrm{H}$ e da onda $\mathrm{M}$ (MEZZARANE et al.,2013).

Segundo o princípio do tamanho, as respostas $\mathrm{H}$ da parte inicial da curva de recrutamento correspondem às unidades motoras (UM) menores (Figura 2.2A). Em contrapartida, ondas $\mathrm{M}$ de pequena amplitude correspondem às UM maiores pois, como argumentado anteriormente, a ordem de recrutamento para estímulo externo (estimulação elétrica transcutânea) é inversa, ou seja, primeiro recruta-se as fibras de diâmetro maior (Figura 2.2B). Pode-se notar na Figura 2.2C que as ondas $\mathrm{H}$ de baixa amplitude localizadas na região descendente da curva estão também associadas à ativação das UM menores, que não sofreram colisão. 
Em alguns sujeitos, a interrupção no aumento da amplitude do reflexo $\mathrm{H}$ não pode ser explicada pela colisão de $\mathrm{PA}$, uma vez que esta interrupção ocorre antes do surgimento da onda $M$ (intensidades de estímulo menores do que $1 \times$ MT - amplitude referente ao limiar da onda $\mathrm{M}$, somada à um aumento de $10 \%$ ). Isto pode ser explicado pela ativação das aferentes lb (que possuem limiar para estímulo externo próximo ao das la) de origem no órgão tendinoso de Golgi, ou pela maior participação das células de Renshaw que inibem de maneira recorrente os $\mathrm{MN}$ que estão sendo recrutados ortodromicamente e antidromicamente (DUMITRU, 1995).

Existem alguns aspectos importantes na utilização da técnica de reflexo $\mathrm{H}$ para pesquisa sobre a neurofisiologia da medula espinhal: 1) Nunca se deve trabalhar com respostas $\mathrm{H}$ na fase descendente da curva, pois não seria possível observar, por exemplo, os efeitos facilitatórios evocados por estímulos condicionantes, dado que a maioria dos $\mathrm{MN}$ já estaria sendo recrutada pelo estímulo teste, não havendo a possibilidade de se recrutar um número maior de MNs pelo efeito condicionante; 2) A obtenção da onda Mmax é necessária para normalizar a amplitude da resposta $\mathrm{H}$ e possibilitar a comparação inter-indivíduos; 3) Alguns trabalhos utilizam a amplitude máxima da resposta $\mathrm{H}$ (Hmax) como variável de estudo, frequentemente utilizando a relação Hmax/Mmax (TAUBE, 2007; ZEHR, 2002). É preciso atentar-se ao fato que a relação Hmax/Mmax, utilizada como a principal variável em alguns trabalhos, varia consideravelmente entre os sujeitos. Isso faz com que seja uma medida não muito confiável (HALLETT, 1993). 4) Em muitos casos, é interessante obter uma pequena onda $\mathrm{M}$ juntamente com a resposta $\mathrm{H}$ para monitorar a eficácia de estimulação, preferencialmente, quando esta resposta encontra-se na fase ascendente da curva.

Logo, os parâmetros extraídos da CR possibilitam avaliar as adaptações neuronais: em diferentes populações de unidades motoras e em resposta ao treinamento físico (MEZZARANE et al.2011).

\subsubsection{Parâmetros extraídos da curva de recrutamento}

A utilização de parâmetros extraídos de um ajuste sigmoidal da alça ascendente da curva de recrutamento, ao invés de apenas um ponto (p. ex., 
Hmax), permite avaliar o grau de excitabilidade reflexa mediada por diferentes populações de motoneurônios (KLIMSTRA \& ZEHR, 2008; MEZZARANE et al., 2011). Ou seja, o perfil da curva de recrutamento pode ser alterado em diferentes condições, como movimentação rítmica de membros (simulando movimentos de locomoção), fases da marcha, condicionamento por estímulos cutâneos e/ou ativação de aferentes de músculos antagonistas, entre outros (MEZZARANE et al., 2013). Desta forma, é possível estudar alterações na ação de alguns mecanismos de modulação reflexa, que pode refletir plasticidade do sistema nervoso, por exemplo, em resposta ao treinamento físico.

Klimstra \& Zehr (2008) propuseram uma abordagem analítica que consiste em um ajuste sigmoidal da alça ascendente da curva de recrutamento do reflexo $\mathrm{H}$ (Figura 2.5). Os autores concluíram que uma curva sigmoide é o ajuste mais adequado para os dados da alça ascendente, em comparação a outros ajustes lineares e não lineares como interpolação de spline cúbica, ajustes logarítimcos e polinomiais. Vários parâmetros podem ser extraídos do ajuste sigmoidal como a inclinação da porção linear da sigmoide (que reflete o ganho de recrutamento) (KERNELL \& HULTBORN 1990), limiar do reflexo $H$, reflexo $H$ máximo, corrente limiar, entre outros.

O presente estudo utilizou os ajustes sigmoidais das alças ascendentes das curvas de recrutamento do reflexo $\mathrm{H}$ de acordo com $\mathrm{O}$ procedimento proposto por Klimstra \& Zehr (2008) (Figura 2.5). 
A

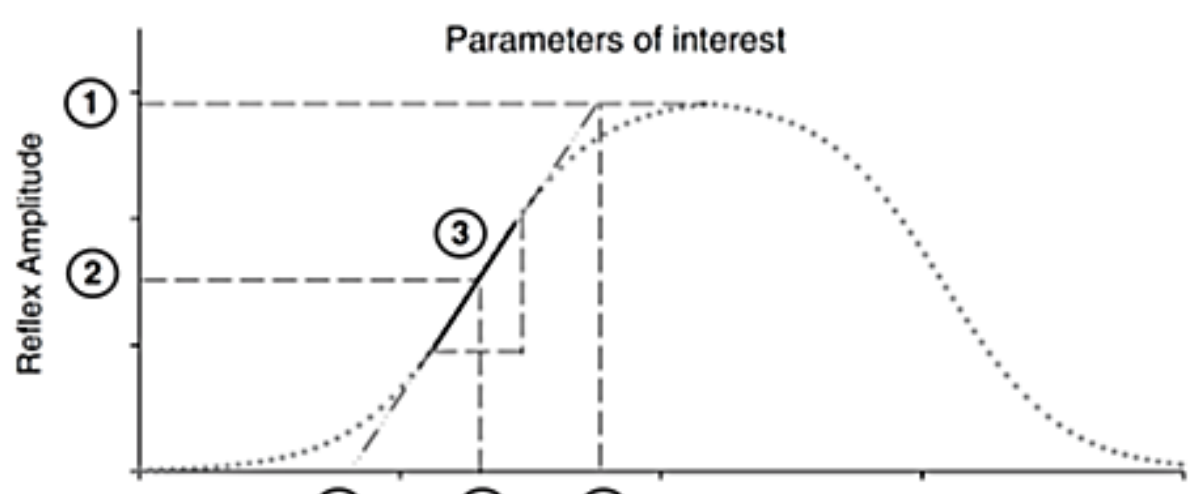

(4) (5) (6) Current
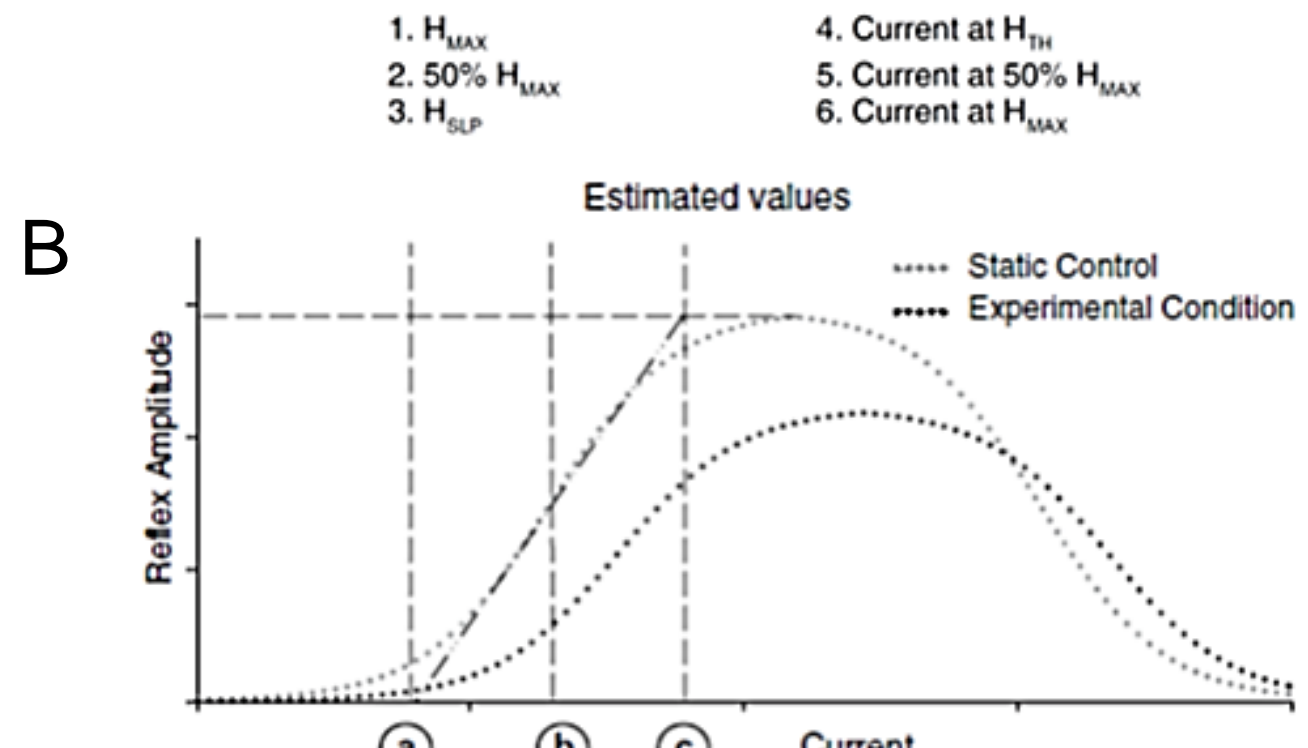

(a) (b) (c) Current
a. Current $\otimes$ Static $\mathrm{H}_{\mathrm{TH}}$
b. Current $\otimes$ Static $50 \% \mathrm{H}_{\text {wax }}$
c. Current $\otimes$ Static $\mathrm{H}_{\mathrm{mu}}$

Figura 2.5 - Ajuste sigmoidal do reflexo $\mathrm{H}$.

Ajuste sigmoidal cujas linhas pontilhadas referem-se: 1) Hmax, 2) 50\% de Hmax, 3) Inclinação (slope - Hslp) da reta de regressão ajustada à alça ascendente, 4) Corrente Limiar do reflexo $\mathrm{H}$ (do inglês, Current at $\mathrm{Hth}$ ), 5) Corrente à $50 \%$ de $\mathrm{Hmax}$ (do inglês, Current at H50), 6) Corrente à $100 \%$ de Hmax (do inglês, Current at H100). a) Corrente aplicada para gerar (corrente em, ou at, ou @) Hth, b) Corrente aplicada para gerar (corrente em, ou at, ou @) H50 c) Corrente aplicada para gerar (corrente em, ou at, ou @) H100 (Klimstra \& Zehr, 2008).

O reflexo $\mathrm{H}$ limiar (menor amplitude reflexa possível) é denominado $H$ th ( $H$ threshold) e é evocado por uma corrente (intensidade de estímulo elétrico) limiar. Este valor é mapeado na curva sigmoide a partir do valor limiar de corrente, que é definido como sendo o ponto em que a reta de regressão da porção linear da sigmoide cruza a abscissa da curva de recrutamento. $\mathrm{O}$ reflexo $\mathrm{H}$ máximo (Hmax) é calculado como a média das 
cinco maiores respostas $\mathrm{H}$. O valor Hmax é um dos parâmetros de entrada para se estimar o ajuste sigmoidal (veja na seção "Métodos").

A corrente para se obter o Hmax é associada ao valor da reta de regressão que atinge o valor Hmax. A corrente associada a $50 \%$ do valor Hmax (ou seja, 50\%Hmax) mapeia a metade da curva sigmoidal, ou seja, onde a inclinação (ou a derivada) é máxima (H50\%). Esses pontos são claramente observados na Figura 2.5.

O mesmo ajuste é realizado nos dados da condição experimental (em nosso caso, após o treinamento) para se obter os parâmetros de comparação. As correntes que evocaram o Hth, o $\mathrm{H} 50 \%$ e o Hmax são usadas como referência para mapear os valores de reflexo $\mathrm{H}$ do novo ajuste. Esses valores (parâmetros) obtidos da comparação das curvas são indicados como "@", ou seja, o valor de amplitude "na" (ou “at"-@, em inglês) corrente que gerou o reflexo $\mathrm{H}$ na situação controle que seriam, respectivamente, H@th, H@50 e H@100.

Portanto, os valores H@ são amplitudes de reflexo H mapeadas na condição experimental (no nosso caso após o treinamento): o valor de corrente para obter Hth está associado ao H@th; 50\%Hmax ao H@50 e Hmax ao H@max. Os respectivos valores de correntes seriam c@th, c@50 e c@100 e são úteis para avaliar deslocamentos laterais (alterações em limiares de ocorrência de resposta reflexa) nas curvas de recrutamento do reflexo $\mathrm{H}$. Isto é possível utilizando-se o ajuste sigmoidal realizado na curva de recrutamento da onda $\mathrm{M}$ como referência (indicadas com cruzes na Figura 2.4) (veja a seção "Métodos").

Os valores "at" (@) indicam as mudanças na relação de entrada-saída do sistema. Isso significa dizer que para um mesmo estímulo, diferentes populações de unidades motoras são recrutadas em cada condição (pré ou pós-treinamento).

A inclinação da reta obtida da regressão linear também representa um parâmetro importante (slope). Quando a inclinação é mais acentuada o "ganho de recrutamento" é maior. Isto é um indício de uma compressão dos limiares de disparo dos MN na medula. Logo, quando o ganho de recrutamento é alto, pequenas alterações na corrente (estímulo) induzem variações relativamente grandes na amplitude do reflexo $\mathrm{H}$. Quando os 
limiares estão mais dispersos, a inclinação fica menos acentuada. Este seria um ganho de recrutamento baixo, e para ocorrer uma variação grande na amplitude do reflexo $\mathrm{H}$ é preciso uma maior variação na corrente.

\subsection{O reflexo H e o estudo da inibição pré-sináptica}

É possível estudar em humanos, utilizando-se a técnica do reflexo $\mathrm{H}$, algumas vias inibitórias da medula que participam no controle da excitabilidade de vias reflexas e na coordenação dos movimentos voluntários, rítmicos e/ou reflexos. Tais vias inibitórias são intermediadas por interneurônios (IN) cujos papéis, em muitos casos, têm sido desvendados em experimentos com animais.

Alterações na amplitude pico a pico do potencial de ação composto medido por eletromiografia de superfície, refletem flutuações na excitabilidade da via do reflexo de estiramento, que é influenciada por comandos descendentes e/ou periféricos (MIZUNO et al.,1971; HUGON 1973, HULTBORN et al.1987). As vias que promovem essa modulação utilizam um ou mais interneurônios, que podem ter ação pré ou pós-sináptica (MEUNIER et al.1993; MEZZARANE et al., 2015).

A inibição pré-sináptica (IPS) é uma das vias inibitórias que modulam a influência das fibras aferentes do fuso neuromuscular sobre os MNs. Acredita-se que a função principal desta via é a regulação do ganho do reflexo de estiramento monossináptico (MCCREA, 1992; MEUNIER \& PIERROT-DESEILLIGNY, 1998) e sua influência periférica é modulada diferencialmente para cada tarefa motora. Essa inibição é intermediada por sinapses axo-axônicas compostas por inter-neurônios GABAérgicos que promovem a redução na liberação de glutamato pelos terminais dos axônios das aferentes la (RUDOMIN \& SCHMIDT, 1999) (Figura 2.6). Estes interneurônios GABAérgicos estão sujeitos a convergências segmentares, descendentes e periféricas (RUDOMIN \& SCHMIDT, 1999) (Figura 2.7). 


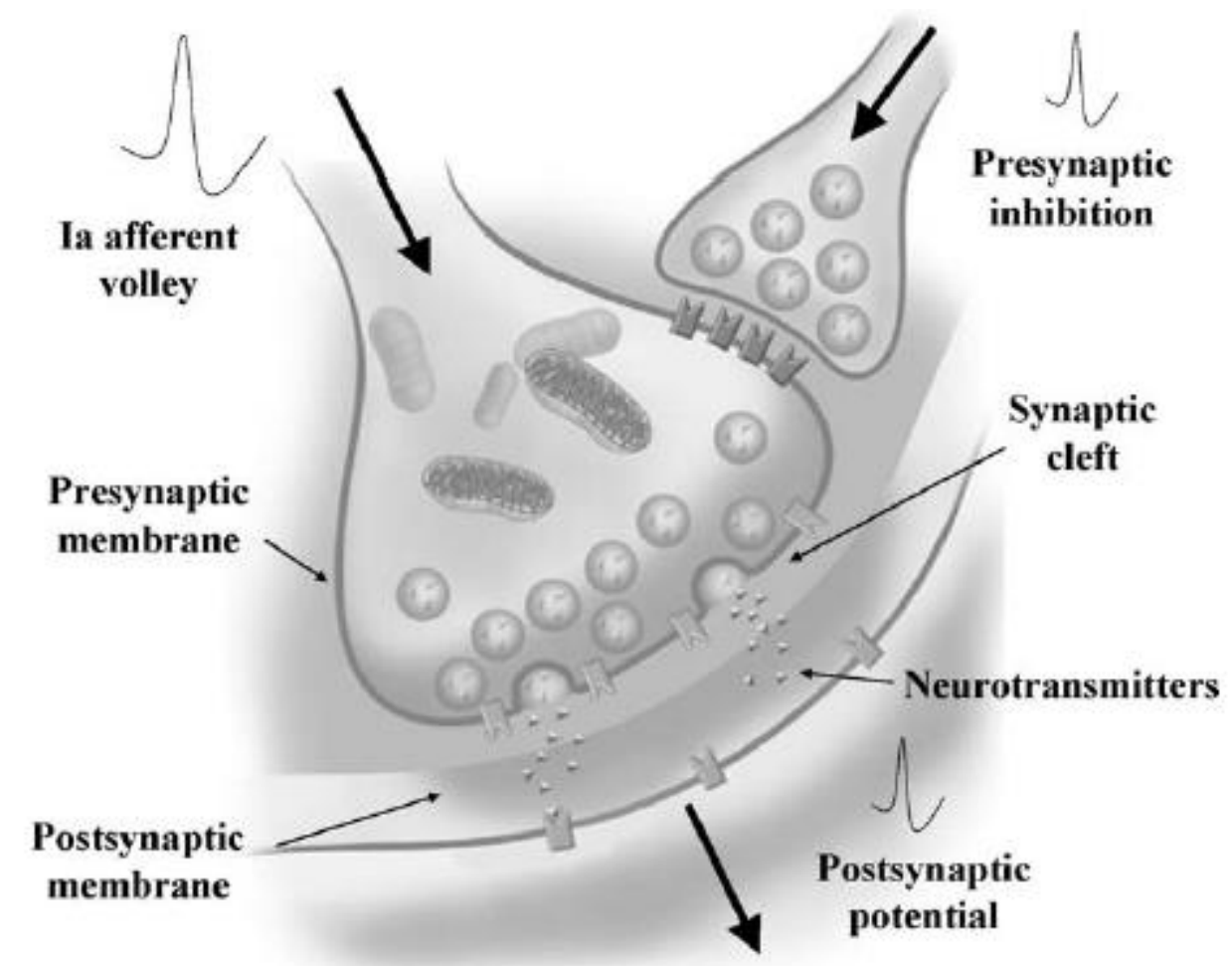

Figura 2.6 - llustração mostrando o mecanismo de inibitição présinaptica.

la afferent volley (indicada pela seta preta no canto superior esquerdo): Potenciais de ação vindos da fibra sensorial, aferente la; Presynaptic membrane (indicada pela pequena seta preta à esquerda posicionada centramente): membrana pré sináptica; Postsynaptic membrane (indicada pela seta média à esquerda no canto inferior da figura): membrana pós sináptica; Presynaptic inhibition (indicada pela peguena seta larga, localizada no canto superior direito da figura): Inibição pré-sinaptica; Synaptic cleft (indicada pela seta fina e longa posicionada centralmente no canto direito da figura): Fenda sináptica; Neurotransmitters (indicados pela pena e fina seta no canto inferior direito da figura): neurotransmissores; Postsynaptic potential (indicado pela seta grande e larga no canto inferior centralizado da figura): potencial pós sináptico (Fonte: CHEN, YUNG-SHERG \& ZHOU, 2011). 


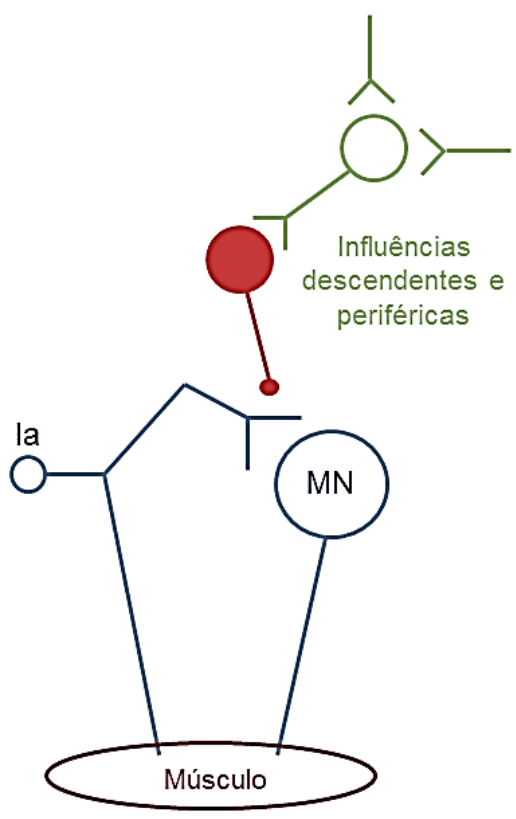

Figura 2.7 - Representação de influências descendentes e periféricas na IPS.

O interneurônio de última ordem está indicado em vermelho. Influências descendentes e periféficas representadas de verde.

A IPS em seres humanos pode ser evocada por uma estimulação no nervo que supre o músculo antagonista. Atualmente, existem diferentes maneiras para se evocar IPS nos terminais das aferentes la do músculo soleus de seres humanos, como vibração no tendão do músculo tibial anterior (MORIN, 1984), estímulos tetânicos sobre o nervo fibular (AYMARD , 2000; KOHN, 1997), estimulação cutânea (STEIN, 1995) e de maneiras indiretas (utilizando estimulação do nervo femural) como demonstrado por HULTBORN (1987).

Um estímulo único sobre o nervo fibular também pode evocar IPS nos terminais la do músculo soleus, como será adotado no presente trabalho (CAPADAY,1990; CIANCHETTI, 1975; MEUNIER \& PIERROTDESEILLIGNY, 1998; MORITA, 2001; MEZZARANE \& KOHN, 2007; MEZZARANE, 2012; MEZZARANE, 2015). Esse estímulo condicionante (liberado no nervo fibular) é seguido pelo estímulo teste aplicado no nervo tibial evocando a resposta reflexa condicionada. Recomenda-se o uso de um reflexo $\mathrm{H}$ teste com amplitude entre $20 \%$ e $30 \%$ da Mmax, uma vez que neste 
intervalo as respostas são mais sensíveis ao condicionamento (CRONE et al.,1990) (Figura 2.8). Este protocolo experimental é conhecido como paradigma condicionante-teste (C-T).

Em geral, o nível (ou grau) da IPS aumenta com o aumento do grau de instabilidade postural (CAPADAY \& STEIN 1987, KATZ et al., 1988). Nielsen \& Kagamihara (1993) sugerem a existência de um controle descendente sobre interneurônios interpostos nesta via inibitória. Os centros supraespinhais controlam o fluxo de informação sensorial ajustando a quantidade de inibição pré-sináptica, de acordo com a tarefa motora a ser realizada. Em relação ao treino de equilíbrio, supõe-se que os comandos supra espinhais induzam um aumento no grau de IPS das aferentes la (GRUBER et al., 2007, TAUBE et al., 2007).

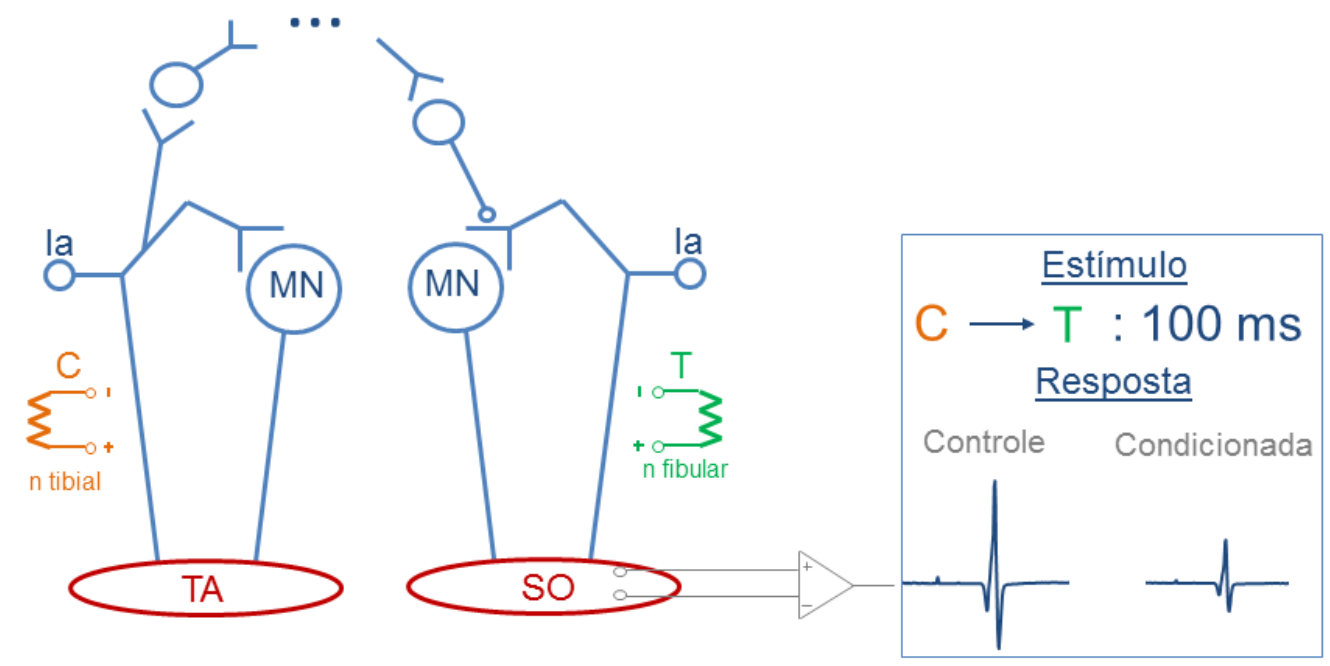

Figura 2.8 - Procedimento para obtenção de IPS.

Representação esquemática mostrando o procedimento para a obtenção da IPS do músculo soleus. Os estímulos condicionante $(\mathrm{C})$ e teste $(\mathrm{T})$ são liberados com um intervalo de $100 \mathrm{~ms}$ (intervalo C-T) (MEZZARANE et al, 2013).

\section{OBJETIVOS}

\subsection{Objetivo Geral}

Avaliar o efeito de um programa de treinamento neuromuscular sobre mecanismos de modulação da excitabilidade de reflexos medulares e sobre o 
recrutamento reflexo eletroevocado de unidades motoras em escolares praticantes de basquetebol.

\subsection{Objetivos Específicos}

- Investigar os diferentes parâmetros de ajuste sigmoidal na alça ascendente da curva de recrutamento do reflexo $H$, que permitem caracterizar alterações na relação estímulo-resposta e no limiar e no ganho de recrutamento de unidades motoras após treinamento neuromuscular.

- Examinar os efeitos do treinamento neuromuscular sobre um dos mecanismos mais importantes de controle de ganho da via reflexa: a inibição pré-sináptica.

\section{MÉTODOS}

\subsection{Amostra}

Os critérios de inclusão dos participantes foram: (1) prática regular ( 50 minutos, 3 vezes semanais (150 minutos semanais), uma turma durante o período matutino e a outra no período vespertino (basquetebol) no Centro de Iniciação Desportiva (CID) do Centro de Ensino Médio da Escola Industrial de Taguatinga (CEMEIT); (2) participação nos treinos de basquetebol e exercícios físicos orientados dentro da modalidade; (3) prática do basquetebol por no mínimo de um ano; (4) ser do gênero masculino; (5) ter entre 13 e 16 anos de idade; (6) não apresentar histórico de doenças do aparelho locomotor, como lesões ou doenças neurodegenerativas nos seis meses antecedentes ao início da pesquisa; (7) apresentar autorização para participação voluntária por meio de assinatura de um termo de assentimento livre esclarecido - TALE (ANEXO I) e de um termo de consentimento livre esclarecido-TCLE (ANEXO II) aprovado por Comitê de Ética Local (ANEXO III) com assinatura do responsável legal pelo menor. Os critérios de exclusão foram: (1) sofrer alguma lesão nas articulações do membro inferior durante o experimento; (2) Não cumprimento do programa de exercícios oferecido nas aulas do CID durante o ano letivo de 2015; (3) Não treinos neuromusculares 
sugeridos pelo protocolo do presente estudo; (4) Ausência durante os testes; (5) problemas durante a captação dos sinais.

A amostra de conveniência foi constituída por um grupo de 30 estudantes da equipe de basquetebol do CID do Centro de Ensino Médio da Escola Industrial de Taguatinga (CEMEIT). O CID é um programa da Secretaria de Estado de Educação do Distrito Federal (SEEDF) que tem como objetivo o desenvolvimento humano dos estudantes por meio da prática esportiva. Todos os professores envolvidos no CID são formados em Educação Física e desenvolvem trabalhos com diferentes modalidades esportivas.

Os treinos ocorreram no horário contrário ao horário escolar dos participantes: Uma turma no período matutino e a outra no período vespertino. As equipes disputam campeonatos escolares no Distrito Federal (DF), na região centro-oeste do país e em alguns casos competições nacionais e internacionais.

Os sujeitos foram divididos aleatoriamente em dois grupos: grupo experimental (GE) e grupo controle (GC) com 15 sujeitos em cada grupo. Esta divisão foi aleatorizada pelo programa Matlab (versão 2012b, Math Works, Inc). Um sujeito que fazia parte do GE desistiu da prática do basquetebol abandonando o treino e a pesquisa por problemas de saúde, deixando o GE com 14 voluntários. Todos os estudantes do GE realizaram as 24 sessões de treino e tiveram o grau de dificuldade aumentado em quatro níveis. Todos os participantes do GC e do GE realizaram o mesmo treino de basquete, orientado pelo mesmo professor tanto no período matutino, quanto no período vespertino.

\subsubsection{Caracterização da Amostra}

A amostra foi caracterizada por meio de (1) avaliação antropométrica (Pollock 7 Dobras) usada para a determinar o percentual de gordura corporal de cada participante; (2) índice de Massa Corporal (IMC), calculado a partir da razão entre a massa corporal (MC) e estatura elevada ao quadrado, (3) idade e (4) tempo de prática da modalidade orientada.

A massa corporal foi aferida pela balança eletrônica (marca Filizola ${ }^{\circledR}$ eletrônica/digital; resolução de 100g; modelo Personal Line) e a estatura por 
meio do estadiômetro Country Tecnology ${ }^{\circledR}$ (modelo 67031; resolução de um $\mathrm{cm})$. O percentual de gordura foi determinado utilizando o kit de avaliação da marca Cescorf Equipamentos ${ }^{\circledR}$. Esses dados foram coletados por meio de um questionário individual representado no ANEXO IV

O questionário AJFAT (Ankle Joint Functional Assessment Tool) (ANEXO V) adaptado, contendo informações sobre instabilidade de tornozelos e comparação funcional entre os tornozelos (ROSS et al.,2009) foi aplicado a todos os escolares. Os voluntários também responderam a mais dois questionários: (1) Questionário Internacional de Atividade Física - IPAQ (Versão Curta) (ANEXO VI), para determinar o nível de atividade física fora dos treinos; (2) Questionário adaptado de Bonetti et al. (2012) (ANEXO VII), sobre a prática de atividade física orientada e exercício físico, realizados fora dos treinos de basquetebol, além de dados sobre lesões, participação em treinos e jogos, e uso de órteses nos mesmos.

\subsection{Coleta de dados}

As coletas de dados referentes aos sinais reflexos pré e pós intervenção aconteceram na Faculdade de Educação Física (FEF) da Universidade de Brasília (UnB) no Laboratório de Processamento Digital de Sinais Biológicos e Controle Motor. A aplicação dos questionários e a avaliação de medidas antropométricas foram realizadas no local de treinos (CEMEIT), antes do treino neuromuscular.

\subsection{Treinamento Neuromuscular}

O Grupo Experimental (GE) foi composto por 14 sujeitos, que além do treino de basquete realizaram a intervenção proposta: treinos neuromusculares orientados antes do treino de basquetebol, durante oito semanas, frequência de três vezes semanais e duração entre dez e quinze minutos.

A rotina de treino neuromuscular foi elaborada com base em exercícios sugeridos na literatura (EILS \& ROSENBAUM, 2001; CARAFFA et al.,1996; PLISKY, RAUH \& KAMINSKI, 2006; SHETH et al.,1997; VERHAGEN et al., 2004; PASANEN, PARKKARI \& PASANEN, 2008) de forma adaptada à 
prática do basquetebol com o auxílio de dois treinadores de basquete da equipe.

A intervenção está descrita a seguir com todos os exercícios neuromusculares realizados. A cada duas semanas, o nível de dificuldade foi elevado, aumentando as exigências para a manutenção da estabilidade corporal e diminuíndo as entradas sensoriais. Cada bloco de duas semanas conteve seis exercícios e variou em graus de dificuldades de um a quatro, em que um representa menor nível de dificuldade e quatro o maior. O critério de progressão foi apenas a partir do tempo, mas todos os participantes foram capazes de realizar todos os movimentos na sequência temporal que foi proposta.

Nos Graus 3 e 4, em que o grau de dificuldade foi aumentado com o uso de diferentes bases de apoio, os alunos foram dispostos em duplas: enquanto um dos indivíduos realizada o exercício, o outro se posicionava próximo para garantir um suporte de apoio em caso de um desequilíbrio e evitar quedas. O apoio físico era sempre feito com os braços do sujeito que não estava realizando a tarefa, porém nunca em contato direto com 0 executante do movimento. Caso fosse necessário, o executante poderia então se apoiar no membro da dupla que ofereceu o auxílio.

\subsubsection{Exercícios Grau 1}

- Marcha descalça duas vezes sobre uma linha de dez metros desenhada no chão, onde a tarefa foi realizada com os participantes autorizados a olhar para a linha como forma de orientação;

- Marcha descalça duas vezes sobre uma linha de dez metros desenhada no chão, onde a tarefa foi realizada com os participantes não autorizados a olhar para a linha como forma de orientação;

- Marcha descalça duas vezes sobre uma linha de dez metros desenhada no chão com os pés em tandem, onde a tarefa foi realizada com os participantes autorizados a olhar para a linha como forma de orientação; esses exercícios estão ilustrados na Figura a seguir (Figura 4.1): 


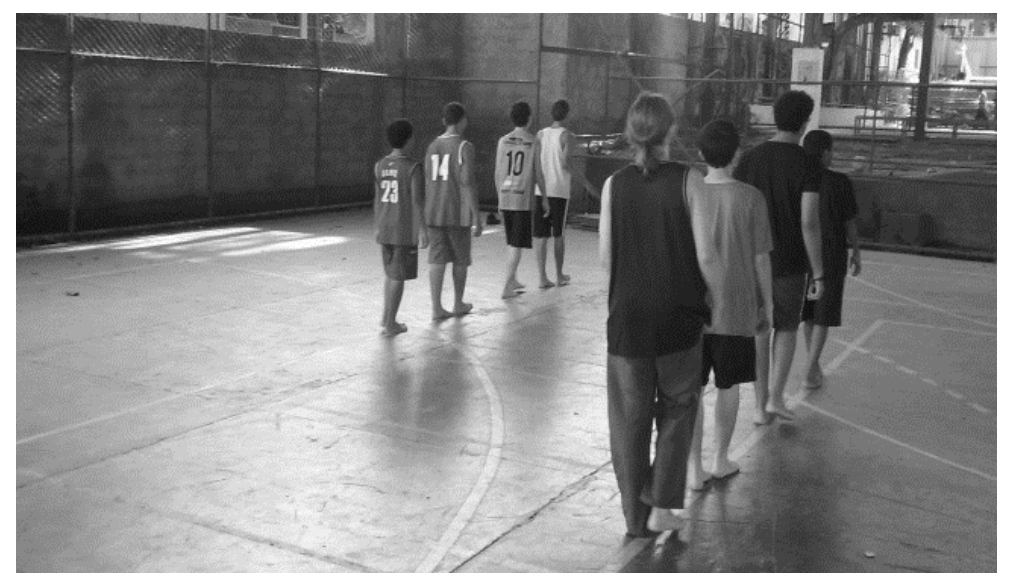

Figura 4.1 - Primeira etapa do exercício dois do Grau 1.

- Marcha descalça duas vezes sobre uma linha de dez 10 metros desenhada no chão com um pé a frente do outro, onde a tarefa foi realizada com os participantes autorizados a olhar para a linha como forma de orientação; esses exercícios estão ilustrados na Figura a seguir (Figura 4.2):

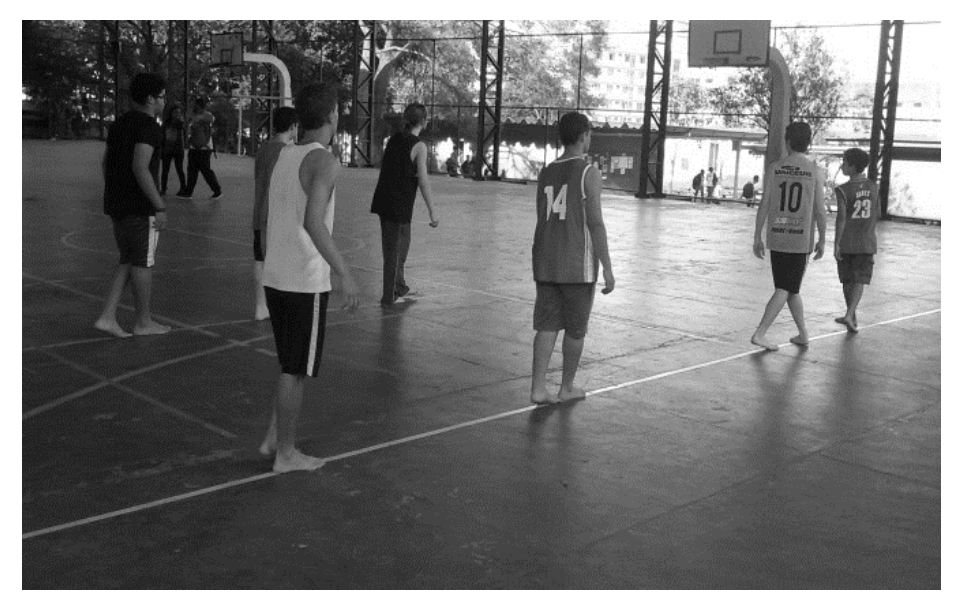

Figura 4.2 - Segunda etapa do exercício dois do Grau 1.

- Marcha descalça duas vezes sobre uma linha de dez metros desenhada no chão sobre diferentes planos intercalados à uma distância de aproximadamente um metro (um colchonete, piso, dois colchonetes, piso, três colchonetes, piso e quatro colchonetes) e utilizando os seguintes apoios podais: toda a planta do pé, calcanhar, ponta dos pés, bordas lateral e borda medial dos pés, por duas vezes em cada situação, podendo olhar para linha.

- Marcha descalça duas vezes sobre uma linha de dez metros desenhada no chão sobre diferentes planos intercalados à uma distância de 
aproximadamente um metro (um colchonete, piso, dois colchonetes, piso, três colchonetes, piso e dois colchonetes) e utilizando os seguintes apoios podais: toda a planta do pé, calcanhar, ponta dos pés, bordas lateral e borda medial dos pés, por duas vezes em cada situação, mas sem poder se orientar pela linha (de olhos fechados). Esses exercícios estão ilustrados na Figura a seguir (Figura 4.3):

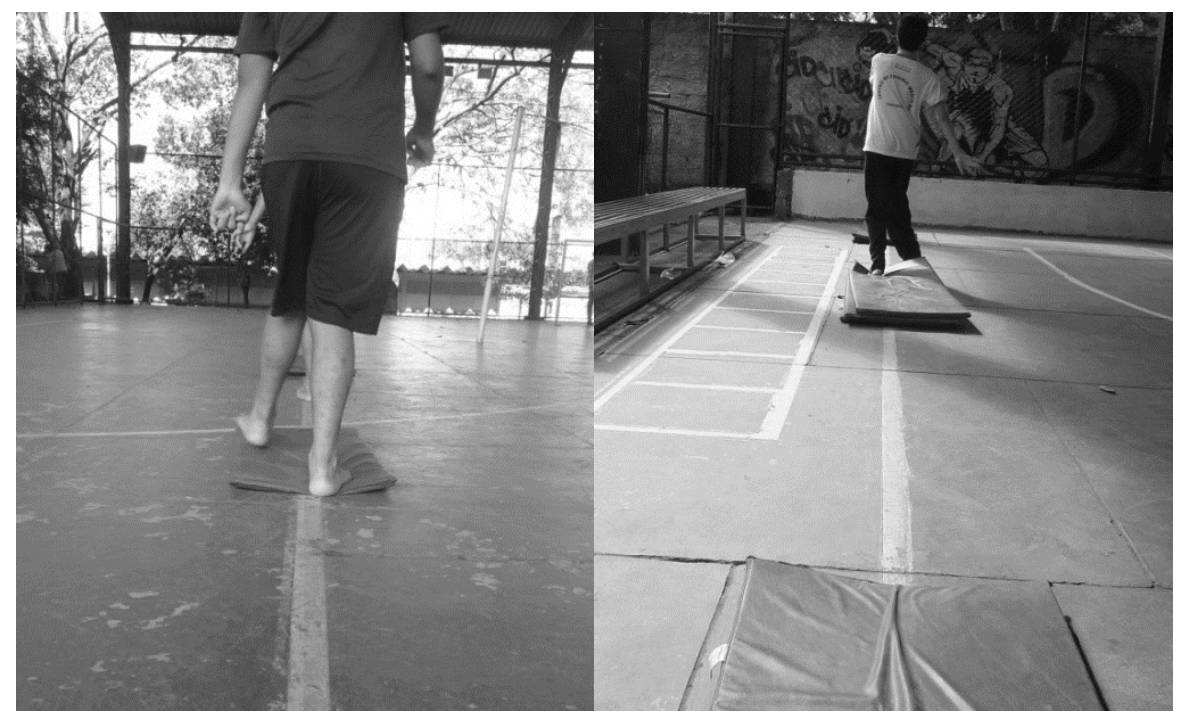

Figura 4.3 - Exercícios três e quatro do Grau 1.

O resumo das atividades desenvolvidas nos exercícios do Grau de dificuldade 1 está representado na Figura 4.4 e na Tabela 1 :

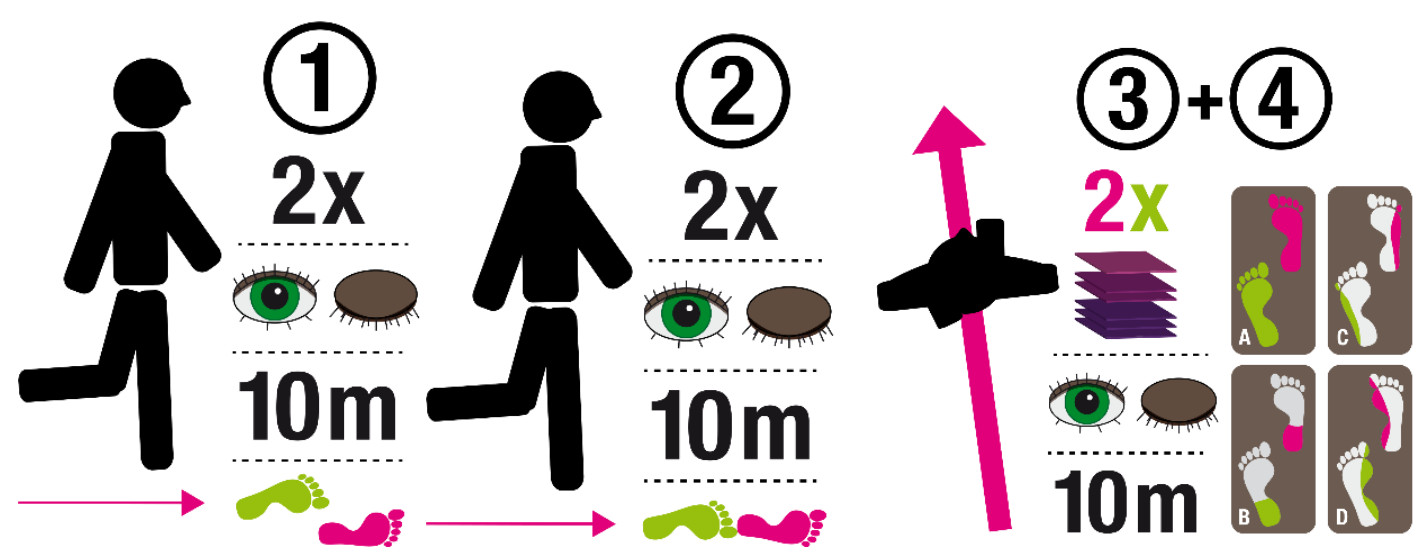

Figura 4.4 - Resumo dos exercícios do Grau 1 de dificuldade.

1 ) Exercício um do Grau 1;2) Exercício dois do grau 1; 3) e 4) Vista superior dos exercícios trê e quatro do Grau 1. Os infográficos estão 
dispostos em ordem sequencial de: exercício, número de repetições, uso de implemento, utilização da visão e tipo de pisada.

Tabela 1 - Resumo dos exercícios do Grau 1 de dificuldade.

\begin{tabular}{|c|c|c|c|c|c|c|c|c|}
\hline Ex & Sér & Atividade & Rep & Rec & Implemento & Vis & Apoio & Cal \\
\hline \multirow[b]{2}{*}{1} & 1 & & & & & $S$ & \multirow[b]{2}{*}{ BIP } & \multirow[b]{2}{*}{$\mathrm{N}$} \\
\hline & 2 & Marcha normal & 2 & 0 & Linha de $10 \mathrm{~m}$ & $\mathrm{~N}$ & & \\
\hline \multirow[b]{2}{*}{2} & 1 & & & & & $S$ & \multirow[b]{2}{*}{ BIP } & \multirow[b]{2}{*}{$\mathrm{N}$} \\
\hline & 2 & Pé frente pé & 2 & 0 & Linha de $10 \mathrm{~m}$ & $\mathrm{~N}$ & & \\
\hline \multirow[b]{4}{*}{3} & 1 & Marcha Planta & \multirow{4}{*}{2} & \multirow{4}{*}{0} & Linha de $10 \mathrm{~m}$ & \multirow{4}{*}{$S$} & \multirow{4}{*}{ BIP } & \multirow{4}{*}{$\mathrm{N}$} \\
\hline & 2 & Marcha Calcanhar & & & $\operatorname{com} 1,2$ e 3 & & & \\
\hline & 3 & Marcha Borda média & & & Colchonetes & & & \\
\hline & 4 & Marcha borda lateral & & & Dispostos & & & \\
\hline \multirow[b]{4}{*}{4} & 1 & Marcha Planta & \multirow{4}{*}{2} & \multirow{4}{*}{0} & Linha de $10 \mathrm{~m}$ & \multirow{4}{*}{$\mathrm{N}$} & \multirow{4}{*}{ BIP } & \multirow{4}{*}{$\mathrm{N}$} \\
\hline & 2 & Marcha Calcanhar & & & $\operatorname{com} 1,2$ e 3 & & & \\
\hline & 3 & Marcha Borda média & & & Colchonetes & & & \\
\hline & 4 & Marcha borda lateral & & & Dispostos & & & \\
\hline
\end{tabular}

Ex= Exercício em ordem; Sér: Série em ordem; Atividade = Tarefa executada; Rep= Repetição; Rec= Tempo de recuperação; - = Não mensurado; Vis= Uso da Visão; $\mathrm{S}=\mathrm{Sim} ; \mathrm{N}=\mathrm{Não} ; \mathrm{BIP}=$ Apoio Bipodal; $\mathrm{Cal}=$ Calçado; $\mathrm{S}=\mathrm{Sim} ; \mathrm{N}=\mathrm{Não}$.

\subsubsection{Exercícios Grau 2}

Os participantes foram divididos em pares antes de começarem a execução com intervalo de recuperação de pelo menos dez segundos entre cada série.

- A partir do apoio uni-podal e de costas para o parceiro de treino, o sujeito passa a bola de basquetebol para trás, girando apenas o tronco, sustentando-se primeiro com a perna direita durante cinco vezes e alternando o sentido de entrega da bola em cima de um colchonete;

- A partir do apoio uni-podal e de costas para o parceiro de treino, o sujeito passa a bola de basquetebol para trás, girando apenas o tronco, sustentando-se com a perna esquerda durante cinco vezes e alternando o sentido de entrega da bola em cima de um colchonete;

Esses exercícios estão ilustrados na Figura a seguir (Figura 4.5): 


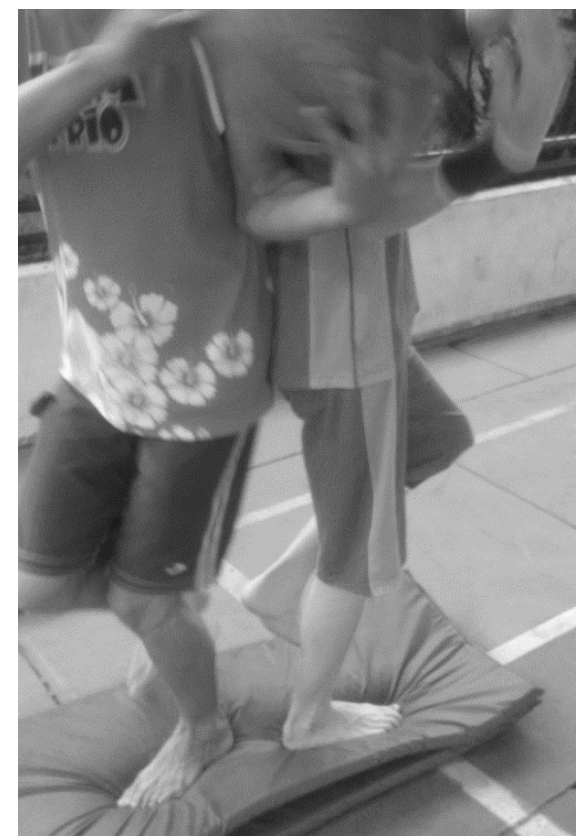

Figura 4.5 - Primeira e segunda etapa do exercício um do Grau 2.

- Cada voluntário executou um total de três agachamentos por série driblando a bola de basquetebol com a mão dominante e apoio uni podal com o membro dominante no chão, em cima de um colchonete, em seguida em cima de dois e por fim em cima de três colchonetes.

- Cada par executou um total de três agachamentos por série driblando a bola de basquetebol com a mão dominante e apoio uni podal com o membro não dominante no chão, em cima de um colchonete, em seguida em cima de dois e por fim em cima de três colchonetes. Esses exercícios estão ilustados na Figura a seguir (Figura 4.6):

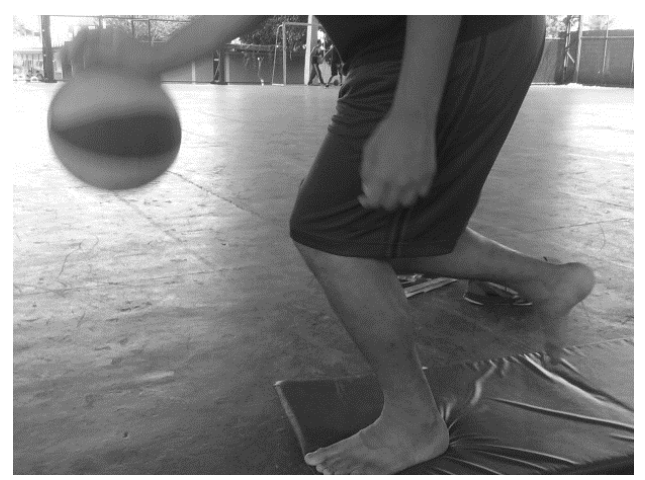

Figura 4.6 - Exercício dois do Grau 2.

O resumo das atividades desenvolvidas nos exercícios do Grau de dificuldade dois está representado na Figura 4.7 e na Tabela 2. 


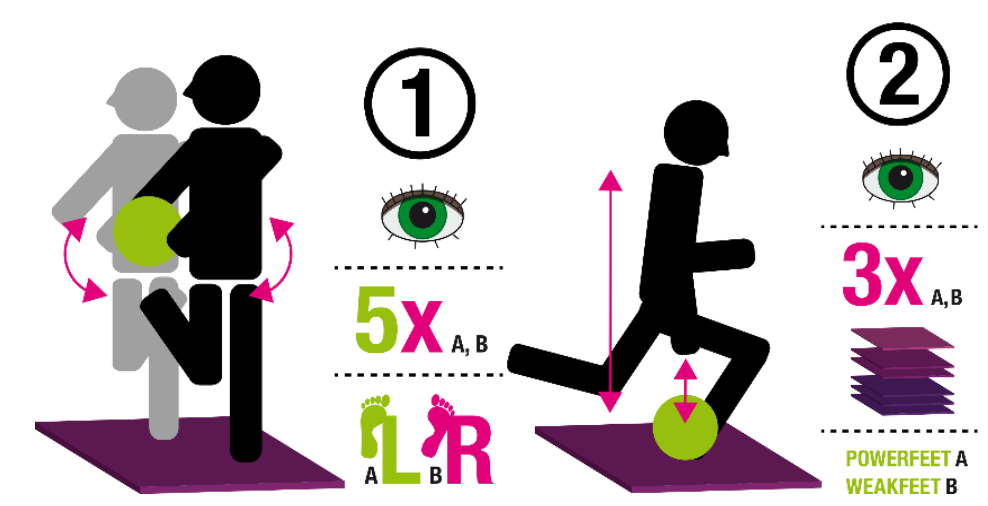

Figura 4.7 - Resumo dos exercícios do Grau 2 de dificuldade.

1) Exercício um do Grau 2; 2) Exercício dois do Grau 2. Os infográficos estão dispostos em ordem sequencial: exercício, utilização da visão, número de repetições, uso de implemento e perna dominante.

Tabela 2 - Resumo dos exercícios do Grau 2 de dificuldade.

\begin{tabular}{|c|c|c|c|c|c|c|c|c|}
\hline Ex & Sér & Atividade & Rep & $\operatorname{Rec}$ & Implemento & Vis & Apoio & Cal \\
\hline \multirow[b]{2}{*}{1} & 1 & $\begin{array}{l}\text { Passe de bola lateral e giro de } \\
\text { tronco }\end{array}$ & \multirow[b]{2}{*}{5} & \multirow[b]{2}{*}{$10 \mathrm{~s}$} & \multirow[b]{2}{*}{$\begin{array}{l}\text { Colchonete e } \\
\text { dupla }\end{array}$} & \multirow[b]{2}{*}{$S$} & UNI Esq & \\
\hline & 2 & $\begin{array}{l}\text { Passe de bola lateral e giro de } \\
\text { tronco }\end{array}$ & & & & & UNI Dir & $\mathrm{N}$ \\
\hline \multirow[b]{2}{*}{2} & 1 & Agachamento Driblando MSD & \multirow[b]{2}{*}{3} & \multirow[b]{2}{*}{$10 \mathrm{~s}$} & Bola e até 3 & \multirow[b]{2}{*}{$S$} & UNI MID & \\
\hline & 2 & Agachamento Driblando MSND & & & Colchonetes & & $\begin{array}{l}\text { UNI } \\
\text { MIND }\end{array}$ & $\mathrm{N}$ \\
\hline
\end{tabular}

Ex= Exercício em ordem; Sér: Série em ordem; Atividade = Tarefa executada; Rep= Repetição; Rec= Tempo de recuperação; - = Não mensurado; Vis= Uso da Visão; $\mathrm{S}=\mathrm{Sim} ; \mathrm{N}=\mathrm{Não}$; $\mathrm{BIP}=$ Apoio Bipodal; $\mathrm{UNI}=$ Apoio Unipodal; $\mathrm{Esq}=$ Esquerdo; $\mathrm{Dir}=$ Direito; $\mathrm{MSD}=$ Membro superior dominante; $\mathrm{MSND}=$ Membro superior não dominante; $\mathrm{MID}=$ Membro Inferior dominante; $\mathrm{MIND}=$ Membro Inferior não dominante; $\mathrm{Cal}=$ Calçado; $\mathrm{S}=\mathrm{Sim} ; \mathrm{N}=$ Não.

\subsubsection{Exercícios Grau 3}

Para cada série proposta pelo menos dez segundos de recuperação foram aplicados. Os exercícios em que o jogador foi orientado a permanecer por no mínio dez segundos, o tempo foi calculado durante a execução das tarefas. Caso o indivíduo não conseguisse permanecer na base neste período, o tempo era pausado e apenas finalizado após a conclusão da tarefa em duração mínima. Neste Grau de dificuldade há a adição de bases de apoio de desinstabilização. Não holve um período de adaptação aos 
aparelhos. Contudo, todos os voluntários foram capazes de executar as tarefas.

- A partir do apoio bi-podal com joelhos parcialmente estendidos, os participantes buscaram manter o equilíbrio durante três séries de pelo menos dez segundos ( dez passes) na prancha de equilíbrio médio-lateral realizando passes de peito. Esse exercício está ilustrado na Figura a seguir (Figura 4.8):

A recepção da bola foi feita por outro aluno que não estava sobre o apoio do implemento. A devolução da bola foi feita devolvendo em mãos a boa para o estudante que estava sobre o implemento.

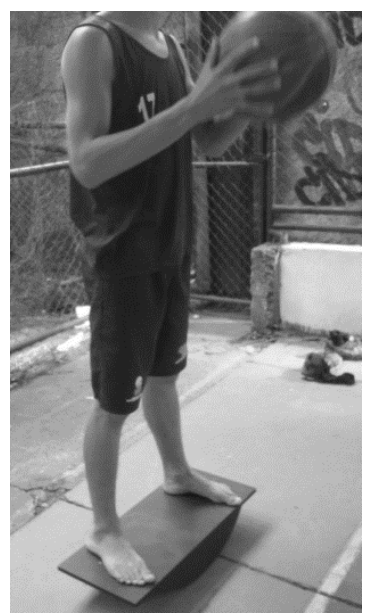

Figura 4.8 - Exercício um do Grau 3.

- A partir do apoio bi-podal com joelhos estendidos, os participantes buscaram manter o equilíbrio durante três séries de pelo menos dez segundos ( dez passes) no disco de equilíbrio realizando passes de peito; esse exercício está ilustrado na Figura a seguir (Figura 4.9): Recepção e devolução da mola igual ao exercício um. 


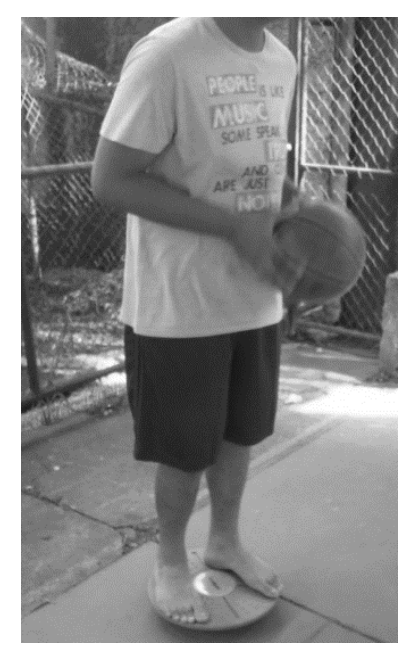

Figura 4.9 - Exercício dois do Grau 3.

- A partir do apoio bi podal com joelhos estendidos, os participantes buscaram manter o equilíbrio durante três séries de pelo menos dez segundos ( dez passes) com o pé não dominante na prancha de equilíbrio médio-lateral, e com o pé dominante no disco de equilíbrio (Acte - plástico, diâmetro de $39 \mathrm{~cm}$ ). Foram realizados (1) passes picados para as laterais de forma a alternar direita e esquerda, alternando a mão do passe; esse exercício está ilustrado na Figura a seguir (Figura 4.10):

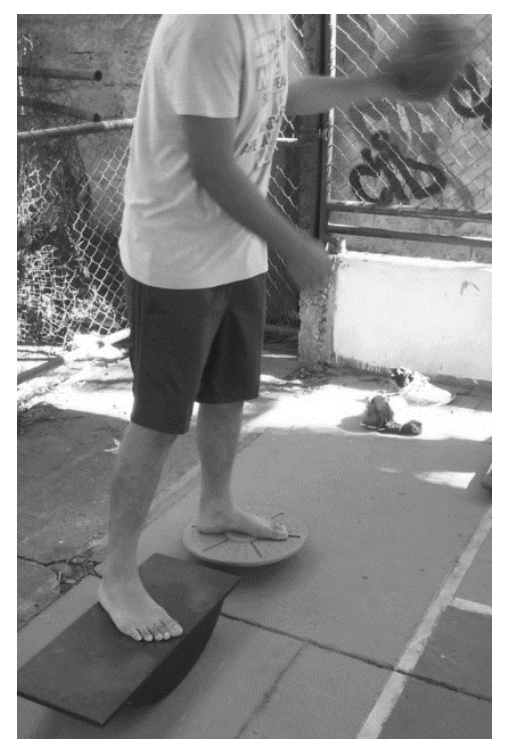

Figura 4.10 - Exercícios 3 e 4 do grau três. 
- Execução de (1) três séries de cinco agachamentos em apoio bi podal com olhos abertos e (2) três séries de cinco agachamentos com os olhos fechados com a base sobre as almofadas de equilíbrio (Mercur $-30 \mathrm{~cm}$ de diâmetro). $O$ intervalo de recuperação entre as séries foi de pelo menos dez segundos. Esse exercício está ilustado na Figura a seguir (Figura 4.11):

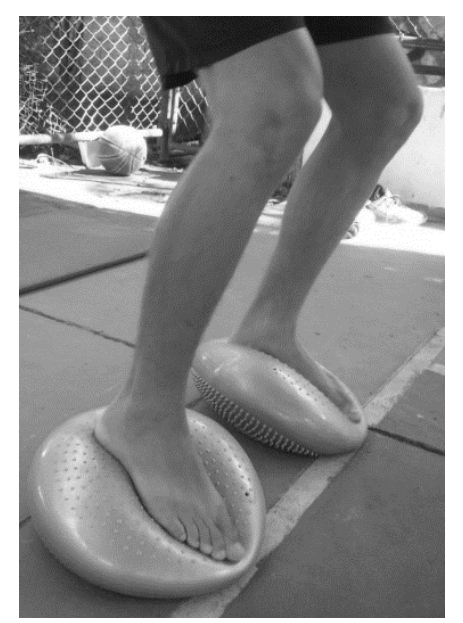

Figura 4.11 - Exercício cinco do Grau 3.

- Execução de três séries de cinco agachamentos driblando a bola com a mão dominante em apoio bi podal sobre almofadas de equilíbrio (Mercur $-30 \mathrm{~cm}$ de diâmetro). O intervalo de recuperação entre as séries foi de dez segundos. Esse exercício está ilustrado na Figura a seguir (Figura 4.12):

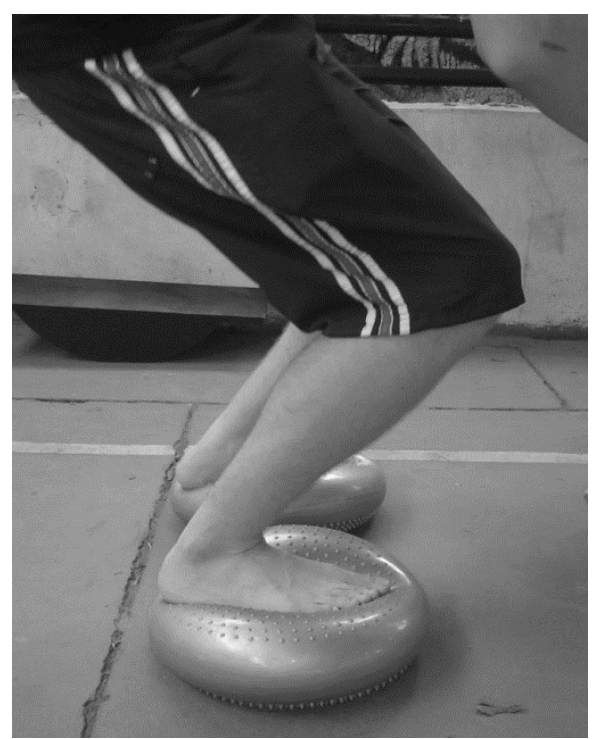

Figura 4.12 - Exercício seis do Grau 3. 
O resumo das atividades desenvolvidas nos exercícios do Grau de dificuldade três está representado na Figura 4.13 e na Tabela 3.

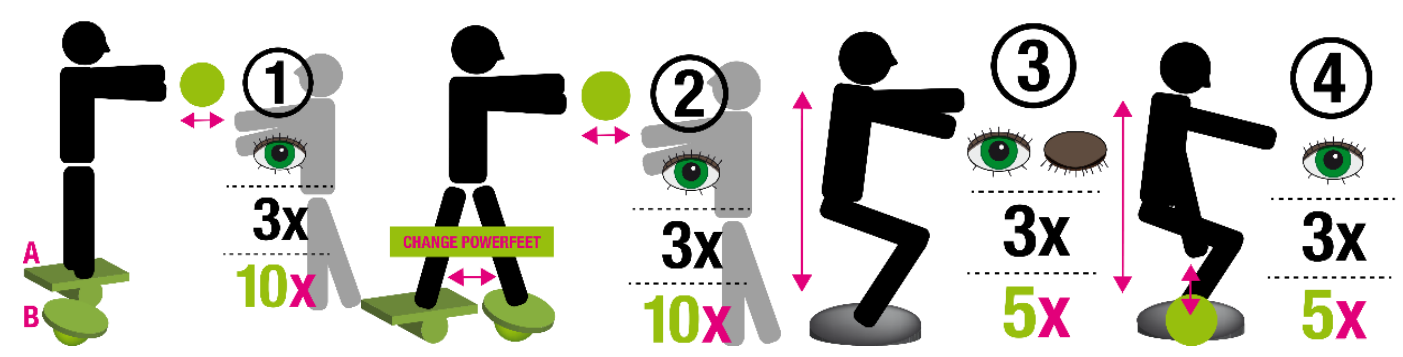

Figura 4.13 - Resumo dos exercícios do Grau 3 de dificuldade.

1 ) Exercício um do Grau 3; 2) Exercício dois do Grau 3; 3) Exercício três do Grau 3; 4) Exercício quatro do Grau 3. Os infográficos estão dispostos em ordem sequencial de: exercício, utilização da visão, número de repetições, uso de repetições por implemento e perna dominante.

\begin{tabular}{|c|c|c|c|c|c|c|c|c|}
\hline Ex & Sér & Atividade & Rep & $\operatorname{Rec}$ & Implemento & Vis & Apoio & Cal \\
\hline \multirow[b]{2}{*}{1} & 1 & & \multirow[b]{2}{*}{3} & \multirow[b]{2}{*}{$10 \mathrm{~s}$} & PML & \multirow[b]{2}{*}{$S$} & \multirow[b]{2}{*}{ BIP } & \multirow[b]{2}{*}{$S$} \\
\hline & 2 & $\begin{array}{l}10 \text { Passes de Peito } \\
\text { sobre implemento }\end{array}$ & & & $\mathrm{DE}$ & & & \\
\hline \multirow[b]{2}{*}{2} & 1 & & \multirow[b]{2}{*}{3} & \multirow[b]{2}{*}{$10 \mathrm{~s}$} & \multirow[b]{2}{*}{ PML e DE } & \multirow[b]{2}{*}{$S$} & \multicolumn{2}{|l|}{ BIPMIDPML } \\
\hline & 2 & $\begin{array}{l}10 \text { Passes picados } \\
\text { sobre implemento }\end{array}$ & & & & & BIPMIDDE & $S$ \\
\hline \multirow[b]{2}{*}{3} & 1 & & \multirow[b]{2}{*}{3} & \multirow[b]{2}{*}{$10 \mathrm{~s}$} & \multirow[b]{2}{*}{ Almofada } & $S$ & \multirow[b]{2}{*}{ BIP } & \multirow[b]{2}{*}{$S$} \\
\hline & 2 & $\begin{array}{l}5 \text { Agachamentos sobre } \\
\text { implemento }\end{array}$ & & & & $\mathrm{N}$ & & \\
\hline 4 & 1 & $\begin{array}{l}5 \text { Agachamentos sobre } \\
\text { implemento driblando }\end{array}$ & 3 & $10 \mathrm{~s}$ & Almofada & $S$ & BIP & $S$ \\
\hline
\end{tabular}

Tabela 3 - Resumo dos exercícios do Grau 3 de dificuldade.

Ex= Exercício em ordem; Sér: Série em ordem; Atividade = Tarefa executada; $R e p=$ Repetição; $R e c=$ Tempo de recuperação; $P M L=$ prancha médio lateral; $\mathrm{DE}=$ disco de equilíbrio; - = Não mensurado; Vis= Uso da Visão; $\mathrm{S}=\mathrm{Sim}$; N= Não; BIP= Apoio Bipodal; UNI= Apoio Unipodal; Esq = Esquerdo; Dir= Direito; $\mathrm{MSD}=$ Membro superior dominante; $M S N D=$ Membro superior não dominante; $M I D=$ Membro Inferior dominante; $\mathrm{MIND}=$ Membro Inferior não dominante; BIPMIDPML = Apoio bipodal com membro inferior dominante em Prancha médio lateral; BIPMIDDE= Apoio bipodal com membro inferior dominante em Disco de Equilíbrio; Cal = Calçado; $\mathrm{S}=$ Sim; N= Não. 


\subsubsection{Exercícios Grau 4}

- Execução de cinco lances livres sobre uma prancha de equilíbrio médio lateral (feito de madeira com $65 \mathrm{~cm}$ de largura e $28 \mathrm{~cm}$ de espessura) em apoio bi podal com os olhos fechados. Esse exercício está ilustado na Figura a seguir (Figura 4.14):

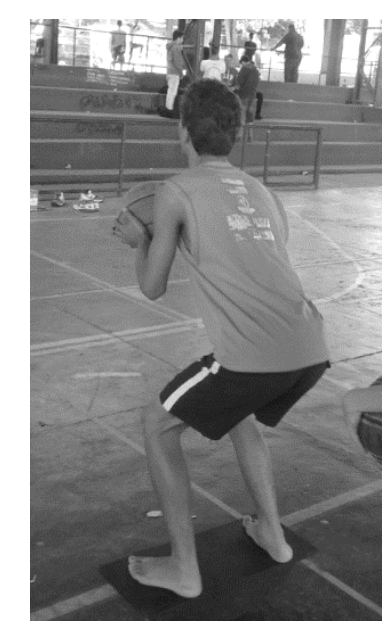

Figura 4.14 - Exercício um do Grau 4

- Execução de cinco lances livres com cada membro inferior (MI) sobre um disco de equilíbrio em apoio bi podal com os olhos fechados. Esse exercício está ilustrado na Figura a seguir (Figura 4.15):

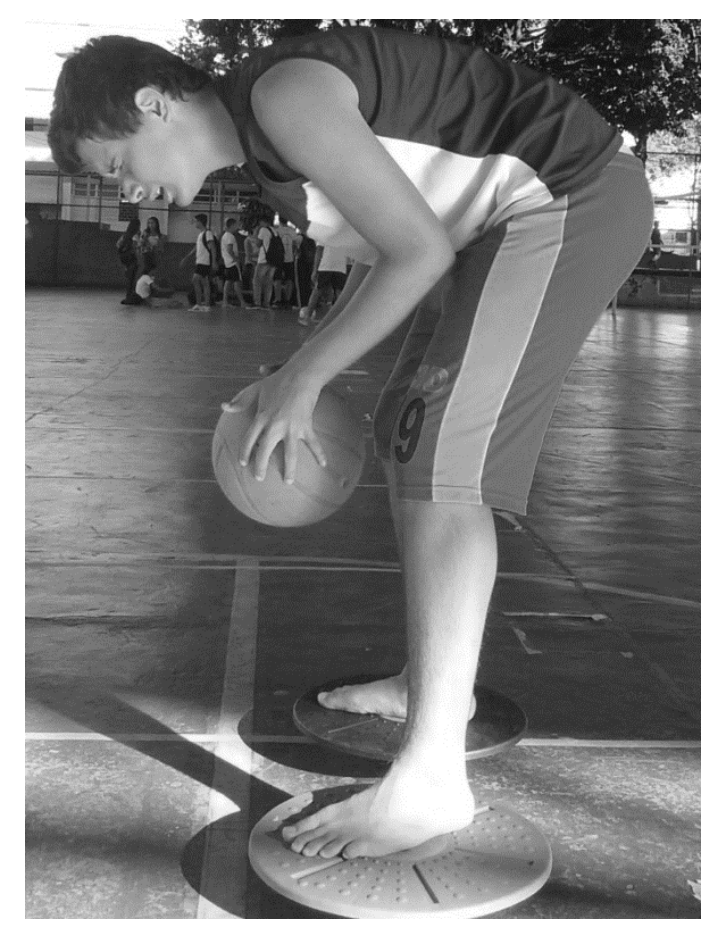

Figura 4.15 - Exercício dois do Grau 4. 
- Execução de cinco lances livres com cada MI sobre almofadas de equilíbrio (Mercur $-30 \mathrm{~cm}$ de diâmetro) em apoio bi podal com os olhos fechados. Esse exercício está ilustrado na Figura a seguir (Figura 4.16):

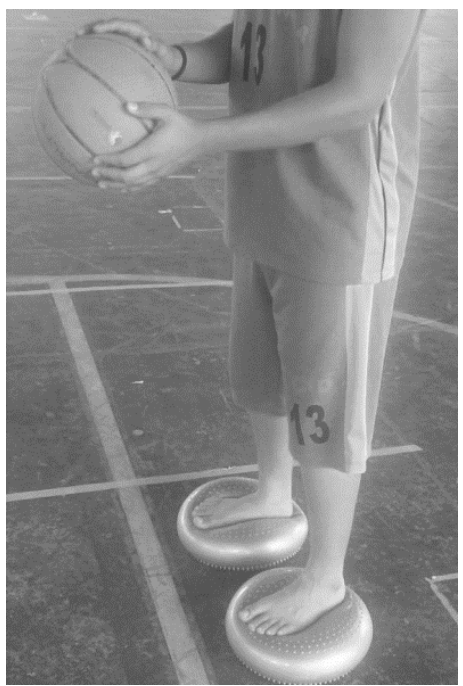

Figura 4.16 - Exercício três do Grau 4.

- Execução de três arremessos à cesta em apoio bi podal sobre prancha de equilíbrio médio lateral (feito de madeira com $65 \mathrm{~cm}$ de largura e $28 \mathrm{~cm}$ de espessura), que foi posicionada em um raio entre 65-75 centímetros do aro com a bola posicionada entre 40-50 (Transferidor - New Line WALEU) da Tabela; esse exercício está ilustrado na Figura a seguir (Figura 4.17):

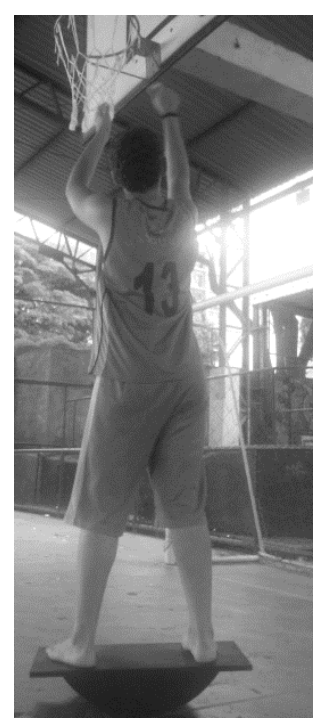

Figura 4.17 - Exercício quatro do Grau 4. 
- Execução de três arremessos à cesta em apoio bi podal sobre disco de equilíbrio (feito de madeira com $65 \mathrm{~cm}$ de largura e $28 \mathrm{~cm}$ de espessura), que foi posicionada em um raio entre 65-75 centímetros do aro com a bola posicionada entre 40-50 (Transferidor - New Line WALEU) da tabela; esse exercício está ilustrado na Figura a seguir (Figura 4.18):

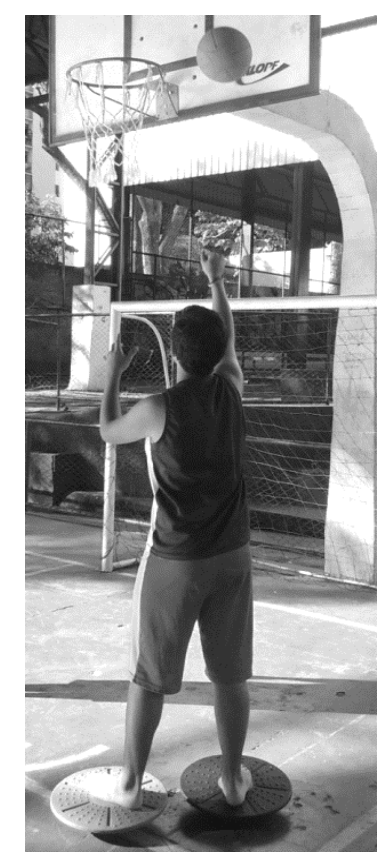

Figura 4.18 - Exercício cinco do Grau 4.

- Execução de três arremessos à cesta em apoio bi podal sobre almofadas de equilíbrio (Mercur $-30 \mathrm{~cm}$ de diâmetro), que foi posicionada em um raio entre 65-75 centímetros do aro com a bola posicionada entre 40-50응 (Transferidor - New Line WALEU) da Tabela; esse exercício está ilustado na Figura a seguir (Figura 4.19): 


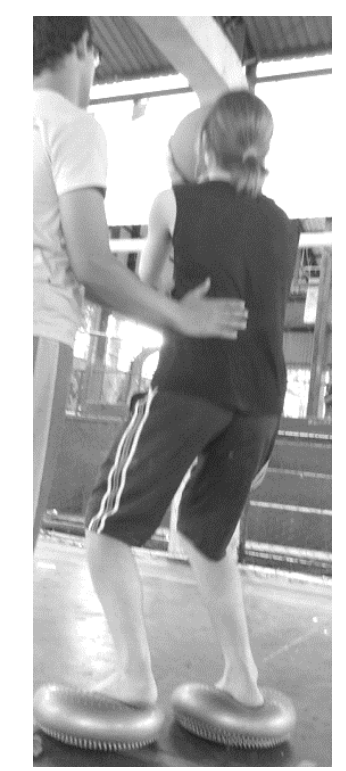

Figura 4.19 - Exercício seis do Grau 4.

- Execução de três jumps em apoio bi podal sobre prancha de equilíbrio médio lateral (feito de madeira com $65 \mathrm{~cm}$ de largura e $28 \mathrm{~cm}$ de espessura), que foi posicionada em um raio entre 65-75 centímetros do aro com a bola posicionada entre 40-50 (Transferidor - New Line WALEU) da Tabela. Esse exercício está ilustado na Figura a seguir (Figura 4.20):

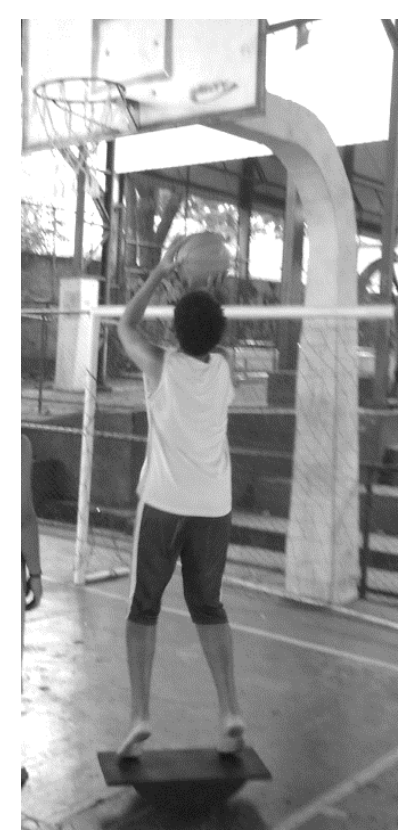

Figura 4.20 - Exercício sete do Grau 4. 
- Execução de três jumps em apoio bi podal sobre disco de equilíbrio médio lateral (feito de madeira com $65 \mathrm{~cm}$ de largura e $28 \mathrm{~cm}$ de espessura), que foi posicionada em um raio entre 65-75 centímetros do aro com a bola posicionada entre 40-50 (Transferidor - New Line WALEU) da Tabela. A aterrizagem foi feita no chão, na área anterior ao implemento da base. Esse exercício está ilustrado na Figura a seguir (Figura 4.21):

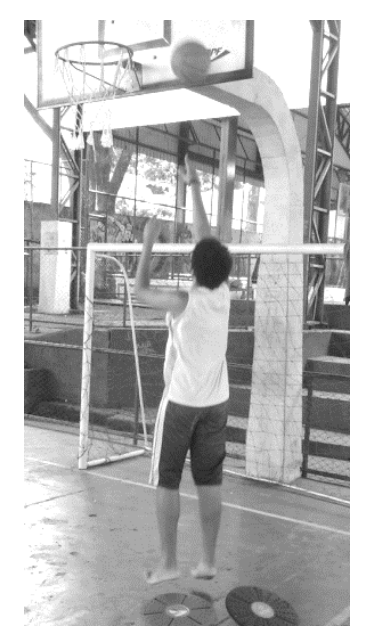

Figura 4.21 - Exercício oito do Grau 4.

- Execução de três jumps em apoio bi podal sobre almofada de equilíbrio (Mercur - $30 \mathrm{~cm}$ de diâmetro), que foi posicionada em um raio entre 65-75 centímetros do aro com a bola posicionada entre 40-50 da Tabela. Esse exercício está ilustrado na Figura a seguir (Figura 4.22):

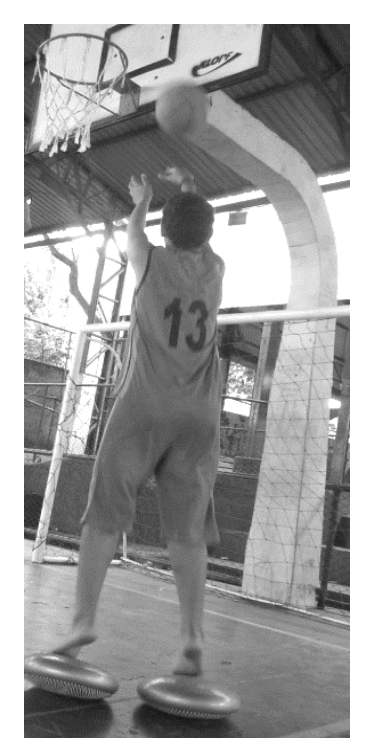

Figura 4.22 - Exercício nove do Grau 4. 
O resumo das atividades desenvolvidas nos exercícios do Grau de dificuldade quatro está representado na Figura 4.23 e na Tabela 4.
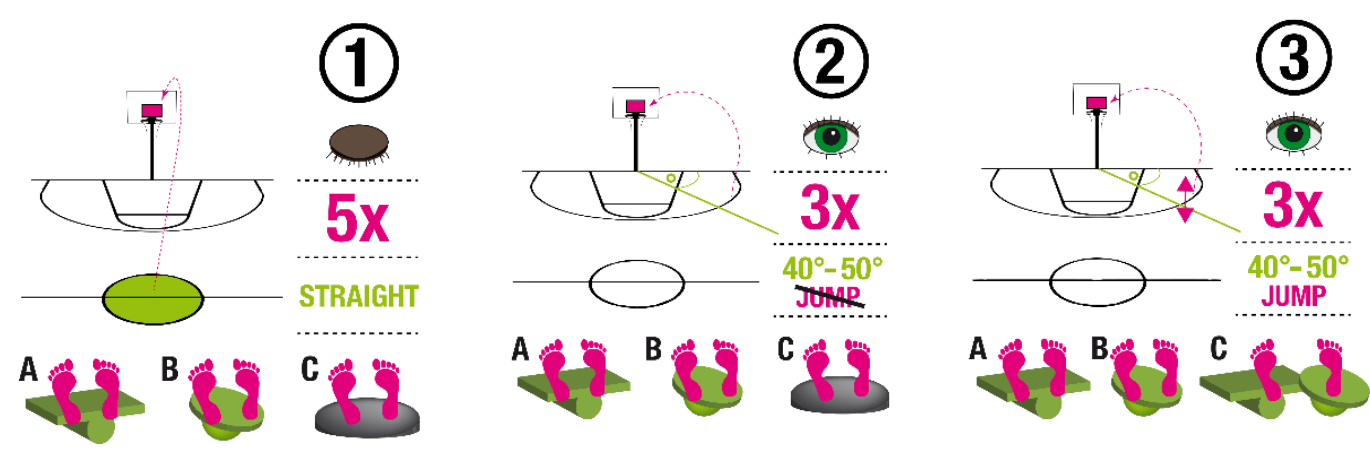

Figura 4.23 - Resumo dos exercícios do Grau 4 de dificuldade.

1) Exercício um do Grau 4;2) Exercício dois do Grau 4; 3) Exercício três do Grau 4;. Os infográficos estão dispostos em ordem sequencial de: exercício, posicionamento na quadra e garrfão; utilização da visão, número de repetições por implemento e uso ou não de salto.

Tabela 4 - Resumo dos exercícios do Grau 4 de dificuldade.

\begin{tabular}{|c|c|c|c|c|c|c|c|c|}
\hline Ex & Sér & Atividade & Rep & Rec & Implemento & Vis & Apoio & Cal \\
\hline \multirow[b]{3}{*}{1} & 1 & \multirow{3}{*}{ Lance livre sobre implemento } & \multirow{3}{*}{5} & \multirow{3}{*}{$10 \mathrm{~s}$} & PML & \multirow{3}{*}{$\mathbf{N}$} & \multirow{3}{*}{ BIP } & \multirow{3}{*}{ S } \\
\hline & 2 & & & & DE & & & \\
\hline & 3 & & & & ALM & & & \\
\hline \multirow[b]{3}{*}{2} & 1 & \multirow{2}{*}{$\begin{array}{l}\text { Arremesso sobre implemento à } \\
65-75 \mathrm{~cm} \text { do Aro e } 40^{\circ}-50^{\circ} \mathrm{da}\end{array}$} & \multirow{3}{*}{3} & \multirow{3}{*}{$10 \mathrm{~s}$} & PML & \multirow{3}{*}{$\mathbf{S}$} & \multirow{3}{*}{ BIP } & \multirow{3}{*}{ S } \\
\hline & 2 & & & & DE & & & \\
\hline & 3 & Tabela & & & ALM & & & \\
\hline \multirow[b]{3}{*}{3} & 1 & \multirow{3}{*}{$\begin{array}{l}\text { Jump sobre implemento à } 65-75 \\
\mathrm{~cm} \text { do Aro e } 40^{\circ}-50^{\circ} \text { da Tabela }\end{array}$} & \multirow{3}{*}{3} & \multirow{3}{*}{$10 \mathrm{~s}$} & PML & \multirow{3}{*}{$\mathbf{S}$} & \multirow{3}{*}{ BIP } & \multirow{3}{*}{$\mathbf{S}$} \\
\hline & 2 & & & & $\mathrm{DE}$ & & & \\
\hline & 3 & & & & ALM & & & \\
\hline
\end{tabular}

Ex= Exercício em ordem; Sér: Série em ordem; Atividade $=$ Tarefa executada; Rep= Repetição; Rec= Tempo de recuperação; $P M L=$ prancha médio lateral; $D E=$ disco de equilíbrio; $A L M=$ Almofada; - = Não mensurado; Vis= Uso da Visão; S= Sim; N= Não; $\mathrm{BIP}=$ Apoio Bipodal; $\mathrm{Cal}=$ Calçado; $\mathrm{S}=\mathrm{Sim} ; \mathrm{N}=\mathrm{Não}$.

\subsection{Aquisição}

Os sinais de eletromiografia foram registrados por meio de eletrodos de superfície de forma esférica $(\mathrm{AgAgCl}, 0,8 \mathrm{~cm}$ de diâmetro, com uma 
distância inter-eletrodos de dois $\mathrm{cm}$ ) posicionados sobre os músculos soleus (SO) (BRUKE et al., 1988) e tibial anterior (TA) (SENIAN) (Figura 4.24). Os eletrodos para captar o sinal do músculo SO foram posicionados quatro centímetros abaixo da margem inferior das duas cabeças dos músculos gastrocnêmio. Para o TA, os eletrodos foram posicionados e fixados com fida adesiva sobre o ventre muscular (SENIAN). Um eletrodo terra foi colocado sobre o punho, sobre a parte distal do rádio.

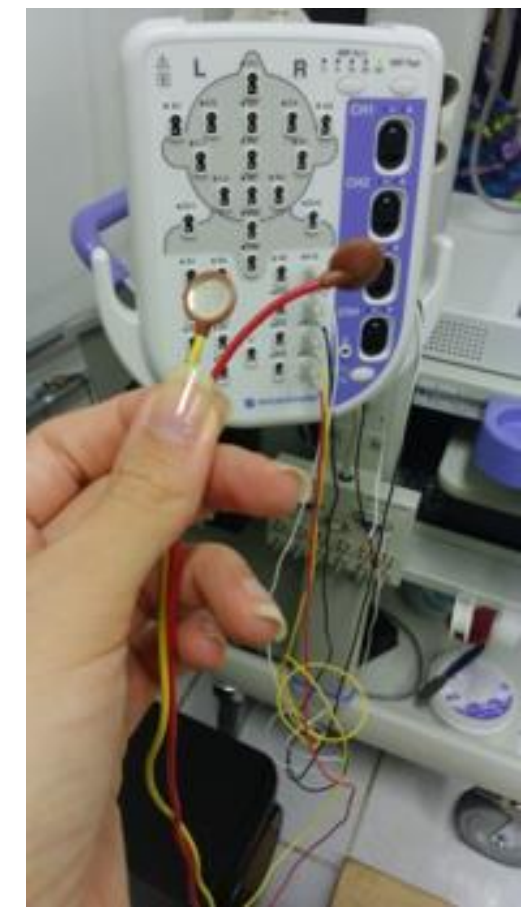

Figura 4.24 - Modelo dos eletrodos de superfície.

Os sinais de eletromiografia foram amplificados e filtrados (5 $\mathrm{Hz}$ a 2 $\mathrm{kHz}$ ) pelo sistema MEB-2300K (Nihon-Kohden, Japão) (Figura 4.25) com taxa de amostragem de $5 \mathrm{kHz}$. Todos os dados foram armazenados em disco rígido para serem posteriormente processados.

\subsection{Estimulação}

O reflexo $\mathrm{H}$ foi obtido por estimulação elétrica (pulso retangular, $1 \mathrm{~ms}$ de duração) aplicado ao nervo tibial posterior por meio de um eletrodo posicionado na fossa poplítea (PANIZZA et al.,1989) acoplado ao sistema MEB-2300. 


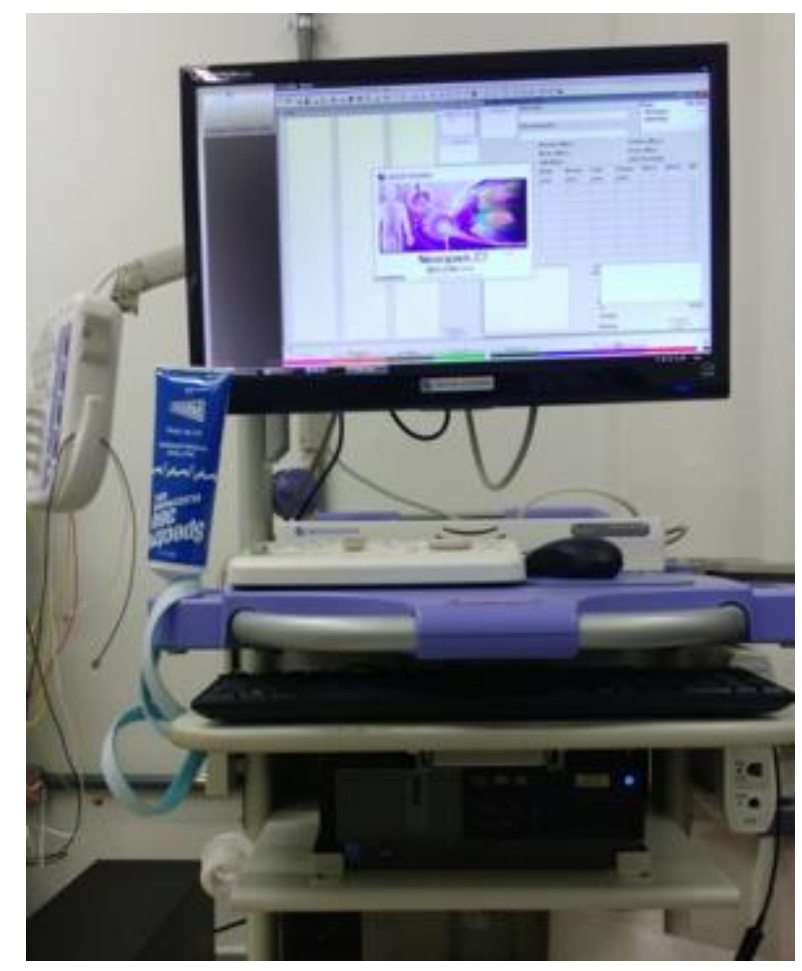

Figura 4.25 - Equipamento Nihon-Kohden do Laboratório de Processamento de Sinas Biológicos e Controle Motor da Faculdade de Educação Fìsica da Universidade de Brasília (UnB).

A presença de uma onda $\mathrm{M}$ estável durante o experimento foi utilizada para assegurar uma estimulação eficaz, ou seja, com intensidade constante. O monitoramento da eficácia do estímulo permitiu relacionar qualquer mudança na amplitude do reflexo $\mathrm{H}$ a fatores neurofisiológicos (SCHIEPPATI, 1987) (Figura 4.26). Para isso, foi preciso manter as entradas periféricas sempre regulares (por meio do controle do local dos eletrodos, construção de uma cadeira estável e onda $M$ semelhante nos testes pré e pós). Uma ficha de controle individual foi diagramada com dados referentes aos testes pré, como posição dos eletrodos, registro eletromiográfico com a onda $\mathrm{M}$ do músculo tibial anterior e demais parâmetros de coleta de dados representados na Figura 4.26. 

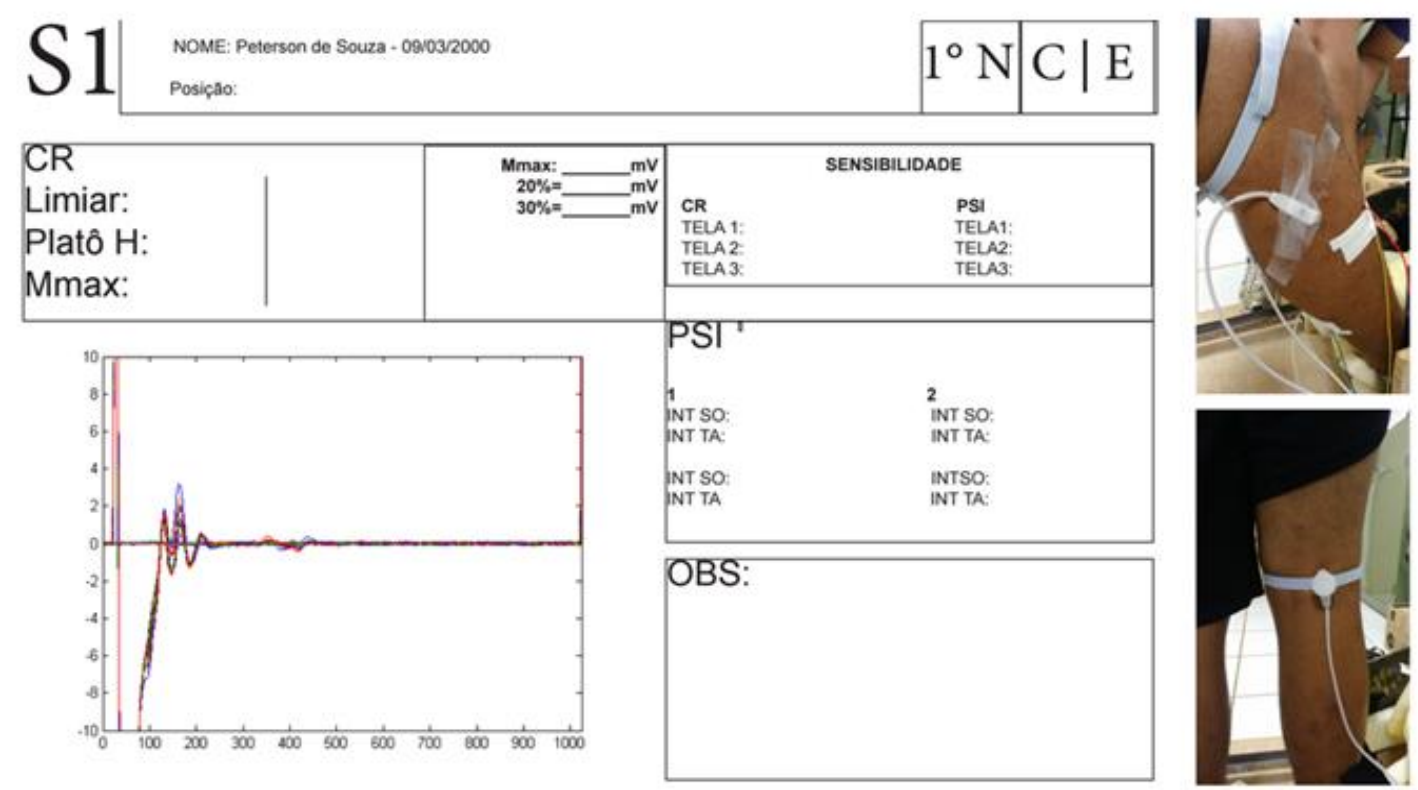

Figura 4.26 - Controle individual de coletas de dados diagramado para cada sujeito.

\subsubsection{Procedimentos}

Os sujeitos permaneceram sentados em uma cadeira projetada para estabilizar as pernas e os pés (Figura 4.27). As articulações do quadril e joelho das duas pernas foram mantidas à $~ 100^{\circ}$ enquanto as do tornozelo estiveram à $\sim 60^{\circ}$.

Para avaliar o grau de IPS sobre os terminais das aferentes la do músculo soleus antes e após o treinamento neuromuscular, foi utilizado um paradigma condicionante-teste (C-T) (ILES, 1996; MEZZARANE et al.,2012; MEZZARANE et al.,2013). Desta forma, o reflexo $\mathrm{H}$ foi condicionado por um pulso elétrico retangular (de $1 \mathrm{~ms}$ de duração) aplicado no nervo fibular com eletrodo de estimulação posicionado na altura da cabeça da fíbula e intensidade de 1,1 vezes o limiar motor (1,1 x MT), 100 ms antes da liberação do estímulo que evoca o reflexo $\mathrm{H}$. 


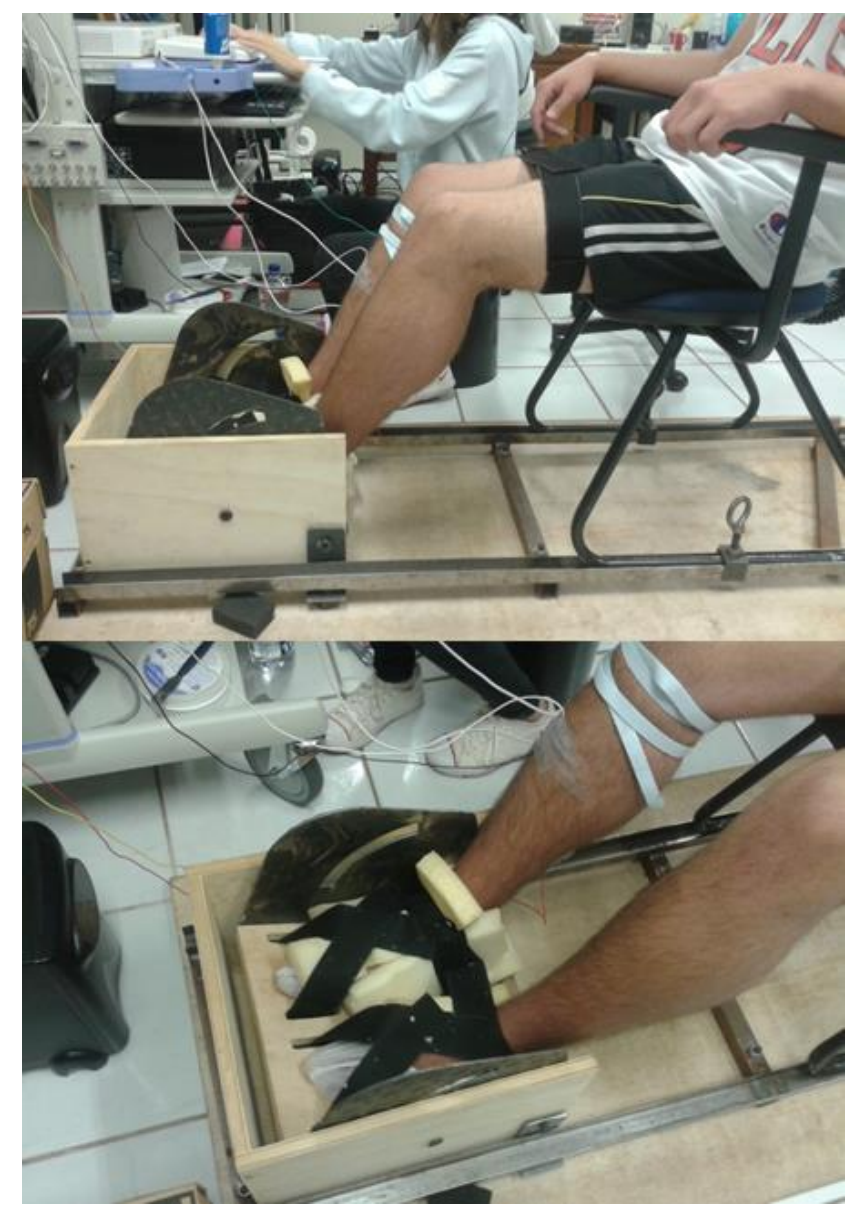

Figura 4.27 - Estrutura para fixação dos pés.

Os estímulos condicionantes foram liberados de maneira aleatória (FOURNIER et al., 2001) por um trigger (Figura 4.28) desenvolvido no Laboratório de Processamento de Sinais Biológicos e Controle Motor da Universidade de Brasília. A temporização dos estímulos e aquisição dos dados foi controlada por um programa escrito em Arduíno Uno (Figura 4.28) e pelo software Neuropack X1 (NIHON KOHDEN - MEB 2300 v. 03 -01). O sistema possui um algorítimo integrado que sincronizou de forma aleatória os pulsos de saída em intervalos entre 1 e 5 segundos (de 1 a $5 \mathrm{~Hz}$ ).

A amplitude do reflexo controle (sem estímulo condicionante) foi de 20$30 \%$ da resposta direta máxima (Mmax), pois respostas reflexas em torno dessa amplitude são mais sensíveis ao condicionamento, independentemente de sua natureza (CRONE et al.,1987). O valor de $25 \%$ da Mmax foi calculado logo após o procedimento da CR e dois cursores foram posicionados na tela de aquisição do equipamento Nihon- Kohden. De maneira semelhante, a presença de uma onda $M$ constante (de amplitude 
com aproximadamente $10 \% \mathrm{Mmax}$ ) foi monitorada para garantir uma eficácia de estimulação apropriada.

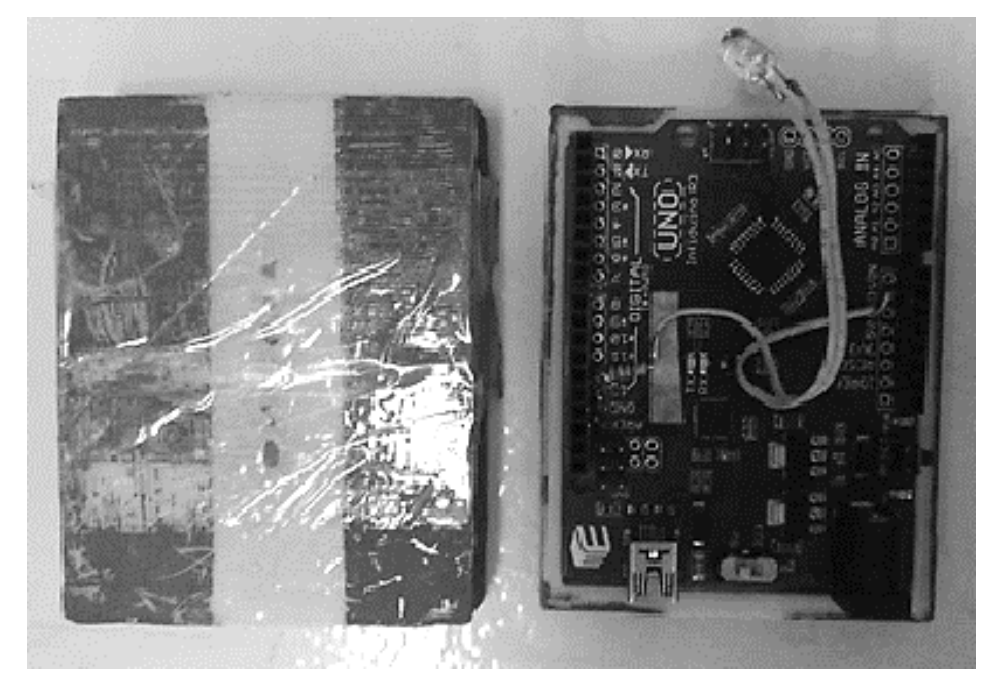

Figura 4.28 - Trigger desenvolvido em Arduino Uno com respectivo algoritmo.

Para controlar a eficácia da estimulação condicionante sobre o nervo fibular, a presença de uma onda $\mathrm{M}$ constante (ou, quando possível, onda $\mathrm{H}$ ) foi monitorada no músculo tibial anterior ao longo do experimento (MEZZARANE, 2012).

As curvas de recrutamento de 50 pontos ( 50 valores de amplitude pico à pico do eflexo $\mathrm{H}$ ) foram obtidas por meio de alterações na intensidade de estimulação para obtenção de 50 respostas $\mathrm{H}$. Os estímulos foram liberados em intervalos aleatórios (entre dois e sete segundos) controlados pelo sistema MEB-2300K para minimizar efeitos de expectativa de ocorrência de estimulação por parte do sujeito (FOURNIER, et al., 2001). As amplitudes obtidas foram baixas o suficiente para determinar o limiar de disparo de unidades motoras menores (primeiras unidades recrutadas). Foram obtidas também respostas reflexas com valores intermediários de amplitude, bem como a amplitude máxima do reflexo $\mathrm{H}$ e da onda $\mathrm{M}$ (resposta direta máxima ou Mmax), de modo a possibilitar um ajuste de curva adequado.

Os dados das amplitudes reflexas e valores de corrente foram armazenados em computador para posterior análise. 


\subsection{Processamento de Dados}

Após a aquisição, os sinais foram convertidos para ASCII e processados em ambiente MatLab (versão 2012b, Math Works, Inc.). As curvas de recrutamento do reflexo $\mathrm{H}$ e da onda $\mathrm{M}$ foram ajustadas por meio de uma curva logística (sigmoide) como descrito detalhadamente em Klimstra e Zehr (2008) de acordo com a equação:

$$
H(s)=\frac{H_{\max }}{1+e^{m(s 50-s)}}
$$

Em que $H_{\max }$ é a resposta $\mathrm{H}$ máxima (limite superior da curva), $m$ é a inclinação da alça ascendente, s50 é a intensidade de estímulo necessária para se evocar $50 \%$ do Hmax e $H(s)$ é a amplitude reflexa para um determinado estímulo $s$. Os coeficientes da curva foram estimados utilizando a técnica dos mínimos quadrados interativos (função nlinfit do Matlab).

Os valores iniciais utilizados como variáveis de entrada na rotina personalizada escrita em ambiente MatLab (versão 2012b, Math Works, Inc.) foram a corrente normalizada, o platô (Hmax) e uma inclinação calculada a partir da reta de regressão estimada da porção linear da alça ascendente da curva de recrutamento. A inclinação da reta, que tangencia a região da curva cuja a derivada é maior, foi calculada de acordo com a equação:

$$
\text { inclinação }=m \frac{H \max }{4}
$$

Um ajuste sigmoidal foi também realizado sobre as amplitudes da onda $\mathrm{M}$ para comparação adequada das curvas de recrutamento do reflexo $\mathrm{H}$ ao longo das intensidades de estimulação. Desta forma, a corrente foi normalizada pela corrente necessária para se evocar $50 \%$ da resposta Mmax utilizando-se $o$ ajuste sigmoidal das ondas $\mathrm{M}$ como referência.

Para saber qual curva de recrutamento melhor se ajusta aos dados, foi escolhida aquela que apresentou menor erro quadrático, variando o valor de $s 50$ do primeiro valor de $s$ (valor mínimo de corrente) até o seu último valor (valor máximo de corrente). Este erro se baseia no somatório da diferença entre o erro esperado e o erro observado. $O$ valor de $s 50$ associado ao 
menor erro quadrático foi o escolhido para fazer o ajuste. Como os valores de corrente utilizados no experimento não foram distribuídos uniformemente, foram interpolados pontos entre os valores mínimos e máximos de corrente para encontrar o valor ideal de $s 50$.

O grau de inibição pré-sináptica foi obtido a partir da subtração das amplitudes (normalizadas pela Mmax) calculadas como valores pico-a-pico dos reflexos $\mathrm{H}$ controle (Hcont), dos valores dos reflexos $\mathrm{H}$ condicionados (Hcond) divididos pelo reflexo $\mathrm{H}$ controle:

$$
I P S=\frac{H \text { cont }-H \text { cond }}{H \text { cont }}
$$

\subsection{Análise Estatística}

As análises estatísticas dos dados estudados foram realizadas pelo software livre R (R Core Team, 2015) e pelo Microsoft Excel (2010). Inicialmente foram apresentadas as estatísticas descritivas (média \pm desviopadrão) de todas as variáveis em estudo.

Os valores das variáveis Slope H, Hmax, Mmax, Hth, H50, H100, Hth@, H50@, H100@, Grau PSI, MC, IMC, \%Gordura e Altura foram medidos para os grupos Experimental e Controle, nos dois períodos: pré- e pós-treinamento. $O$ efeito do treinamento neuromuscular dessas variáveis foi verificado por meio de uma ANOVA (Análise de Variância) mista com dois fatores e medidas repetidas, considerando a intervenção (grupo experimental ou controle) como efeito entre-indivíduos e o momento (pré- e póstratamento) como efeito intra-indivíduo. No caso da distribuição não ser normal, o teste realizado foi uma Anova não paramétrica de dois fatores e medidas repetidas (BRUNNER et al., 1999; Equação 3.13 e Teorema 3.7), também considerando a intervenção como efeito entre-indivíduos e o momento como efeito intra-indivíduo.

As variáveis que só foram testas uma vez e as diferenças entre os momentos pré e pós intervenção das demais variáveis foram calculadas. $\mathrm{O}$ prefixo "Diff" foi acrescentado à nomenclatura de cada variável de medidas repetidas e refere-se a diferenças entre momentos. As variáveis DiffHTh, DiffH50, Diff H100, DifcorHTh, DifcorH50, DifcorH100, Tempo de Basquete, 
Idade, DifeMmax, DifeSlopeH, DifeH50, DifeH100, DifePSI, DifeAltura, DifeMC, DifelMC, Dife\%Gordura, DifeSlopeM, DifeHth@, DifeH50@ e DifeH100@ foram observadas apenas a variação (diferença) dos valores pós-tratamento. Neste caso, a comparação entre os dois grupos foi realizada pelo teste $t$ não pareado ou pelo teste $U$ de Mann-Whitney quando a suposição de normalidade foi rejeitada.

Além das análises convencionais de hipóteses foi possível analisar o comportamento dos dados de acordo com a sua natureza, ou seja, uma medida que não sofra a influência do tamanho da amostra $(\mathrm{N})$ e que analise a importância prática da diferença ou relação observada (CONBOY, 2000). Conboy (2000) comenta que amostras grandes podem dar origem a valores reduzidos de $\mathrm{p}$, exagerando a importância aparente das diferenças. Em contrapartida, diferenças clinicamente significativas podem dar origem a valores de $p$ grandes, se a amostra considerada no estudo for de tamanho reduzido. O mesmo autor comenta que o tamanho do efeito traz informações sobre a intensidade das relações e informações para uma eventual reprodutibilidade dos resultados observados (CONBOY, 2000).

No caso de distribuição normal, a magnitude do efeito do treinamento neuromuscular foi calculada através da medida d de Cohen (COHEN, 1988) que é definida por:

$$
d-\text { Cohen }=\frac{\operatorname{dif}_{G E}-d i f_{G C}}{\sqrt{\frac{\operatorname{Var}_{G E}+V a r_{G C}}{2}}},
$$

Em que $\operatorname{dif}_{G E}$ e $\operatorname{dif}_{G C}$ são as médias das diferenças (pós - pré) dos valores observados dos grupos Experimental e Controle, respectivamente e; $\operatorname{Var}_{G E} \mathrm{e}$ VarGc são as variâncias das diferenças (pós - pré) dos valores observados dos grupos Experimental e Controle. Segundo Cohen (1988), o tamanho de efeito pode ser classificado como: efeito pequeno se $|\mathrm{d}|<0,5$; efeito médio se $0,5 \leq|\mathrm{d}| \leq 0,8$ e; efeito grande se $|\mathrm{d}|=>0,8$.

Quando os dados não foram normais, o tamanho de efeito foi calculado pelo delta de Cliff (CLIFF, 1993), que é definido por:

$$
d-\text { Cliff }=\frac{2 U}{N_{E} N_{C}}-1
$$


Em que, $U$ é a estatística do teste $U$ de Mann-Whitney da comparação das diferenças dos grupos controle e experimental e $N_{E}$ e NC são os tamanhos da amostra dos grupos experimental e controle, respectivamente.

Ao contrário do d de Cohen, segundo Macbeth, Razumiejczyk \& Ledesma (2011), o delta de Cliff é limitado no intervalo -1 (um negativo) a 1 (um positivo) pois seria uma medida de dominância, referente ao grau de sobreposição entre duas distribuições. Esta estatística estima a probabilidade de que um valor selecionado de um dos grupos ser maior do que um valor selecionado do outro grupo, subtraindo a probabilidade inversa.

Tendo em vista a importância da diferença entre os grupos, para um valor p significativo espera-se associação a um efeito de valor aproximado à -1 (um negativo) ou 1 (um positivo): Quando o cruzamento entre dois grupos gera um conjunto vazio, o resultado esperado é o extremo do delta de Cliff: \pm 1 ; já quando este cruzamento gera grupos sobrepostos, o valor-p encontrado não é significativo e o valor de delta de Cliff fica próximo a 0,0 (zero). Quando o tamanho de efeito é de -1 (um negativo) ou 1 (um positivo), este resultado indica a ausência de sobreposição entre os dois grupos; enquanto que o resultado de 0 (zero) indica que as distribuições de grupos se sobrepõem completamente (MACBETH, RAZUMIEJCZYK \& LEDESMA, 2011).

Cliff não sugere valores correspondentes para representar pequenas, médias e grandes efeitos. No entanto o estudo de Romano et al. (2006) relata que Cohen (1988) apresentou as interpretações do tamanho do efeito do índice d em termos de não sobreposição entre duas distribuições normais, o que possibilitou o cálculo entre $d$ e delta. Isto é, com duas distribuições normais, uma diferença de médias que representa o tamanho do efeito $d$ de Cohen de 0,20 terá de valor delta de 0,147 ; já o tamanho do efeito $d$ de 0,50 corresponderia a um valor de delta de 0,33 ; enquanto que o tamanho do efeito $d$ de 0,80 corresponderia a um delta de 0,474 (ROMANO et. al, 2006).

A normalidade dos dados foi verificada pelo teste de Shapiro-Wilk. Todos os testes consideraram um nível de significância de $5 \%$.

\section{RESULTADOS}

No presente trabalho realizamos um estudo eletrofisiológico baseado em medidas de amplitude do reflexo $\mathrm{H}$ obtidas no músculo SO para detectar 
possíveis alterações em diferentes processos medulares após o regime de treinamento neuromuscular proposto. Além de medidas pontuais de amplitude, como a relação Hmax/Max comumente utilizada na literatura, o padrão de recrutamento das UMs motoras foi avaliado por meio de parâmetros extraídos de um ajuste sigmoidal da alça ascendente da CR do reflexo $\mathrm{H}$. Entre os parâmetros afetados após o treinamento estão o SlopeH, H@th e SlopeM.

O aumento da variável SlopeH foi maior para o GE $(\delta=0,469)$ indicando uma diminuição na variabilidade dos limiares de ativação dos $\mathrm{MN}$ e efeiciência neural. Ou seja, quando comparado ao GC, pequenos aumentos na estimulação (corrente) induziram o recrutamento de um número maior de UM no GE após a intervenção. Essa compressão de limiares de ativação dos MN na medula representa um ganho de recrutamento maior de UM após o treinamento neuromuscular. Comportamento semelhante ocorreu para a variável H@Th, em que o crescimento da variável foi maior para o grupo experimental $(\delta=0,367$; um aumento médio de $20 \%)$. Esse resultado sugere que o treinamento gerou alterações na relação estímulo-resposta, ou seja, a mesma relativa baixa intensidade de corrente liberada no momento prétreinamento produziu uma resposta de amplitude maior no momento póstreinamento. Isso provavelmente ocorreu graças a um aumento na excitabilidade das UMs menores que respondem à esta faixa da CR, ou seja, as primeiras UMs recrutadas.

Por outro lado, a variável SlopeM apresentou uma redução menor para o grupo experimental em comparação ao grupo controle no momento pós ( $\delta=0,357 ; P=0,035)$, apesar da variável Mmax não ter se alterado entre os momentos, nem entre grupos. Este resultado pode ser consequência de alterações nas características de recrutamento dos axônios motores para estímulo externo. Contudo, não foi encontrado na literatura nenhum estudo que descreva ou mencione tal fenômeno.

Além de avaliar o efeito do programa de treinamento neuromuscular sobre o padrão de recrutamento de UMs de escolares praticantes de basquetebol, um mecanismo de regulação da excitabilidade de reflexos medulares também foi estudado: a IPS. 
O efeito do treinamento neuromuscular sobre a IPS do SO foi analisado por meio do paradigma C-T antes e após o treinamento com os voluntários em posição sentada e em repouso (JESSOP et al., 2013). Apesar de diversos estudos indicarem um aumento da IPS após este tipo de treinamento (GRUBER et al., 2007, TAUBE et al., 2007), o GraulPS não foi alterado entre os momentos e os grupos.

Dentre as variáveis antropométricas, o percentual de gordura foi a única que apresentou alteração significativa após o treinamento $(p=0,030)$. Porém, como a tendência foi de redução para os dois grupos, o tamanho do efeito foi muito pequeno $(\delta=-0,240)$. Assim, não esperamos que as respostas reflexas tenham sido afetadas por essa variável. Já a massa corporal teve um efeito médio ( $d=0.531$ ), mas não apresentou diferença significativa ( $p=0137)$. A altura é a variável que poderia afetar a resposta reflexa, mas não apresentou diferenças antes e após o regime de treinamento $(p=0,271)$ e nem o tamanho de efeito relevante. Raciocínio semelhante vale para a massa corporal (EYRE \& RAMESH, 1991). No entanto, a pesar de não ter sido encontrado estudos que afimem ou quantifiquem a influência da impedência sobre as respostas periféricas, a redução da porcentagem de gordura pode justificar a redução da variável Slope $M$.

\subsection{Caracterização da amostra}

A amostra foi constituída inicialmente por 30 sujeitos nos quais apenas 28 permaneceram até o final da pesquisa e tiveram os dados analisados. Um dos sujeitos do GE foi afatado do programa de pesquisa por problemas de saúde, e um sujeito do GC não participou do teste ao final do período de intervenção. Os demais sujeitos foram enquadrados nos critérios de inclusão para análise de sinais ou não realização do treinamento proposto. Os sujeitos recrutados para amostra foram adolescentes com idade variando em torno de quatorze anos (14 $\pm 0,978)$, jogavam basquete por aproximadamente dezenove meses $(19 \pm 8,391)$ e tiveram o nível de atividade física avaliada pelo questionário IPAQ em média como muito ativos. A instabilidade articular dos adolescentes foi verificada por meio do questionário AJAFT com um valor médio de 28,13 , demonstrando pouca instabilidade funcional ou não 
acentuada. Pontuações próximas à 48 representam maior função e menos sintomas. A nota de corte estabelecida foi de 22 para classificação do nível de instabilidade (WIKSTROM \& HUBBARD, 2010; WIKSTROM et al., 2009) para além de categorizar o grupo como estável em nível articular, garantir que a intervenção é apenas preventiva. As variáveis antropométricas foram aferidas para todos os voluntários no momento antes e após a intervenção. Durante a primeira avaliação antropométrica, a estatura média foi de 1,72 \pm 0,087 m, a massa corporal de $63 \pm 12,395 \mathrm{~kg}$, o Índice de massa corporal (IMC) de $20,53 \mathrm{~kg} / \mathrm{m}^{2}$ e o porcentual de gordura de $16,3 \%$. Já na última avaliação os adolescentes apresentaram um aumento médio da estatura de meio centímetro $(1,73 \pm 0,092 \mathrm{~m})$ e na massa corporal de oitocentos e cinquenta gramas $(63,85 \pm 12,395 \mathrm{~kg})$, fazendo com que o índice de massa corporal caísse em zero vírgula quinhentos e trinta e três pontos $(20,005 \pm 2,690$ $\mathrm{kg} / \mathrm{m}^{2}$ ). O percentual de gordura no momento após a intervenção também reduziu, em média de zero vírgula sessenta e cinco por cento $(15,65 \pm$ 4,127\%) e está apresentado na Tabela 8.

A análise amostral final $(n=28)$ está presente na Tabela 5 , onde cada variável está descrita em valores de média e desvio padrão (DP) pelo momento de análise (1= pré intervenção e 2=pós intervenção).

A pesar de amostra ser de conveniência, os sujeitos recrutados para o estudo foram divididos de forma aleatória entre os grupos experimental (GE) e controle (GC). As datas e períodos de mensuração dos testes também foram agendados de forma aleatória. Todos os dados referentes as análises neurofisiológicas foram testados quanto a normalidade para a posterior aplicação dos testes estatísticos adequados. Além dos parâmetros extraídos da curva de recrutamento, os dados referentes às diferenças entre amplitudes e correntes, grau de inibição pré-sinaptica e diferenças entre os momentos pós e pré também foram analisados com o mesmo teste. 
Tabela 5 - Descrição dos sujeitos analisados.

Variável

Momento

Média \pm DP

\begin{tabular}{|c|c|c|}
\hline & 1 & $1,725 \pm 0,087$ \\
\hline Estatura (cm) & 2 & $1,73 \pm 0,092$ \\
\hline \multirow[b]{2}{*}{ Massa Corporal (Kg) } & 1 & $63 \pm 13,531$ \\
\hline & 2 & $63,85 \pm 12,395$ \\
\hline \multirow[b]{2}{*}{$\mathrm{IMC}^{\mathrm{a}}$} & 1 & $20,538 \pm 3,156$ \\
\hline & 2 & $20,005 \pm 2,690$ \\
\hline \multirow[b]{2}{*}{ \%Gordura } & 1 & $16,3 \pm 5,509$ \\
\hline & 2 & $15,65 \pm 4,127$ \\
\hline Idade (anos) & 1 & $14 \pm 0,978$ \\
\hline Tempo basquete (meses) & 1 & $19 \pm 8,391$ \\
\hline AJAFT ${ }^{b}$ & 1 & $28,13=\downarrow$ Instabilidade \\
\hline $\mathrm{IPAQ}^{\mathrm{C}}$ & 1 & Muito ativo \\
\hline
\end{tabular}

Momento: $1=$ pré intervenção e $2=$ pós intervenção; DP:Desvio Padrão; ándice de Massa corporal ; ${ }^{b}$ Ankle joint functional assessment toll: questionário discriminativo; ' IPAQ: Questionário Internacional de atividade Física.

\subsection{Parâmetros da curva e GraulPS}

A população de dados que apresentou distribuição normal $(p>0,05)$ e não normal $(p<0,05)$ pelo teste de Shapiro Wilk está representada na Tabela 6. A Tabela 6 possui os dados referentes ao valor $p$ do teste de normalidade Shapiro-Wilk aplicado às variáveis extraídas antes e após a intervenção com o treinamento neuromuscular. Nesta Tabela estão dispostos para cada variável os valores pré e pós-treinamento aos grupos controle (C) e experimental (E).

O conjunto de variáveis que apresentou distribuição paramétrica antes $(p>0,05)$ da intervenção com o treinamento neuromuscular tanto para o grupo controle como para o grupo experimental foi: Mmax; HTh; H50; 100; H@Th; 50@; 100@; Hmax; Grau PSI; MC; IMC; Altura; O conjunto de variáveis que apresentou distribuição paramétrica antes da intervenção com o treinamento 
neuromuscular apenas para o grupo experimental foi o Percentual de Gordura com o valor $p$ de 0,121.

Tabela 6 - Valores p do teste de normalidade Shapiro-Wilk.

\begin{tabular}{|c|c|c|c|}
\hline Variável & Grupo & Pré ${ }^{*}$ & Pós* \\
\hline \multirow[b]{2}{*}{ Slope M } & C & $0,002+$ & $0,035+$ \\
\hline & $E$ & $0,000+$ & 0,928 \\
\hline \multirow[b]{2}{*}{ Slope H } & $\mathrm{C}$ & $0,004+$ & $0,001+$ \\
\hline & $E$ & 0,109 & 0,117 \\
\hline \multirow[b]{2}{*}{ Mmax } & $\mathrm{C}$ & 0,164 & 0,720 \\
\hline & $E$ & 0,492 & 0,502 \\
\hline \multirow[b]{2}{*}{ HTh } & C & 0,280 & 0,083 \\
\hline & $E$ & 0,469 & 0,785 \\
\hline \multirow[b]{2}{*}{$\mathrm{H} 50$} & C & 0,280 & 0,083 \\
\hline & $E$ & 0,469 & 0,785 \\
\hline \multirow[b]{2}{*}{$\mathrm{H} 100$} & $\mathrm{C}$ & 0,280 & 0,083 \\
\hline & $E$ & 0,469 & 0,785 \\
\hline \multirow[b]{2}{*}{ HTh@ } & $\mathrm{C}$ & 0,280 & $0,000+$ \\
\hline & $E$ & 0,469 & $0,001+$ \\
\hline \multirow[b]{2}{*}{ H50@ } & $\mathrm{C}$ & 0,280 & $0,013+$ \\
\hline & $E$ & 0,469 & $0,037+$ \\
\hline \multirow[b]{2}{*}{ H100@ } & $\mathrm{C}$ & 0,280 & $0,043+$ \\
\hline & $E$ & 0,469 & 0,289 \\
\hline \multirow[b]{2}{*}{ Mmax } & $\mathrm{C}$ & 0,280 & 0,083 \\
\hline & $E$ & 0,469 & 0,785 \\
\hline \multirow[b]{2}{*}{ Hmax } & $\mathrm{C}$ & 0,122 & 0,193 \\
\hline & $E$ & 0,469 & 0,785 \\
\hline \multirow[b]{2}{*}{ Grau PSI } & $\mathrm{C}$ & 0,823 & 0,248 \\
\hline & $E$ & 0,797 & 0,986 \\
\hline \multirow[b]{2}{*}{ MC } & $\mathrm{C}$ & 0,471 & 0,390 \\
\hline & $E$ & 0,091 & 0,095 \\
\hline \multirow[b]{2}{*}{ IMC } & C & 0,065 & 0,258 \\
\hline & $E$ & 0,152 & 0,147 \\
\hline \multirow[b]{2}{*}{ \%Gordura } & $\mathrm{C}$ & $0,004+$ & $0,018+$ \\
\hline & $E$ & 0,121 & 0,199 \\
\hline \multirow[b]{2}{*}{ Altura } & $\mathrm{C}$ & 0,917 & 0,905 \\
\hline & $E$ & 0,792 & 0,793 \\
\hline
\end{tabular}

+ $\mathrm{P}<0,05$ representando uma distribuição não normal; ${ }^{*} \mathrm{P}$ Verificando normalidade por meio dos dados brutos nos momentos Pré e Pós; Grupo C: Grupo 
Controle; Grupo E: Grupo Experimental; Pré: Momento pré Intervenção; Pós: momento após Intervenção; GE Grupo Experimental; GC Grupo Controle.

Outra variável, que apresentou distribuição não normal $(p<0,05)$ antes da intervenção com o treinamento neuromuscular tanto para o grupo controle como para o grupo experimental foi SlopeM. O conjunto de variáveis que apresentou distribuição não normal antes da intervenção com o treinamento neuromuscular apenas para o grupo controle foram SlopeH e Percentual de Gordura.

As variáveis que apresentaram distribuição normal ( $p>0,05)$ após a intervenção com o treinamento neuromuscular tanto para o grupo controle como para o grupo experimental foram Mmax; HTh; H50; H100; Hmax; Grau PSI; MC; IMC. Altura; As variáveis que apresentaram distribuição normal antes da intervenção com o treinamento neuromuscular apenas para o grupo experimental foram SlopeM; SlopeH; H100@ e o Percentual de Gordura.

Já as variáveis que apresentaram distribuição não normal $(p<0,05)$ após a intervenção, tanto para o grupo controle como para o grupo experimental foram: H@Th e H@50. As variáveis que apresentaram distribuição não normal após a intervenção apenas para o grupo controle foram Slope M; Slope H; 100@ e Percentual de gordura.

Alguns dos parâmetros extraídos da CR tiveram dados independentes com apenas uma medida, normalmente relacionados às diferenças entre 0 momento pós e pré intervenção- Estes dados estão descritos na Tabela 7 cuja probabilidade $(p)$ do teste de normalidade de Shapiro-Wilk também foi aplicado.

O conjunto de variáveis que apresentou distribuição normal $(p>0,05)$ tanto para o grupo controle como para o grupo experimental foi Diff50; Diff100; DifcorTh; Difcor50; Difcor100; DifeSlopeH; DifeMmax; DifeTh; Dife50; Dife100; DifePSI; Dife50@; e Dife100. Já as variáveis que apresentaram distribuição normal apenas para o grupo controle foram tempo de basquete; Idade; DifeMC; DifelMC e DifeSlopeM. O conjunto de variáveis que apresentou distribuição não normal $(p<0,05)$ tanto para o grupo controle como para o grupo experimental foi: DiffTh; DifeAltura; Dife\%Gordura e 
DifeTh@. As variáveis que apresentaram distribuição não normal $(p<0,05)$ apenas para o grupo experimental foram: Tempo de Basquete; Idade; DifeMC; DifelMC e DifeSlopeM.

Após a verificação de normalidade dos dados, as variáveis cuja distribuição foi normal foram analisadas em testes paramétricos, enquanto às de distribuição não normal foram analisadas com testes não paramétricos. Os resultados são apresentados na Tabela 8.

Tabela 7 - Valores $p$ do teste de normalidade Shapiro-Wilk para dados independentes de uma medida (diferença pós-pré).

\begin{tabular}{|c|c|c|}
\hline Variável & $\mathrm{GC}^{+}$ & $\mathrm{GE}^{+}$ \\
\hline Diff Th & $0,000+$ & $0,039+$ \\
\hline Diff 50 & 0,307 & 0,989 \\
\hline Diff 100 & 0,825 & 0,975 \\
\hline Diff25 & $0,011+$ & $0,034+$ \\
\hline DifcorTh & 0,443 & 0,276 \\
\hline Difcor50 & 0,193 & 0,130 \\
\hline Difcor100 & 0,091 & 0,247 \\
\hline Tempo de Basquete & 0,250 & $0,030+$ \\
\hline Idade & 0,058 & $0,049+$ \\
\hline DifeSlopeH & 0,558 & 0,841 \\
\hline DifeMmax & 0,120 & 0,326 \\
\hline DifeTh & 0,718 & 0,667 \\
\hline Dife50 & 0,718 & 0,667 \\
\hline Dife100 & 0,718 & 0,667 \\
\hline DifePSI & 0,693 & 0,212 \\
\hline DifeAltura & $0,002+$ & $0,001+$ \\
\hline DifeMC & 0,313 & $0,010+$ \\
\hline DifelMC & 0,480 & $0,026+$ \\
\hline Dife\%G & $0,000+$ & $0,015+$ \\
\hline DifeSlopeM & 0,101 & $0,000+$ \\
\hline DifeTh@ & $0,000+$ & $0,039+$ \\
\hline Dife50@ & 0,128 & 0,989 \\
\hline Dife100@ & 0,982 & 0,975 \\
\hline
\end{tabular}

$+P<0,05$ representando uma distribuição não normal; "P Verificando normalidade por meio das diferenças entre o memento Pós e o momento Pré; GC - Grupo Controle; GE - Grupo Experimental 
Tabela 8 - Valores de significância para os dados de medidas repetidas.

\begin{tabular}{|c|c|c|c|c|c|c|c|c|}
\hline & & Pré & Pós & DIFF & Interação & $\begin{array}{l}\text { Tam. do } \\
\text { efeito }\end{array}$ & $P^{*}$ & Estatística \\
\hline \multirow{2}{*}{$\begin{array}{l}\operatorname{Mmax}^{\mathrm{a}} \\
(\mathrm{mV})\end{array}$} & C & $5,621 \pm 0,733$ & $6,496 \pm 0,640$ & $0,874 \pm 4,559$ & $\uparrow$ & \multirow[b]{2}{*}{0.328} & \multirow[b]{2}{*}{0,393} & \multirow[b]{2}{*}{0,755} \\
\hline & $E$ & $5,224 \pm 0,733$ & $7,390 \pm 0,640$ & $2,166 \pm 3,184$ & $\uparrow$ & & & \\
\hline \multirow{2}{*}{$\begin{array}{l}\text { Tha } \\
\text { (\%Mmax) }\end{array}$} & $\mathrm{C}$ & $7,414 \pm 0,611$ & $6,640 \pm 0,682$ & $-0,774 \pm 2,729$ & $\downarrow$ & \multirow[b]{2}{*}{-0.048} & \multirow[b]{2}{*}{0,900} & \multirow[b]{2}{*}{0,016} \\
\hline & $\mathrm{E}$ & $5,948 \pm 0,611$ & $5,055 \pm 0,611$ & $-0,893 \pm 2,237$ & $\downarrow$ & & & \\
\hline \multirow{2}{*}{$\begin{array}{l}50^{\mathrm{a}} \\
\text { (\%Mmax) }\end{array}$} & $\mathrm{C}$ & $31,100 \pm 2,564$ & $27,854 \pm 2,860$ & $-3,246 \pm 11,449$ & $\downarrow$ & \multirow[b]{2}{*}{-0.048} & \multirow[b]{2}{*}{0,900} & \multirow[b]{2}{*}{0,016} \\
\hline & $\mathrm{E}$ & $24,949 \pm 2,564$ & $21,202 \pm 2,860$ & $-3,746 \pm 9,386$ & $\downarrow$ & & & \\
\hline \multirow{2}{*}{$\begin{array}{l}100^{\mathrm{a}} \\
(\% \operatorname{Mmax})\end{array}$} & C & $54,786 \pm 4,516$ & $49,067 \pm 5,038$ & $-5,719 \pm 20,168$ & $\downarrow$ & \multirow[b]{2}{*}{-0.047} & \multirow[b]{2}{*}{0,900} & \multirow[b]{2}{*}{0,016} \\
\hline & $E$ & $43,950 \pm 4,516$ & $37,349 \pm 5,038$ & $-6,600 \pm 16,535$ & $\downarrow$ & & & \\
\hline \multirow[b]{2}{*}{$\mathrm{MC}^{\mathrm{a}}(\mathrm{kg})$} & $\mathrm{C}$ & $61,936 \pm 3,720$ & $62,164 \pm 3,424$ & $0,228 \pm 1,170$ & $\uparrow$ & \multirow[b]{2}{*}{-0.531} & \multirow[b]{2}{*}{0,173} & \multirow[b]{2}{*}{1,974} \\
\hline & $E$ & $65,521 \pm 3,720$ & $64,371 \pm 3,424$ & $-1,150 \pm 3,479$ & $\downarrow$ & & & \\
\hline \multirow{2}{*}{$\begin{array}{l}\mathrm{IMC}^{\mathrm{a}} \\
\left(\mathrm{kg} / \mathrm{m}^{2}\right)\end{array}$} & $\mathrm{C}$ & $20,396 \pm 0,841$ & $20,386 \pm 0,722$ & $-0,010 \pm 0,397$ & $=$ & \multirow[b]{2}{*}{-0.501} & \multirow[b]{2}{*}{0,196} & \multirow[b]{2}{*}{1,760} \\
\hline & $\mathrm{E}$ & $22,124 \pm 0,841$ & $21,676 \pm 0,722$ & $-0,448 \pm 1,171$ & $\downarrow$ & & & \\
\hline \multirow{2}{*}{$\begin{array}{l}\text { Hmax }^{\mathrm{a}} \\
(\% \operatorname{Mmax})\end{array}$} & C & $60,230 \pm 5,448$ & $53,916 \pm 5,594$ & $-6,314 \pm 23,172$ & $\downarrow$ & \multirow[b]{2}{*}{-0.056} & \multirow[b]{2}{*}{0,883} & \multirow[b]{2}{*}{0,022} \\
\hline & $E$ & $49,898 \pm 5,448$ & $42,404 \pm 5,594$ & $-7,493 \pm 18,772$ & $\downarrow$ & & & \\
\hline \multirow{2}{*}{$\begin{array}{l}\text { GrauPSIa } \\
(\%)\end{array}$} & $\mathrm{C}$ & $24,378 \pm 7,897$ & $28,839 \pm 4,291$ & $4,460 \pm 31,832$ & $\uparrow$ & & & \\
\hline & $\mathrm{E}$ & $26,279 \pm 7,897$ & $24,647 \pm 4,291$ & $-1,632 \pm 19,516$ & $\downarrow$ & $-0,230$ & 0,547 & 0,373 \\
\hline Altura ${ }^{a}$ & $\mathrm{C}$ & $1,740 \pm 0,024$ & $1,749 \pm 0,025$ & $0,009 \pm 0,009$ & $\uparrow$ & & & \\
\hline$(\mathrm{m})$ & $E$ & $1,708 \pm 0,024$ & $1,714 \pm 0,024$ & $0,005 \pm 0,007$ & $=$ & -0.425 & 0,271 & 1,265 \\
\hline Gordurab & $\mathrm{C}$ & $18,486 \pm 1,523$ & $17,364 \pm 1,136$ & $-1,121 \pm 1,738$ & $\downarrow$ & & & \\
\hline$\%$ & $E$ & $17,871 \pm 1,523$ & $16,486 \pm 1,136$ & $-1,385 \pm 1,578^{*}$ & $\downarrow$ & $-0,240$ & $0,030^{*}$ & 0,177 \\
\hline & $\mathrm{C}$ & $1,394 \pm 0,410$ & $1,017 \pm 0,207$ & $-0,38 \pm 0,882^{*}$ & $\downarrow$ & & & \\
\hline Slope $\mathrm{M}^{\mathrm{b}}$ & $E$ & $1,379 \pm 0,410$ & $1,335 \pm 0,207$ & $-0,04 \pm 12,933$ & $\downarrow$ & $0,357^{+}$ & $0,035^{\star}$ & 0,692 \\
\hline $\mathrm{H} @ \mathrm{th}^{\mathrm{b}}$ & $\mathrm{C}$ & $7,414 \pm 0,611$ & $6,513 \pm 2,901$ & $-0,901 \pm 12,933$ & $\downarrow$ & & & \\
\hline (\%Mmax) & $\mathrm{E}$ & $5,948 \pm 0,611$ & $7,143 \pm 2,901$ & $1,1950 \pm 8,32966$ & $\uparrow$ & $0,367^{+}$ & 0,078 & 0,260 \\
\hline & $\mathrm{C}$ & $2,493 \pm 0,426$ & $1,972 \pm 0,515$ & $-0,520 \pm 1,723$ & $\downarrow$ & & & \\
\hline SlopeH $^{b}$ & $\mathrm{E}$ & $1,199 \pm 0,462$ & $1,427 \pm 0,515$ & $0,227 \pm 0,532$ & $\uparrow$ & $0.469^{+}$ & 0,081 & 3,052 \\
\hline $50 @^{\mathrm{b}}$ & $\mathrm{C}$ & $31,100 \pm 2,564$ & $22,065 \pm 5,782$ & $-9,035 \pm 24,382$ & $\downarrow$ & & & \\
\hline (\%Mmax) & $\mathrm{E}$ & $24,949 \pm 2,564$ & $22,639 \pm 5,782$ & $-2,309 \pm 19,481$ & $\downarrow$ & 0.245 & 0,262 & 1,259 \\
\hline $100 @^{\mathrm{b}}$ & $\mathrm{C}$ & $54,786 \pm 4,516$ & $35,413 \pm 6,355$ & $-19,372 \pm 27,868$ & $\downarrow$ & & & \\
\hline$\%$ Mmax) & $E$ & $43,950 \pm 4,516$ & $34,772 \pm 6,355$ & $-9,177 \pm 21,936$ & $\downarrow$ & 0.245 & 0,458 & 0,550 \\
\hline
\end{tabular}

aDados de distribuição paramétrica com Teste da interação ANOVA mista com dois fatores e medidas repetidas considerando a intervenção (GE e GC) como fator entre indivíduos e o momento (pré e pós) como fator intra-indivíduos com estatística $\mathrm{F}$; $\mathrm{O}$ tamanho do Efeito utilizado para os dados normais foi o $d$ de Cohen= Esquema de Cohen (1988) $|d|<0.5=$ pequeno, $0.5 \leq|d| \leq 0.8=$ médio, $|d|>0.8$ =grande; ${ }^{b}$ Dados de distribuição não normal com teste de interação ANOVA não paramétrica de dados ordinais com medidas repetidas considerando a intervenção (GE e GC) como fator entre indivíduos e o momento (pré e pós) como fator intra-indivíduos com estatística $\chi^{2}$; 0 tamanho do Efeito utilizado o Delta de Cliff = Esquema de Romano (2006) $|\delta|<0.33=$ pequeno, $0.33 \leq|\delta| \leq 0.474=$ médio, $|\delta|>0.474$ =grande; + Efeito Médio; ${ }^{*} \mathrm{P}<5 \%$. 
Os dados que apresentaram diferença significativa foram o Percentual de Gordura $(p=0,030)$ com uma redução maior no grupo experimental e a variável SlopeM $(p=0,035)$ com uma redução maior no grupo controle. As demais variáveis não apresentaram diferença significativa com valores de $p$ maiores do que $5 \%$ (cinco porcento).

Além das análises convencionais baseadas no teste de hipóteses, é possível analisar o comportamento dos dados de acordo com a sua natureza, ou seja, uma probabilidade que não esteja apenas em função do "N" amostral e analise a importância prática da diferença ou relação observada (CONBOY, 2000). Segundo Romano et. al (2006), testar o tamanho do efeito é recomendado para amostras cujo $\mathrm{N}$ amostral não é grande. Enquanto o Teste $d$ de Cohen avalia a diferença entre as médias de cada grupo em unidades de desvio padrão para variáveis distribuídas de forma normal, o Teste Delta de Cliff testa equivalência das probabilidades de escores de tamanhos diferentes entre grupos independentes e distribuição não paramétrica.

Ao analisar o tamanho do efeito das variáveis estudadas, é possível constatar que apesar de não ter apresentado diferença significativa $(p=0,081)$, a variável SlopeH apresentou um efeito de tamanho intermediário $(\delta=0,469)$ e interação com uma diferença maior para o grupo experimental $(0,227 \pm 0,532)$. Neste parâmetro as médias reduziram para o grupo controle, enquanto que para o grupo experimental as médias aumentaram. Esse resultado indica que a variabilidade dos potenciais de membrana diminuiu após o treinamento neuromuscular, ficando em média mais próxima ao potencial de disparo. Essa compressão dos limiares de ativação dos MNs refere-se ao ganho de recrutamento de Unidades Motoras. O mesmo ocorreu para a variável H@Th que não apresentou diferença significativa $(p=0,078)$, mas possui um tamanho de efeito médio $(\delta=0,367)$ com uma diferença maior para o grupo experimental $(1,195 \pm 8,329)$. Isso significa que ao aplicar a mesma intensidade de corrente antes do treinamento, que gerava a amplitude reflexa mais baixa da curva de recrutamento pré, uma resposta de amplitude de reflexo $\mathrm{H}$ maior será obtida no momento pós. Isso 
provavelmente ocorre graças a um aumento na excitabilidade das UMs menores presentes nesta faixa da curva de recrutamento.

Já a variável Slope $M$ apresentou diferença significativa $(p=0,035)$ e efeito de tamanho médio $(\delta=0,357)$, porém com uma diferença maior para o grupo controle.

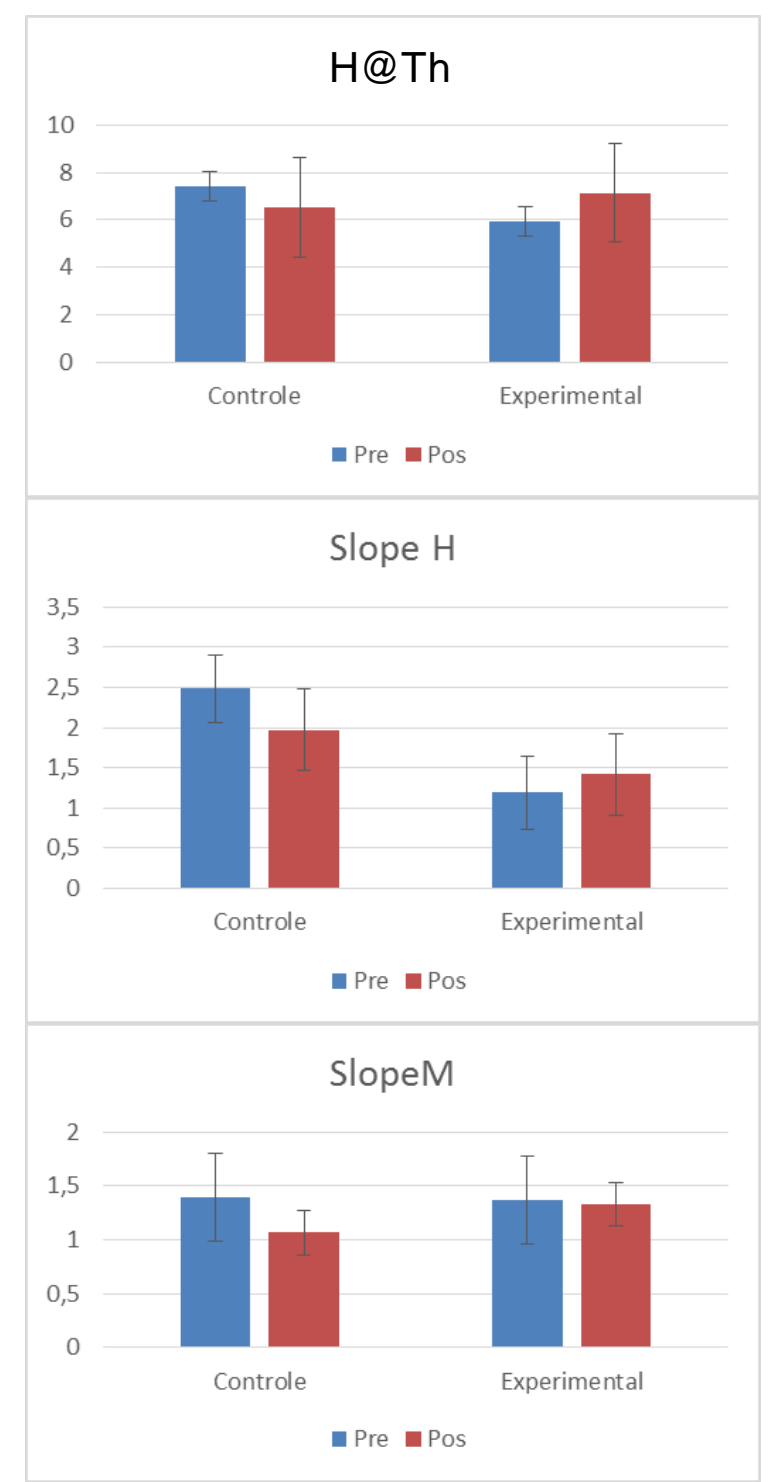

Figura 5.1 - Média e desvio padrão das variáveis com Tamanho do Efeito intermediário.

A partir destes resultados, podemos sugerir que com uma amostra de $\mathrm{N}$ maior, o que aumentaria o poder do teste, a diferença observada poderia ser estatisticamente significativa, e as interações cujo tamanho do efeito foram médios permaneceriam as mesmas após a intervenção. Assim, o valor 
de $p$ maior que $5 \%$ estaria relacionado apenas à quantidade reduzida da amostra.

As variáveis que apresentaram tamanho médio de efeito estão ilustradas na Figura 5.1, onde os dados foram separados por barra entre grupos e momentos.

Outras variáveis apresentaram interação, no entanto com o tamanho do efeito pequeno. Entre as variáveis que apresentaram aumento das médias para o grupo controle e redução para o grupo experimental estão: MC e Grau PSI. As únicas variáveis que demonstraram uma redução das médias para o grupo controle e crescimento para o grupo experimental foram H@Th e SlopeH. As variáveis que apresentaram interação estão ilustradas na Figura 5.2 , onde os dados também foram separados por barra entre grupos e momentos.

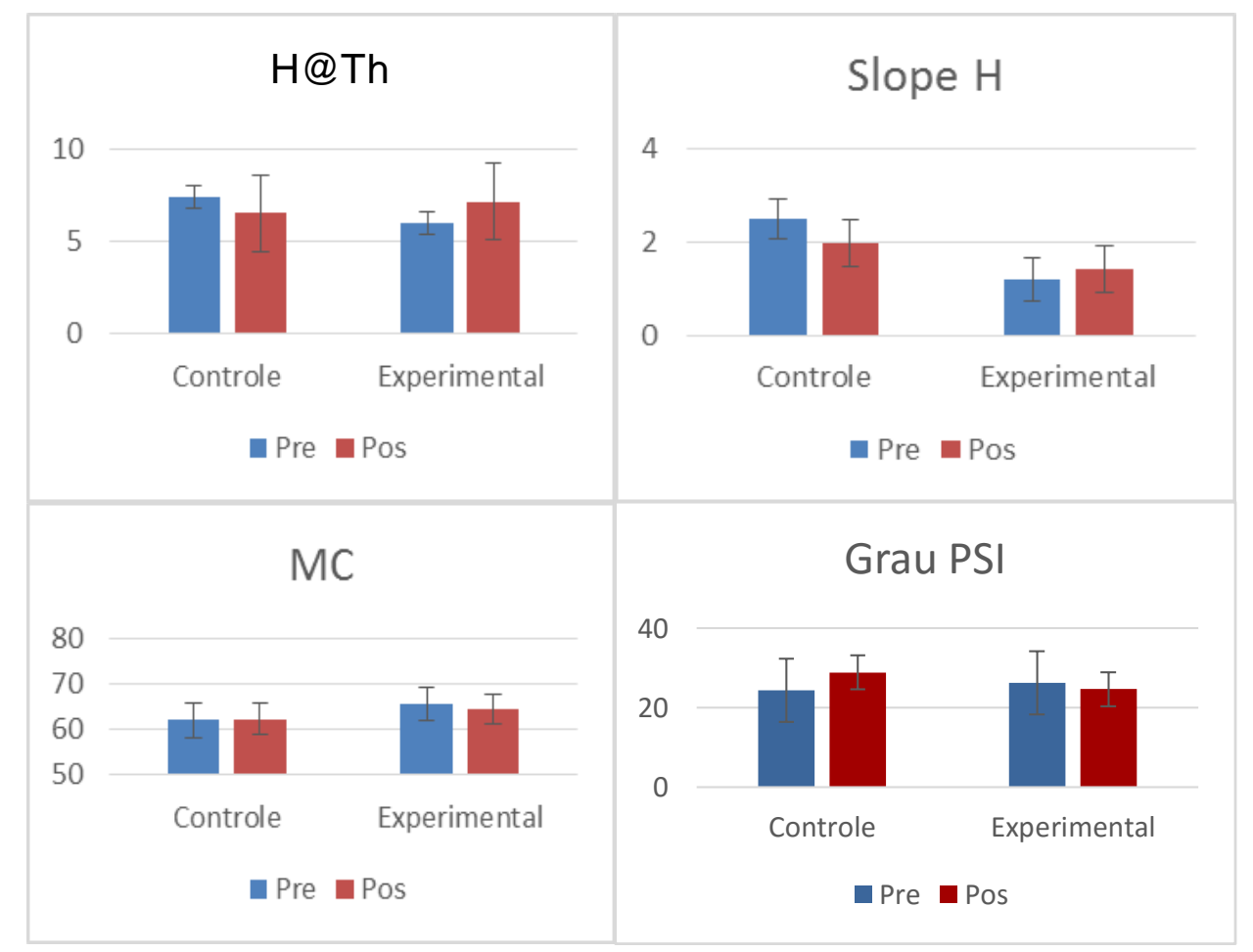

Figura 5.2 - Média e desvio padrão das variáveis que apresentam interação entre grupo e momento.

Os resultados das análises das variáveis, cujas observações apresentaram somente uma medida (diferença pós-pré) estão descritos na Tabela 9. 
Nenhuma das variáveis independentes apresentou diferença significativa $(p<0,05)$, tão pouco efeito de tamanho intermediário ou grande. Isso significa que mesmo com um valor de $\mathrm{N}$ alto, provavelmente a intervenção não mudaria significantemente os valores das variáveis estudadas.

Tabela 9 - Valores de significância para os dados independentes.

\begin{tabular}{|c|c|c|c|c|c|}
\hline & & DIFF & Tam, do efeito & $P$ & $F=t^{2}$ \\
\hline \multirow[b]{2}{*}{ Dif $50^{a}$} & C & $-6,669 \pm 24,779$ & \multirow[b]{2}{*}{0.196} & \multirow[b]{2}{*}{0,609} & \multirow[b]{2}{*}{0,268} \\
\hline & $E$ & $-2,309 \pm 19,481$ & & & \\
\hline \multirow[b]{2}{*}{ Dif $100^{a}$} & C & $-15,018 \pm 29,312$ & \multirow[b]{2}{*}{0.226} & \multirow[b]{2}{*}{0,556} & \multirow[b]{2}{*}{0,356} \\
\hline & $E$ & $-9,177 \pm 21,936$ & & & \\
\hline \multirow[b]{2}{*}{ DifCTha } & C & $4,028 \pm 4,432$ & \multirow[b]{2}{*}{-0.708} & \multirow[b]{2}{*}{0,072} & \multirow[b]{2}{*}{3,508} \\
\hline & $E$ & $-0,442 \pm 4,951$ & & & \\
\hline \multirow[b]{2}{*}{ DifC50a } & C & $4,196 \pm 10,155$ & \multirow[b]{2}{*}{$-0,516$} & \multirow[b]{2}{*}{0,183} & \multirow[b]{2}{*}{1,865} \\
\hline & $E$ & $-0,010 \pm 5,437$ & & & \\
\hline \multirow[b]{2}{*}{ DifC100 a } & C & $6,110 \pm 12,071$ & \multirow[b]{2}{*}{-0.550} & \multirow[b]{2}{*}{0,158} & \multirow[b]{2}{*}{2,117} \\
\hline & $E$ & $0,422 \pm 8,256$ & & & \\
\hline \multirow[b]{2}{*}{ DifTH $^{b}$} & $\mathrm{C}$ & $0,348 \pm 12,745$ & \multirow[b]{2}{*}{0.235} & \multirow[b]{2}{*}{0,291} & \multirow[b]{2}{*}{0,070} \\
\hline & $E$ & $1,195 \pm 8,329$ & & & \\
\hline
\end{tabular}

aDados de distribuição paramétrica com Teste $\mathrm{T}$ de Student não pareado considerando a intervenção (GE e GC) como fator entre indivíduos; O tamanho do Efeito utilizado para os dados normais foi o $d$ de Cohen= Esquema de Cohen (1988) $|d|<0.5=$ pequeno, $0.5 \leq|d| \leq 0.8=$ médio, $|d|>0.8=$ grande; ${ }^{b}$ Dados de distribuição não normal com Teste $U$ de Mann-Whitney considerando a intervenção (GE e GC) como fator entre indivíduos; O tamanho do Efeito utilizado $\circ$ Delta de Cliff $=$ Esquema de Romano (2006) $|\delta|<0.33=$ pequeno, $0.33 \leq|\delta| \leq 0.474=$ médio, $|\delta|$ $>0.474=$ grande;

A Figura 5.3 mostra uma curva de recrutamento típica obtida de um sujeito experimental. $\mathrm{Na}$ abscissa encontram-se os valores da intensidade de estimulação sobre o nervo tibial em miliamperes (mA), e na ordenada a amplitude pico-a-pico do reflexo $\mathrm{H}$ em milivolts $(\mathrm{mV})$. 


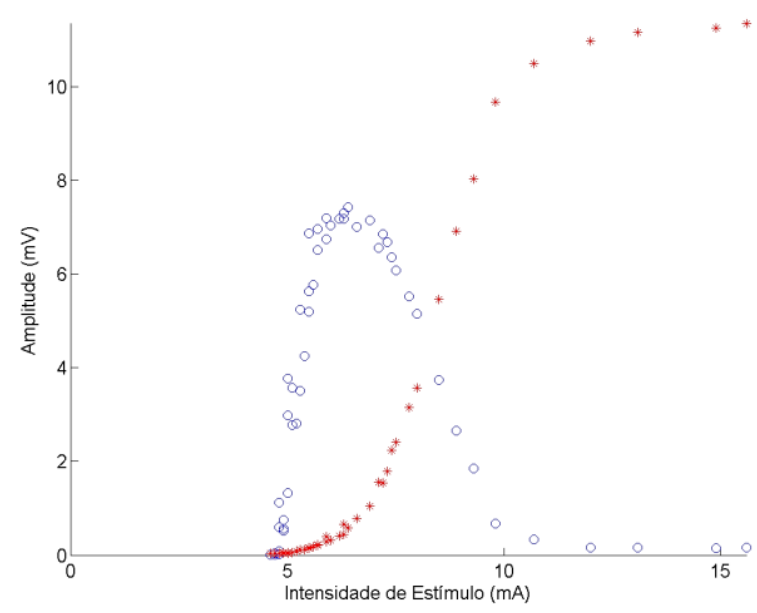

Figura 5.3 - Curva de recrutamento do reflexo $\mathrm{H}$ (azul) e da onda M (vermelho).

Circúlos azuis representam as amplitudes pico à pico do reflexo $\mathrm{H}$; Asteríscos vermelhos representam as amplitudes pico à pico da onda $\mathrm{M}$.

Os sinais eletromiográficos que deram origem à Figura 5.3 estão representados na Figura 5.4.

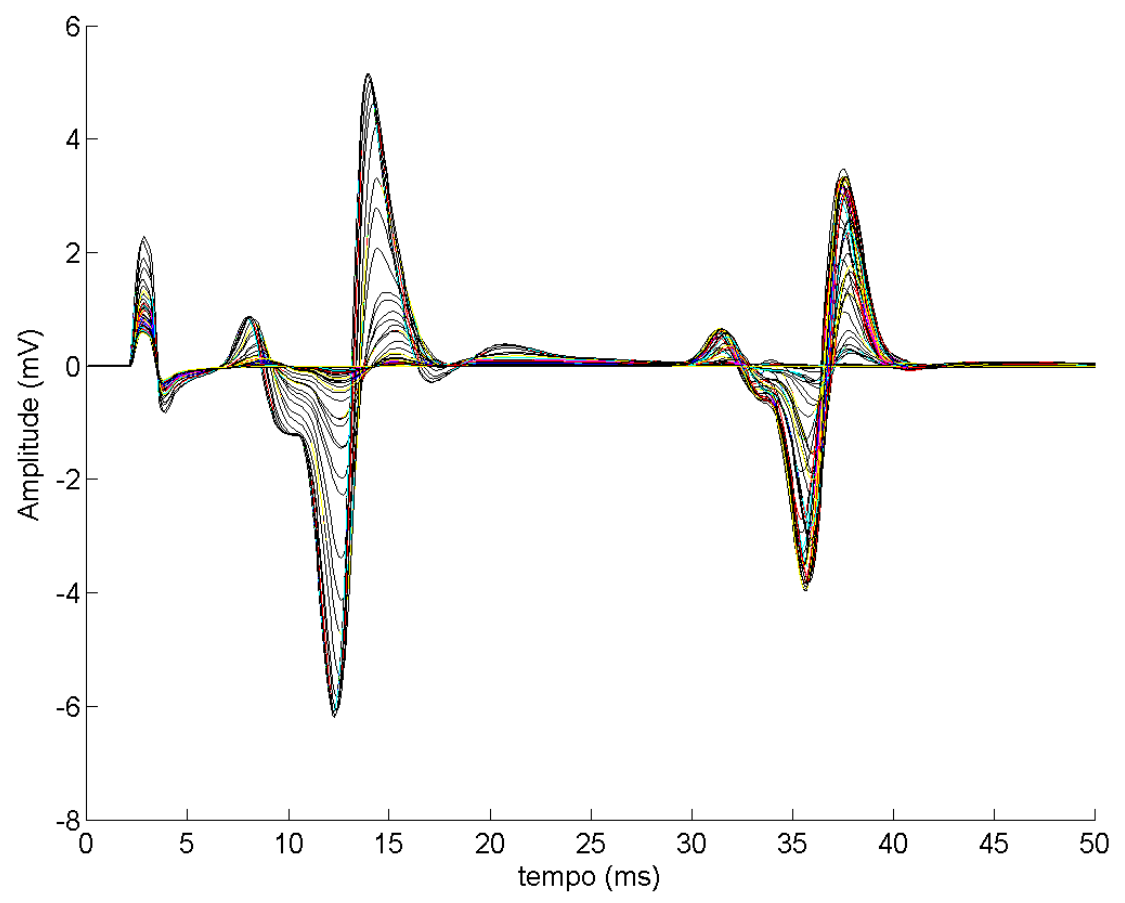

Figura 5.4 - Sinais eletromiográficos mostrando as ondas $M$ e os reflexos $\mathrm{H}$ de um sujeito do GC. Estão superimpostos 50 sinais evocados com diferentes intensidades de estímulo e cores. 
Os ajustes sigmoidais destes dados estão representados nas Figuras 5.5 a 5.6. Ao plotar os valores de pico à pico da onda $M$ contra os valores de intensidade de estímulo, é possível obter a curva de recrutamento da onda $\mathrm{M}$. Assim, os círculos azuis representam as amplitudes pico à pico do reflexo $\mathrm{H}$ em função da intensidade de estímulo, enquanto que as estrelas vermelhas representam as amplitudes pico à pico da resposta motora direta (onda $\mathrm{M}$ ). Note que a onda $\mathrm{M}$ é tipicamente maior do que a onda do reflexo $\mathrm{H}$ e alcança um valor Platô, chamado de Mmax. Já o platô da resposta reflexa é a variável Hmax.

Para extrair os parâmetros da curva de recrutamento, um ajuste sigmoidal é feito na alça alcendente da $\mathrm{CR}$ do reflexo $\mathrm{H}$ e na onda $\mathrm{M}$.

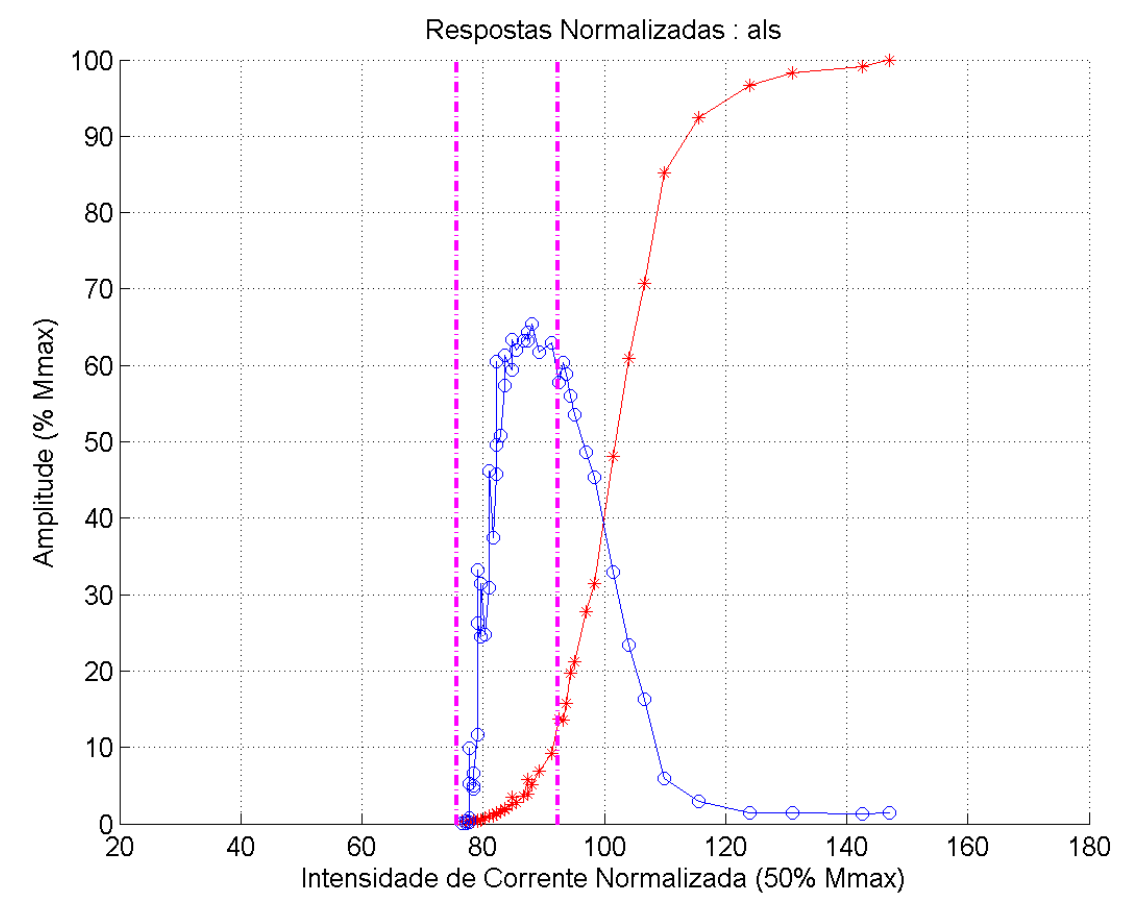

Figura 5.5 - Os mesmos dados apresentados na Figura $5.4 \mathrm{com}$ os valores de amplitude e corrente normalizados pela onda Mmax e pela corrente necessária para se obter $50 \%$ da onda Mmax, respectivamente. As retas verticais em magenta indicam os limites para o ajuste sigmoide. 

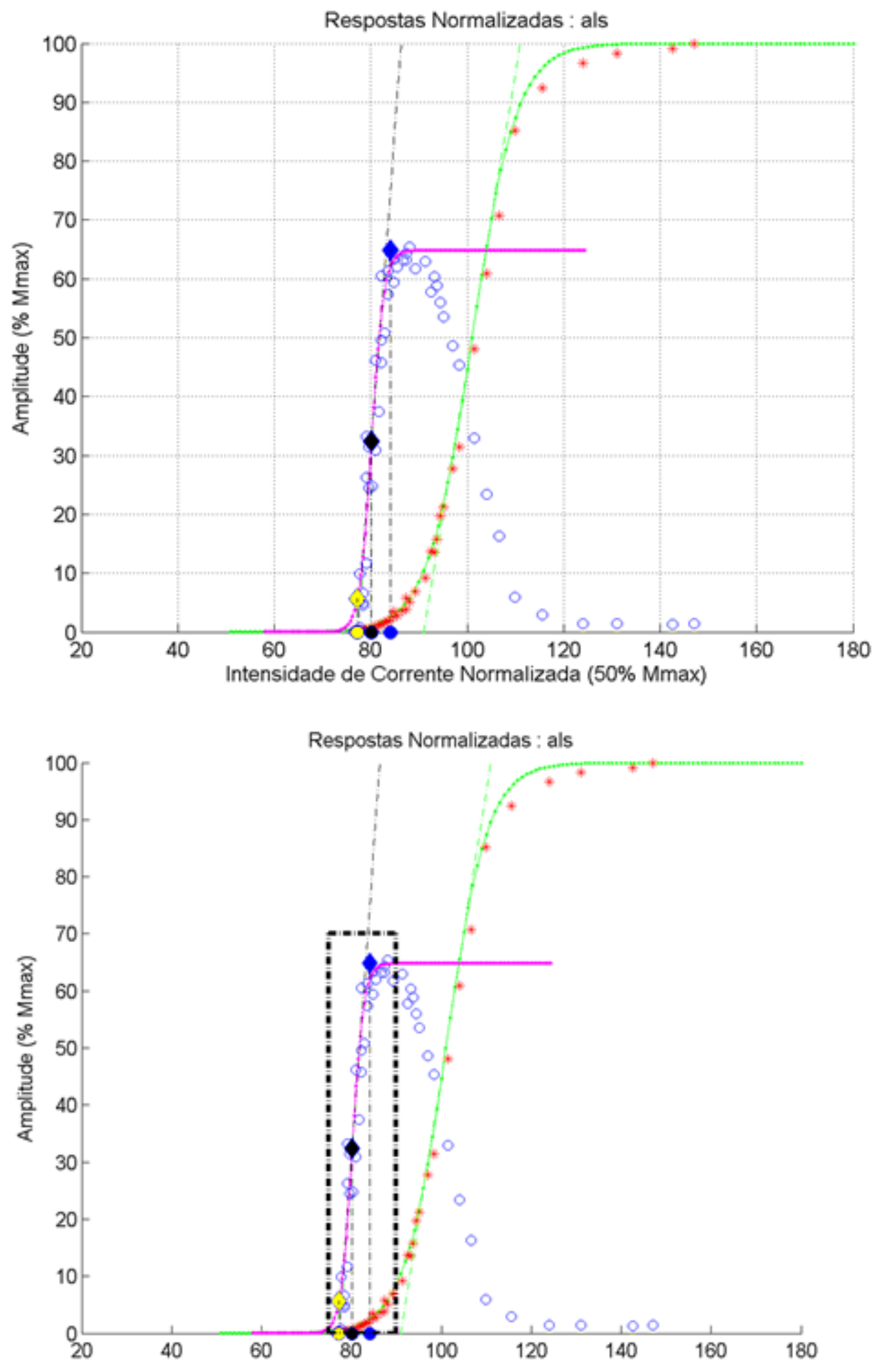

Figura 5.6 - Novamente, os mesmos valores de amplitude, agora com os ajustes sigmoidais na alça ascendente do reflexo $\mathrm{H}$ (em magenta) e na curva de recrutamento da onda $M$ (em verde). As retas de regressão (para fornecer o parâmetro slope) estão indicadas com linhas pontilhadas. 


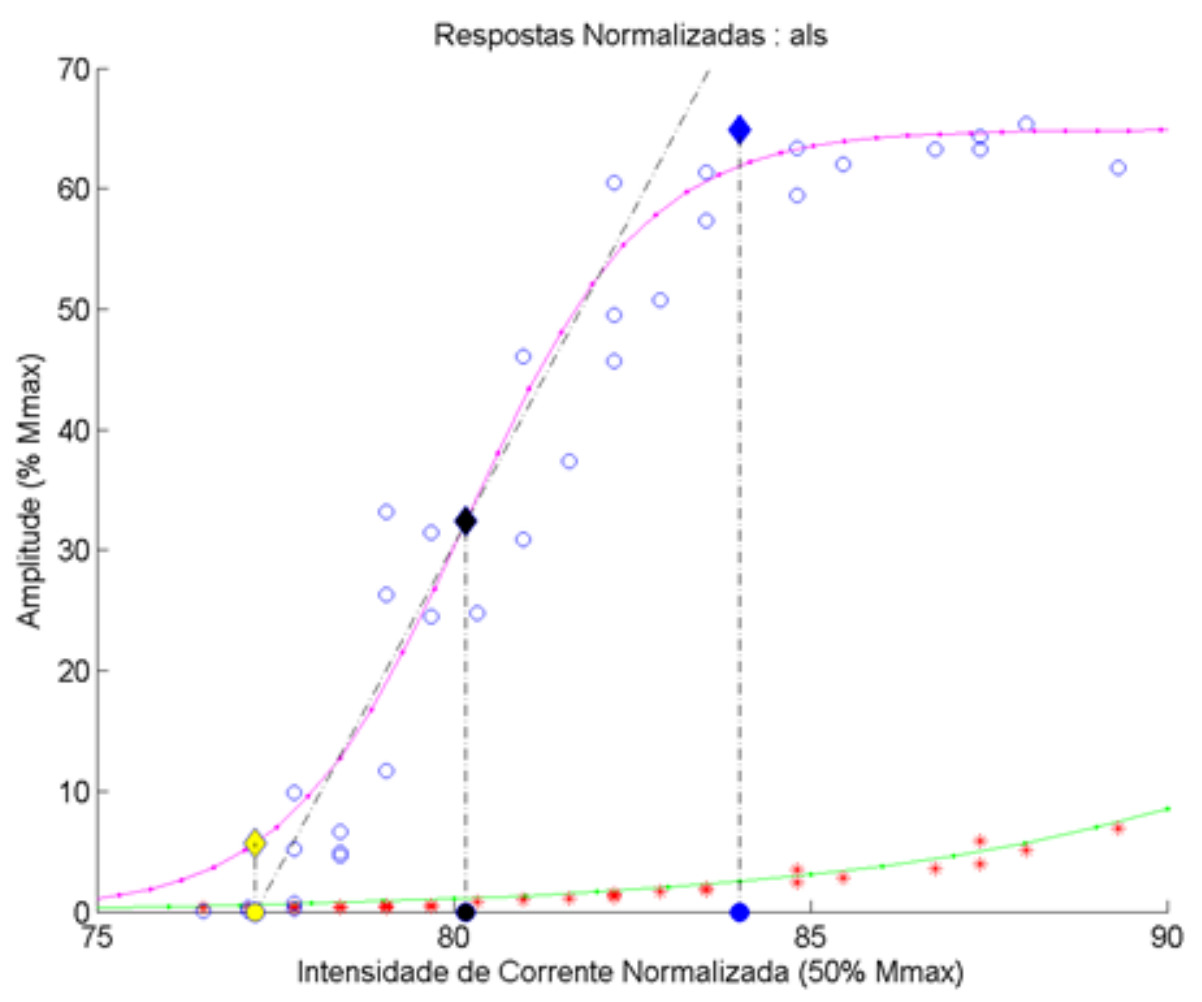

Figura 5.7 - Detalhe da região demarcada com um retangulo preto na Figura 5.6.

Detalhe da região demarcada com um retângulo preto na figura 5.4 mostrando o limiar do reflexo $\mathrm{H}$ (losango amarelo), 50\% do Hmax (losango preto) e Hmax (losango azul). As respectivas correntes (c@th, c@50, e c@100), normalizadas pelas correntes necessárias para se evocar $50 \%$ da Mmax, estão demarcadas com círculos.

$\mathrm{O}$ ajuste sigmoidal feito à $\mathrm{CR}$ do reflexo $\mathrm{H}$ permite obter parâmetros sobre os padrões de recrutamento reflexo eletroevocado das UM e comparaá-los entre os momentos antes e após a intervenção.

A Figura 5.8 mostra os ajustes sigmoidais do reflexo $\mathrm{H}$ e da onda $\mathrm{M}$ obtidos de um sujeito antes (em azul e azul claro, respectivamente) e após (em vermelho e rosa, respectivamente) treinamento neuromuscular. Pode-se notar um aumento no parâmetro Hmax após a intervenção. Contudo, os outros parâmetros (slope, H@th, H@50 e H@100) não se alteraram significativamente. Esses parâmetros estão indicados como losangos e são facilmente identificados na Figura 5.9, que mostra um trecho ampliado da Figura 5.8. 


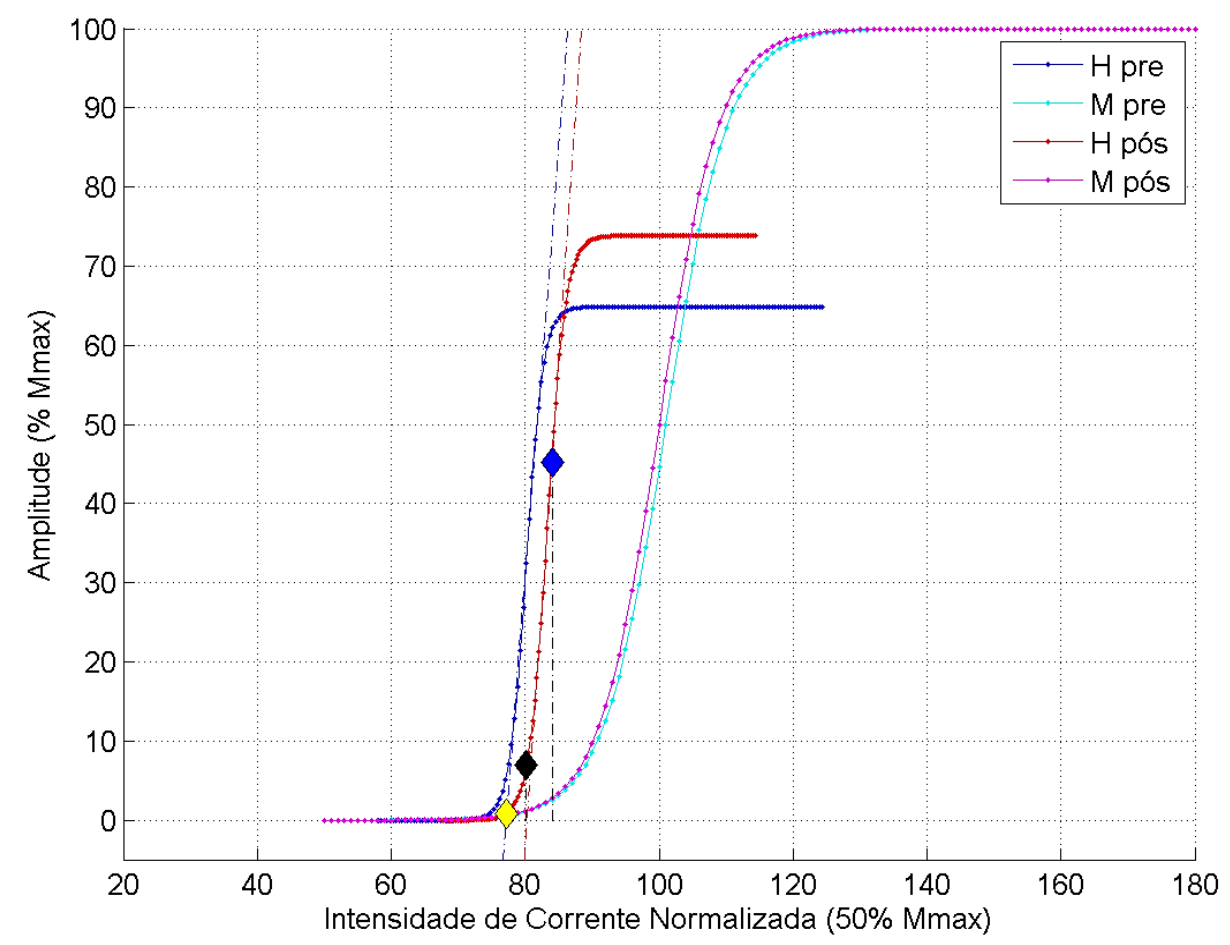

Figura 5.8 - Exemplo de ajuste sigmoidal pré e pós-intervenção da alça ascendente da curva de recrutamento do reflexo $\mathrm{H}$ de um dos sujeitos do GC. Exemplo de ajuste sigmoidal pré e pós-intervenção da alça ascendente da curva de recrutamento do reflexo $\mathrm{H}$ de um dos sujeitos coletados. Note a grande semelhança nos padrões de recrutamento das ondas $\mathrm{M}$ pré e pós-intervenção (veja também a Figura 5.6). Legendas: $\mathrm{H}$ pre referece ao ajuste sigmoidal da $\mathrm{CR}$ do reflexo $\mathrm{H}$ no momento pré; $\mathrm{H}$ pos referece ao ajuste sigmoidal da $\mathrm{CR}$ do reflexo $\mathrm{H}$ no momento pós; $M$ pre referece ao ajuste sigmoidal da $C R$ da onda $M$ no momento pré; $M$ pós referece ao ajuste sigmoidal da CR da onda M no momento pós.

Também é possível notar na Figura 5.8 a grande semelhança no perfil do recrutamento das ondas $\mathrm{M}$, evidenciando que as alterações ocorridas na curva do reflexo $\mathrm{H}$ são atribuídas a fatores fisiológicos e não às alterações na eficácia de estimulação. 


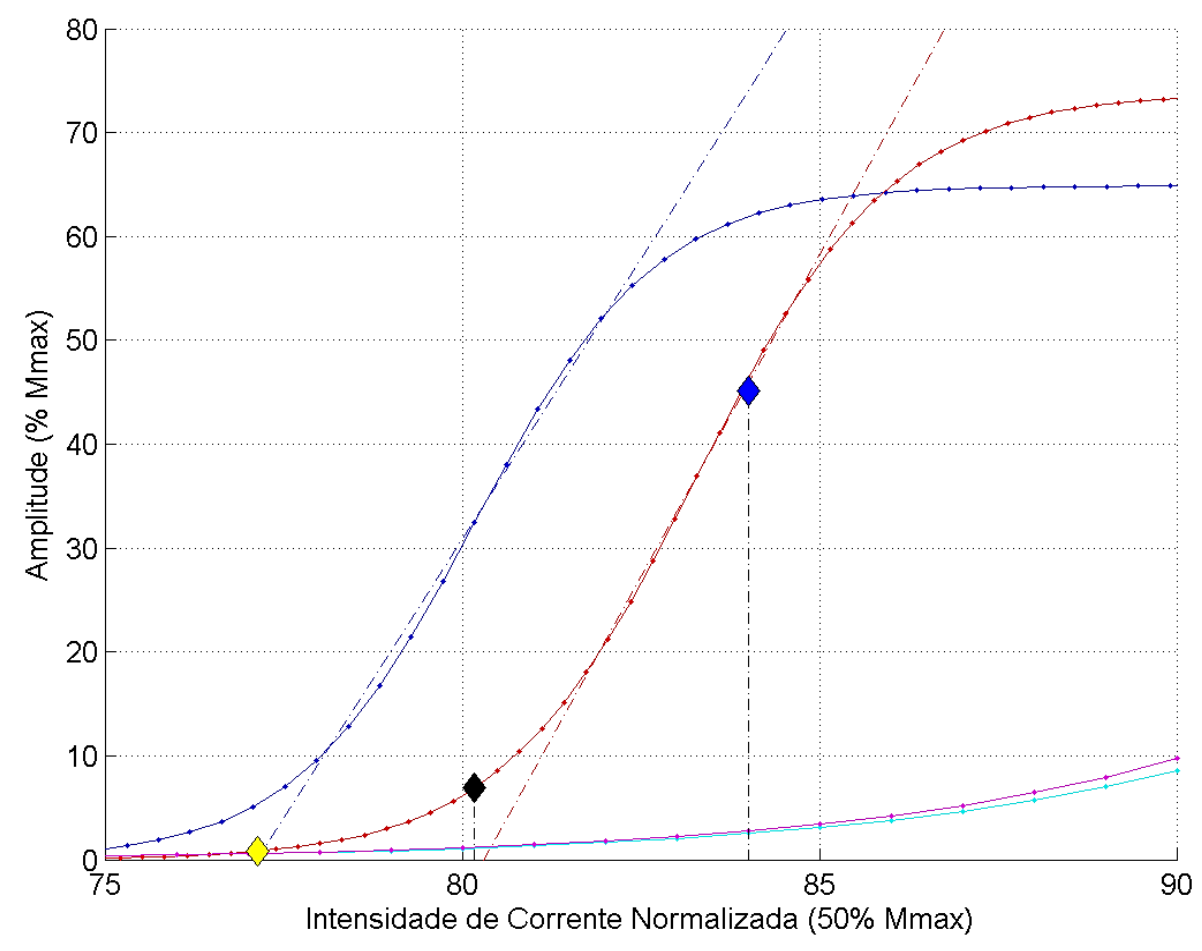

Figura 5.9 - Detalhe ampliado da Figura 5.8 mostrando o H@th (losango amarelo), H@50 (losango preto) e H@100 (losango azul).

A obtenção das variáveis no GE foi feita da mesma forma que no GC e está ilustrada na Figura 5.10. Porém, o efeito do treinamento neuromuscular indica uma diferença no padrão de recrutamento reflexo eletroevocado: Aumento nas variáveis H@th e Slope H. Estas diferenças estão indicadas na Figura 5.11.

Além dos lozangolos, indicando as medidas de amplitude após intervenção (variáveis at - @), as correntes ulizadas no momento pré para gerar essas variáveis estão representadas por cículos. O círculo azul referese a corrente utilizada para gerar Hth (cur@Hth), enquanto o círuclo verde refere-se a corrente utilizada para gerar H50 (cur@H50) e o amarelo H100 (cur@H100). 


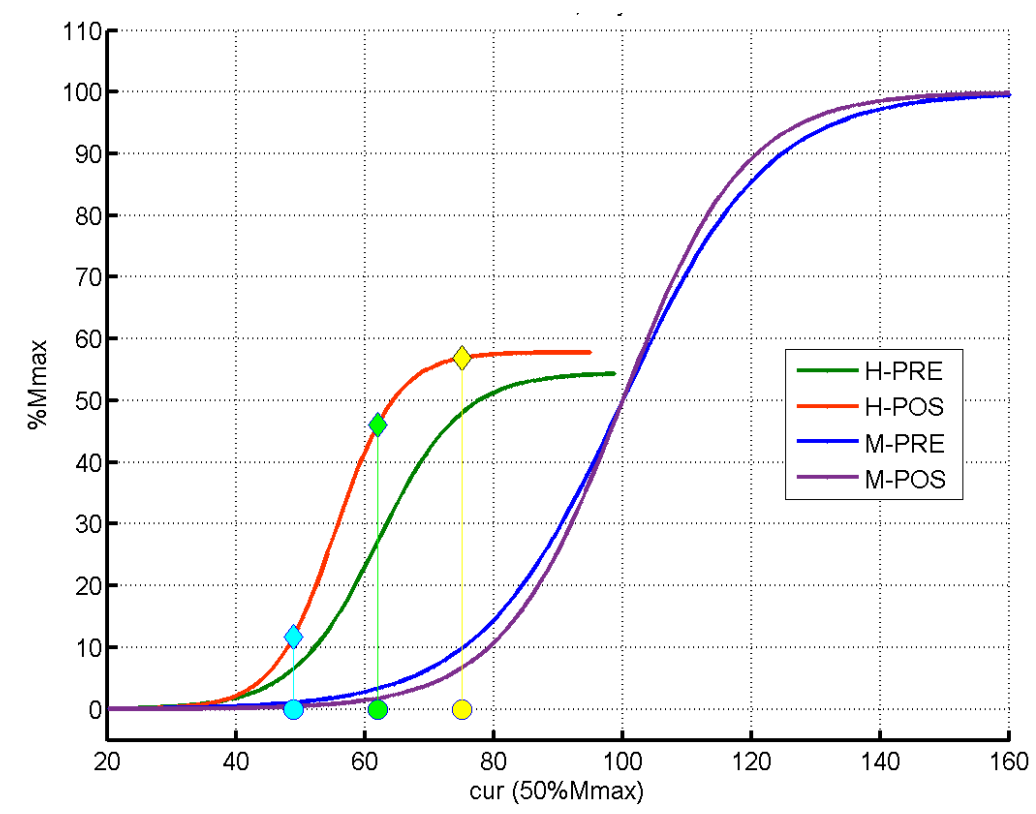

Figura 5.10 - Exemplo de ajuste sigmoidal pré e pós-intervenção da alça ascendente da curva de recrutamento do reflexo $\mathrm{H}$ de um do GE.

Exemplo de ajuste sigmoidal pré e pós-intervenção da alça ascendente da curva de recrutamento do reflexo $\mathrm{H}$ de um dos sujeitos coletados. Note a grande semelhança nos padrões de recrutamento das ondas M pré e pós-intervenção.

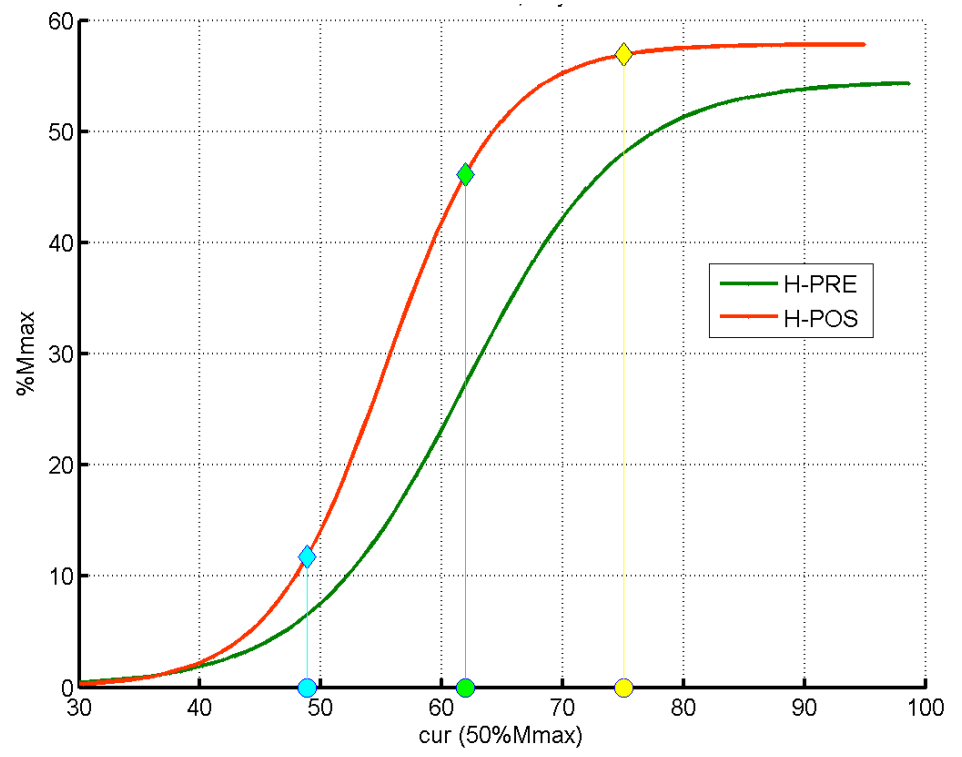

Figura 5.11 - Detalhe ampliado da Figura 5.10 mostrando o H@th (losango azul), H@50 (losango verde) e H@100 (losango amarelo).

\subsection{Dados de IPS}

A Figura 5.12 mostra um exemplo de registro de reflexo $\mathrm{H}$ controle e condicionado por estimulação do nervo fibular para induzir a IPS. Os reflexos $\mathrm{H}$ condicionados (vermelho) apresentaram amplitudes menores do que as do 
reflexo $\mathrm{H}$ controle (preto). Pode-se notar uma onda $\mathrm{M}$ estável acompanhando cada resposta reflexa, evidenciada no trecho ampliado no painel inferior da Figura 5.12, indicando boa eficácia de estimulação.
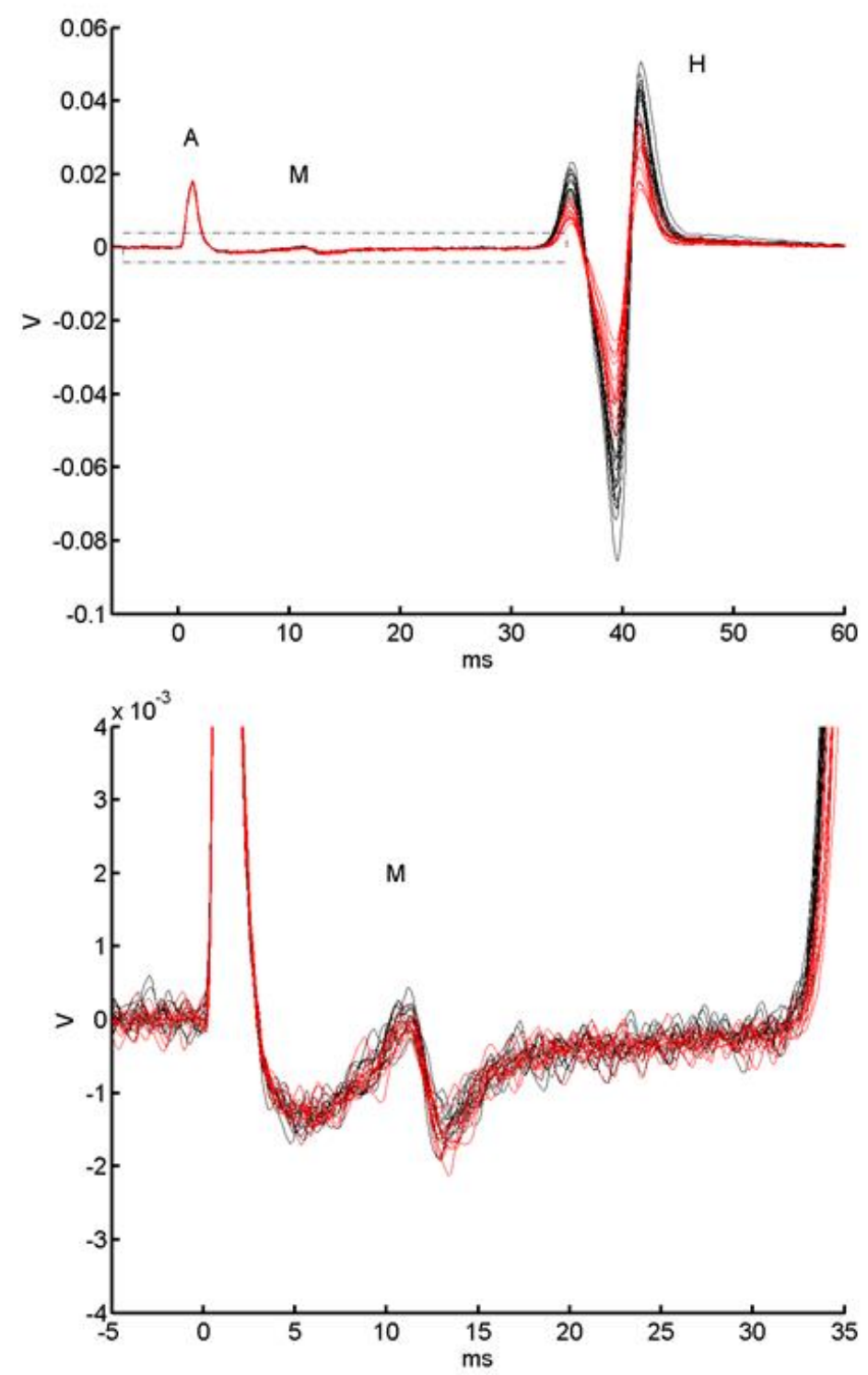

Figura 5.12 - Registros de EMG mostrando reflexo $\mathrm{H}$, onda $\mathrm{M}$ e artefato de estímulo.

Painel superior: 24 registros eletromiográficos superpostos mostrando reflexo $\mathrm{H}$ $(H)$, a onda $M(M)$ e o artefato de estímulo $(A)$. As respostas com condicionamento $(n=$ 12) estão representadas em vermelho, e as controle $(n=12)$ em preto. Painel inferior: trecho ampliado do painel superior evidenciando a onda $M$ que permaneceu estável ao longo do experimento, indicando boa eficácia de estimulação. 


\section{DISCUSSÃO}

Os experimentos realizados no presente trabalho foram suficientes para responder ao objetivo principal: prover evidências sobre adaptações em mecanismos de modulação reflexa e no padrão de recrutamento de unidades motoras em resposta ao treinamento. Alterações em quantificadores eletrofisiológicos relacionados à excitabilidade da via reflexa após treinamento neuromuscular têm sido reportadas (GRUBER et al., 2007; SEFTON et al., 2011). Contudo, a ausência de alterações na relação Hmax/Mmax e na IPS no presente estudo pode ser atribuída às diferenças metodológicas entre o estudo atual e os anteriores, a saber: (1) volume de treino neuromuscular menor do que os apresentados pela literatura; (2) treinamento neuromuscular associado a movimentos específicos da modalidade esportiva; (3) configuração postural durante as aquisições (SEFTON et al., 2011); (4) adaptações morfológicas dos músculos, já que o treinamento realizado teve duração maior do que 6 semanas (MORITANI \& VRIES, 1979);

Estudos que avaliam respostas crônicas em atletas são escassos na literatura por serem menos robustas, quando comparada às respostas agudas (WOLPAW \& O'KEEFE, 1984). No entanto não são menos importantes para a compreensão funcional das adaptações em mecanismos neurofisiológicos responsáveis pelas mudanças no desempenho motor após o treinamento neuromuscular.

Apesar da IPS ter sido apontada como fator relevante em mecanismos de modulação reflexa após o treinamento de equilíbrio (GRUBER et al., 2007; SEFTON et al., 2011), esta via inibitória não é a única responsável pela pelas alterações de excitabilidade na via reflexa após o treinamento. Para ajudar a compreender melhor as adaptações em padrões de conectividade da medula espinhal (que pode refletir plasticidade neuronal) após o treinamento, um número maior de trabalhos que abordem diversos mecanismos modulatórios, além da IPS, como a depressão homossináptica ou inibição recíproca (MEZZARANE et al., 2013) precisam ser realizados.

Como não foi encontrado nenhum estudo que verificou mudanças geradas em variáveis extraídas da CR, o aumento nas variáveis H@th e SlopeH após o treinamento neuromuscular é um novo achado. Esses 
resultados indicam que os efeitos de um regime de treinamento neuromuscular se manifestam de maneira mais evidente nas UMs menores (que são recrutadas antes, seguindo o princípio do tamanho) e alteram o ganho de recrutamento do reflexo $H$. Tais conclusões não poderiam ser alcançadas a partir de resultados pontuais obtidos por relações como, por exemplo, Hmax/Mmax.

Cumpre-se ressaltar ainda que estas alterações nos limiares de recrutamento das UM, não poderiam estar associadas às alterações em mecanismos de inibição pré-sináptica atuantes nos terminais das aferentes la.

A redução na variável SlopeM provavelmente ocorreu em decorrência do treinamento de basquete. Como não foi encontrado na literatura nenhum estudo que mencione tal efeito, outros trabalhos devem mensurar esta variável para quantificar possíveis alterações nas características de recrutamento dos axônios motores para estímulo externo. Até o momento, apenas a mudança na estatura tem sido considerada como fator que poderia afetar as respostas das vias periféricas (EYRE \& RAMESH, 1991), variável que não apresentou alteração significativa no presente estudo.

\subsection{Efeitos do treinamento neuromuscular}

Resultados anteriores reportam que treinamento cujas condições posturais desafiadoras são aplicadas em um período longo de tempo modifica a excitabilidade de circuitos reflexos. Isto leva à redução do reflexo $\mathrm{H}$ de sujeitos (TAUBE et al., 2008; NIELSEN et al. 1993).

Gruber et al. (2007) examinaram a CR do reflexo $\mathrm{H}$ do $\mathrm{SO}$ em participantes saudáveis que realizaram 4 semanas de treinamento com frequência de 4 vezes semanais, totalizando 16 sessões de treino com duração maior do que o realizado no presente estudo. Foram reportadas reduções nas amplitudes pico-a-pico do reflexo de estiramento máximo (evocado por estímulo mecânico supra-máximo), e melhora da estabilidade postural medida em plataforma bidimensional. Os autores não encontraram mudanças nas amplitudes do reflexo $\mathrm{H}$. Similar ao estudo atual, Gruber et al. (2007) mensuraram as respostas reflexas enquanto os sujeitos estavam sentados com os músculos em repouso (protocolo de GOLLHOFER \& RAPP, 
1993). As diferenças na excitabilidade reflexa após o treinamento foram interpretadas como decorrentes da participação de diferentes mecanismos neurais subjacentes de adaptação. Os autores apontam uma provável influência supra-segmentar associada à mecanismos de IPS (particularmente das fibras aferentes la). Porém, os autores não realizaram medidas de IPS diretamente, como foi feito pelo presente estudo.

Sefton et al. (2011) avaliaram o efeito do treinamento de equilíbrio e do treinamento de força com os participantes em repouso, porém as medições foram realizadas com os sujeitos em pé. $O$ treinamento de equilíbrio consistiu em 6 semanas de intervenção e as medidas sensório-motoras foram realizadas em sujeitos com instabilidade crônica do tornozelo. Os autores aferiram, além da relação Hmax/Mmax, a inibição pré e pós-sináptica com os sujeitos em posição bipodal ou unipodal. Entre os resultados encontrados por Sefton et al. (2011) estão o melhor desempenho de equilíbrio dinâmico, ausência de diferença significativa para equilíbrio estático; aumento da relação Hmax/Mmax quando os voluntários estiveram em posição bipodal (indicando possível maior excitabilidade dos MNs e maior capacidade de recrutar UMs) e aumento da IPS quando os sujeitos estiveram posicionados com a base unipodal, sem diferença para posição bipodal. Além disso, os autores mensuraram as amplitudes do reflexo de estiramento por meio da percussão mecânica do tendão (reflexo T). Após 4 semanas de treino, as amplitudes pico-a-pico tanto do reflexo $\mathrm{T}$ quanto do reflexo $\mathrm{H}$ diminuíram para o grupo que realizou treino de equilíbrio e permaneceram inalteradas as respostas do grupo de força.

Para Sefton et al. (2011) o aumento no recrutamento poderia levar a uma maior eficiência na ativação do SO durante a manutenção da postura ereta. Outro resultado encontrado pelos autores foi o aumento no grau de IPS, indicando uma maior capacidade de modular a excitabilidade reflexa e, consequentemente, o equilíbrio. Contudo, o aumento na proporção Hmax/Mmax foi encontrado durante medições com os sujeitos na posição bipodal e o efeito da depressão reflexa foi encontrado apenas na posição unipodal, mais instável.

Ao contrário dos resultados encontrados por Gruber et al. (2007) e Sefton et al. (2011), as respostas deste estudo, geradas pelo treinamento 
neuromuscular nos escolares praticantes de basquetebol, parecem não afetar o GraulPS.

Já os parâmetros da CR analisados no presente trabalho, o limiar de recrutamento ficou maior (H@th) para o GE, resultado similar ao encontrado com o uso do treinamento de resistência (KEEN, 1994; VILA-CHÃ, 2012). Isto mostra que 0 treinamento neuromuscular proposto pode ter tido características semelhantes ao treinamento de resistência. Apesar do nível de contração muscular não ter sido controlado, o treino é marcado por perídos curtos de recuperação entre as séries de exercícios e a ausência de uma carga extra como implemento.

A ausência de mudanças na relação Hmax/Mmax e IPS do estudo atual pode ter ocorrido graças às diferenças metodológicas em relação aos estudos anteriores:

- Volume de treino baseado na literatura (EILS \& ROSENBAUM, 2001; CARAFFA et al.,1996; PLISKY, RAUH \& KAMINSKI, 2006; SHETH et al.,1997; VERHAGEN et al., 2004; PASANEN, PARKKARI \& PASANEN, 2008) menor do que os apresentados pelos trabalhos que aplicaram testes semelhantes (GRUBER et al., 2007; SEFTON et al., 2011);

A disponibilidade reduzida de tempo para a aplicação do treinamento neuromuscular foi uma limitação do estudo. Maior volume e frequência para realizar o teste em até 6 semanas é uma sugestão para estudos posteriores.

- Treinamento neuromuscular foi associado à movimentos específicos da modalidade esportiva e direcionado ao basquetebol;

A recomendação de Parkkari et al (2011) para aplicação de exercícios neuromusculares para jogadores de basquete é uma adaptação dos exercícios de equilíbrio associados aos gestos executados durante a modalidade esportiva. Contudo, não foi encontrado outro estudo que aplicasse este modelo de intervenção e mensurasse medidas reflexas. Assim, a comparação com estudos que realizaram exercícios de equilíbrio ou neuromusculares sem a adição de outros movimentos é meramente especulativa. 
- Medições realizadas em diferentes posturas (SEFTON et al., 2011);

Os testes foram realizados em posição sentada e repouso, pois nesta posição as interferências decorrentes da manutenção da postura aguda são minimizadas e o efeito basal pode ser detectado. No entanto, as respostas modulatórias podem ser mais discretas (WOLPAW \& O'KEEFE, 1984) quando comparadas com testes realizados em posições que desafiam o equilíbrio (SEFTON et al, 2011). A realização do Paradigma C-T em posição unipodal em repouso e durante vários perídos ao longo da intervenção também são indicações para novos estudos, tendo em vista que as respostos modulatórias não necessariamente persistem em intervenções realizadas durante um longo período e podem se manifestar de forma discreta (WOLPAW \& O'KEEFE, 1984), principalmente ao se tratar de indivíduos treinados.

- Possível influência de adaptações neuromusculares decorrentes do treinamento de basquete ou de adaptações musculares morfológicas, uma vez que o treinamento realizado no presente estudo teve duração maior do que 6 semanas (MORITANI \& deVRIES, 1979).

Para quantificar se ha adaptações musculares, outros testes devem ser aplicados, como a ecografia muscular e as medidas de circunferência dos membros. Como estes testes não foram aplicados, não podemos excluir a ocorrência destas adaptações. Sabendo que mudanças como a hiperplasia podem modificar a resposta de contração final da musculatura, assim como a impedância, novos estudos devem controlar este fator. A pesar do período de 6 semanas ser recomendado por Moritani \& deVRIES (1979) para adaptações vindas de exercícios de força e resistência, o controle deve ser feito em vários momentos durante a intervenção para garantir em qual período pode ocorrer para o treinamento neuromuscular.

Como não foi encontrado nenhum estudo que verificou mudanças associadas às variáveis extraídas da CR, o aumento nos valores das variáveis $\mathrm{H} @$ th e SlopeH encontradas no estudo atual é um novo achado. As diferenças observadas são decorrentes do treinamento neuromuscular, pois aquelas encontradas para o GC não alcançaram significância estatística. 
Aparentemente a IPS não é a única responsável pelas mudanças na excitabilidade da via reflexa após o treinamento físico (MEZZARANE et al., 2013). Como sugestão para futuros estudos sobre as mesmas condições, está a realização de testes de depressão homossináptica e inibição recorrente para procurar encontrar qual tipo de modulação está presente. Esses testes são indicados porque o estudo atual não encontrou diferença no GraulPS e o estudo de Vila-chã (2012) nos testes de Inibição Recíproca.

A alteração da variável SlopeM também é inédita e permite inferir possíveis efeitos periféricos. Acreditamos que a diminuição do SlopeM seja decorrência do treinamento de basquete, uma vez que foi observada apenas no GC, ou ainda da rezução da impedância representada pela porcentagem de gordura (\%Gordura).

\subsubsection{Especificidades do treinamento neuromuscular}

Uma diminuição na excitabilidade do reflexo de estiramento foi observada após quatro semanas de treinamento com frequência de quatro vezes semanais, totalizando 16 sessões de treino (GRUBER et al. 2007). Apesar do volume de sessões ser menor do que o realizado pelos escolares do presente trabalho, cada sessão de treinamento durou uma hora, das quais 40 minutos foram destinados apenas ao treino específico de propriocepção. Os exercícios aplicados por Gruber et al. (2007) foram realizados em 4 sessões diárias, cada uma utilizando um implemento diferente durante 4 vezes de 20 segundos cada e tempo de recuperação de 40 segundos para cada exercício. O tempo de descanso entre as sessões foi de 3 minutos para evitar fadiga. Após a oitava sessão, o treino foi intensificado e a frequência de exercícios passou para 6 vezes por sessão. Sefton et al. (2011) aferiram a relação Hmax/Mmax e as inibições pré e pós-sináptica antes e após um regime de treinamento de equilíbrio que consistiu em sessões de treino com cinco minutos de prática, mais três blocos de três minutos de treino de equilíbrio dinâmico com um minuto de recuperação entre os blocos. A frequência de treino foi de três vezes semanais durante seis semanas, totalizando 28 sessões e um período maior do que o utilizado pelo estudo atual. Isso pode ter contribuído para uma resposta mais sensível de efeito do treino do estudo de Sefton et al (2011). 
Alterações decorrentes de regimes de treinamento com duração inferior a 6 semanas são primariamente neurais, mas períodos maiores não podem excluir adaptações musculares (MORITANI \& VRIES, 1979; GRUBER et al. 2007). $O$ treino de equilíbrio realizado durante pelo menos 4 semanas, ou entre 16-18 sessões de treino, mostraram supressão da resposta reflexa (GRUBER et al. 2007; TAUBE et al., 2007). A partir dos resultados coletados pela revisão sistemática de Zech et al. (2010), pode-se sugerir que efeitos sobre a oscilação postural gerados por treinamentos de 15 minutos, como o período disponibilizado pelo treinador dos escolares, seriam apenas detectáveis com um volume de treino maior. No presente estudo, em que os voluntários só tiveram disponibilidade três vezes semanais, estima-se que o período total para possível detecção de controle postural biomecânico deveria ocorrer em pelo menos 10 semanas de intervenção. No caso das alterações primariamente neuronais, para que o volume de treino aumentasse, a frequência deveria ser aumentada, já que o período máximo deveria ser menor do que 6 semanas (MORITANI \& VRIES, 1979; GRUBER et al., 2007). Esta limitação pode ter sido responsável pelas diferenças observadas em alguns parâmetros fisiológicos entre a literatura e 0 atual estudo.

\subsection{Aspectos da modalidade Basquetebol}

Além da temporização e volume de treino, as características mecânicas de cada tarefa motora interferem diretamente nas adaptações do sistema neuromuscular (DE MATTOS, 2009). O conhecimento das características do basquetebol e o tipo de musculatura recrutada é importante para entender se/como as respostas encontradas foram afetadas apenas pela prática do esporte.

O basquetebol é um esporte que não pode ser classificado apenas como exercício de potência ou resistência. Alemdaroğlu (2012), considera esta modalidade como anaeróbica e aeróbia (DELEXTRAT \& COHEN, 2009; MECKELI et al., 2009; METAXAS et al., 2009), pois além das atividades de alta intensidades relacionadas ao desenvolvimento de força muscular (CASTAGNA et al., 2008; TOMLIN \& WENGER, 2001), como o salto, também há um número grande de movimentações como giros, dribles, sprint 
e caminhadas relacionados à agilidade e à velocidade (CASTAGNA et al., 2007; HEDRICK, 1993; MECKELL et al., 2009).

Segundo Tukey et al. (2005), a velocidade e a magnitude das tarefas dos membros inferiores afetam a modulação do reflexo $\mathrm{H}$. Por exemplo, durante tarefas com salto, quanto maior a velocidade e o tamanho do salto, mais o reflexo $\mathrm{H}$ do SO diminuiu, ocorrendo o contrário para o gastrocnêmio medial. Esta diferença na modulação é resultante dos papéis funcionais de cada músculo (MORITANI et al., 1990), já que o gastrocnêmio medial tem uma maior percentagem de UMs rápidas quando comparado com o SO, cuja maior composição é de UMs lentas.

No presente estudo, nenhuma das sessões de treinamentos realizadas pelos escolares apresentou sobrecarga durante a execução do movimento, porém movimentos referentes à modalidade possuem características de potência, como saltos. Como os atletas já eram treinados há pelo menos um ano no basquetebol, isso também poderia justificar a ausência de diferença significativa para as variáveis estudadas.

De forma geral, as demais características apresentadas pela modalidade de basquete se enquadram mais em treinamentos de resistência, pois nos treinos de cada grupo a frequência da atividade e volume de treino foram manipulados sem adicionar uma carga de peso extra. Essa hipótese é reforçada por estudos que avaliaram o efeito do treinamento de resistência, e tiveram como resposta a diminuição do limiar de recrutamento de UMs (KEEN, 1994; VILA-CHÃ, 2012). Estes resultados são semelhantes aos apresentados pelos escolares para a variável Hth que tiveram uma tendência à redução tanto para o GC (10,43\%), quanto para o GE (15\%), o que poderia comprovar a influência da modalidade sobre os resultados encontrados.

Um estudo que comparou a resposta reflexa durante uma série de saltos (em uma única sessão) entre corredores e saltadores (AVELA et al., 2006), mostrou ainda que os atletas saltadores, já treinados ao movimento, não apresentaram mudança na relação Hmax/Mmax, enquanto que o grupo dos corredores apresentou redução significativa na relação Hmax/Mmax. Conclui-se, portanto, que a influência dos saltos não induz qualquer alteração na relação $\mathrm{Hmax} / \mathrm{Mmax}$ dos escolares. Adicionalmente, a modulação do reflexo $\mathrm{H}$ em resposta ao treinamento pode desaparecer com o treino 
prologando. $O$ fato dos escolares já praticarem salto durante o período mínimo de um ano reforça a hipótese de um efeito teto (VOIGT et al. 1998).

Zech et al. (2010) mostraram que os resultados do treinamento de equilíbrio nem sempre apresentaram mudanças no aumento de força. Porém, uma questão que permanece é se os exercícios de força, como o agachamento, podem afetar os resultados do treinamento neuromuscular.

Aagaard et al. (2002) avaliaram a relação Hmax/Mmax do SO em um estudo longitudinal em que os sujeitos foram submetidos a treinamento com agachamento durante 14 semanas. A excitabilidade do reflexo aumentou apenas durante a contração voluntária máxima, mas não no repouso. $A$ resposta de adaptação cortical e possíveis alterações na IPS, segundo os autores, possibilitaria uma ativação mais eficaz das aferente la graças ao estiramento do SO durante a fase de contato do calcanhar com o solo, o que poderia contribuir para um aumento na propulsão e aceleração dos membros inferiores.

Como o efeito do salto não foi aferido no estudo atual, tão pouco foi encontrado estudos longitudinais que realizassem os testes de IPS e CR, outros estudos devem fazer essa avaliação para esclarecer possíveis efeitos deste movimento em paradigmas experimentais que utilizam treinos neuromusculares. Como Aagaard et al. (2002) não encontraram alterações na excitabilidade reflexa durante as medidas realizadas em repouso, possíveis alterações geradas pelo agachamento associado ao treino neuromuscular dificilmente seriam detectadas pelo atual estudo.

\subsection{Análise da plasticidade neuronal após treinamento neuromuscular por meio da $C R$ e medidas de inibição reflexa}

A diminuição da relação HmaxIMmax após o treinamento pode indicar inibição pré-sinaptica da via aferente la, com consequente menor ativação muscular. Isso porque a amplitude Hmax normalizada pela corrente Mmax, é formada por ondas de despolarização muscular captadas à distância por eletrodo de superfície. Quando o inter-neurônio GABAérgico promove Inbição Pré-sinaptica, há uma redução na liberação de glutamato pelos terminais dos axônios aferentes la, reduzindo a ativação de MNs e conseguentemente a liberação de acetilcolina. Logo, a amplitude é reduzida. Funcionalmente, isso 
poderia impedir movimentos mediados por reflexos (LLEWEILYN et al., 1990) que poderiam ser desestabilizadores e, consequentemente, melhorar o controle do movimento pelos centros supra-segmentares (SOLOPOVA et al., 2003).

Considerando que a região inicial da $\mathrm{CR}$ do reflexo $\mathrm{H}$ reflete 0 comportamento das UMs menores, os resultados do presente estudo permitem inferir que a plasticidade neuronal foi mais evidente nas fibras do tipo S (chamadas assim pela característica lenta de contração; do inglês "slow"). Essas pequenas fibras musculares "vermelhas" se contraem lentamente e geraram forças relativamente pequenas; mas, por causa de seu conteúdo rico em mioglobina, abundantes mitocôndrias e capilares ricos, essas pequenas fibras vermelhas são resistentes à fadiga. Por meio de parâmetros extraídos da CR o estudo atual reportou alteração no ganho de recrutamento para onda $\mathrm{He} \mathrm{M}$.

Enquanto a resposta ao treinamento neuromuscular gerou um aumento na variável SlopeH no GE, o GC obteve uma redução maior do que o GE para a variável SlopeM. Sugere-se que os achados do GE foram predominantemente decorrentes do treinamento neuromuscular, enquanto que os do GC foram decorrentes unicamente do treinamento de basquetebol.

No presente estudo as alterações no ganho de recrutamento da onda M foram verificadas por meio da variável SlopeM que diminuiu significativamente $(p=0,035)$ no $G C$ após o treinamento, com tamanho de efeito moderado $(\delta=0,357)$. Não é possível explicar a alteração do parâmetro slopeM do GC em termos de mecanismos centrais, uma vez que a onda M é uma resposta direta e só depende de fatores periféricos. A única explicação razoável seria uma mudança no limiar de disparos dos axônios motores para estímulo externo após o treino de basquetebol. Qualquer outra alteração (de origem central ou na placa motora) poderia afetar de mesma maneira o reflexo $\mathrm{H}$. Até onde pudemos constatar, não existe na literatura nenhuma evidência que tenha apontado alterações em propriedades biofísicas (especificamente das fibras eferentes) após treinamento ou qualquer outra intervenção. 
A inclinação da reta obtida da regressão linear representada pelo parâmetro SlopeH está diretamente relacionada ao ganho de recrutamento: quando a inclinação é mais acentuada o "ganho de recrutamento" é maior, o que representa um indício de uma compressão dos limiares de ativação dos MNs (KERNELL \& HULTBORN 1990). Assim, quando o ganho de recrutamento é alto, pequenas alterações na corrente (estímulo) induzem variações relativamente grandes na amplitude do reflexo $\mathrm{H}$. Já quando os limiares estão mais dispersos, como no caso da variável SlopeM do GC, a inclinação fica menos acentuada.

Em outras palavras, se antes do treino a inclinação da $\mathrm{CR}$ do reflexo $\mathrm{H}$ era baixa, os MNs precisavam de um estímulo relativamente mais alto para serem ativados e assim gerar a fase ascendente da CR. Após o treino, a inclinação da $\mathrm{CR}$ do reflexo $\mathrm{H}$ aumentou, indicando que para estímulos pequenos, a amplitude da resposta reflexa foi maior.

Esta alteração no ganho de recrutamento pode refletir alterações em processos medulares que atuam diretamente sobre os MNs (pós-sinápticos) ou em vias reflexas (pré-sinápticos). Contudo, a IPS nos terminais la parece não ser responsável por esta alteração, uma vez que não houve diferença significativa no GraulPS para nenhum grupo estudado.

Segundo o modelo proposto por Kernell \& Hultborn (1990), o ganho de recrutamento é definido como a relação entre o número de células ativadas e a intensidade média de corrente aplicada por célula. Pelo fato do estudo atual ter verificado um aumento na variável SlopeH da $\mathrm{CR}$, somada à alteração da variável H@th, supomos que este aumento no ganho seja efeito de uma inibição constante que influenciou principalmente neurônios de baixo limiar.

Adicionalmente, tendo em vista que a resposta Mmax não foi alterada de maneira significativa e o tamanho do efeito referente às mudanças pré e pós foi pequeno, pode-se supor que alterações na inclinação da $C R$ da onda $M$ não afetaram os parâmetros associados ao reflexo $\mathrm{H}$. Ou seja, a análise realizada a partir dos parâmetros do reflexo $\mathrm{H}$, normalizadas pela onda Mmax, continuam sendo válidas.

Tem-se sugerido que o aumento na IPS sobre as fibras la, sob influência supra-segmentar, pode ser responsável pela redução da excitabilidade dos MNs do SO após treinamento neuromuscular (GRUBER et 
al., 2007). A relativa menor participação da via do reflexo de estiramento na regulação de contrações musculares permite maior independência do controle efetuado pelos centros suprassegmentares (TAUBE, 2008). Especula-se que esta diminuição na excitabilidade reflexa ocorra por meio de mecanismos medulares intermediados por vias inibitórias como a de IPS (TAUBE, 2008). Além disso, os mecanismos pré-sinápticos podem se manifestar diferencialmente em UM com características de recrutamento distintas (MEZZARANE et al., 2011), justificando a análise de parâmetros extraídos da $\mathrm{CR}$ (por meio de ajustes não lineares dos dados da alça ascendente da CR).

O presente estudo aferiu alterações na excitabilidade de vias de IPS pela variável o GraulPS, por meio paradigma C-T que foi aplicado antes e após a intervenção com os voluntários em repouso. Contudo, os níveis de IPS não apresentaram diferença estatisticamente significativa após o treinamento neuromuscular entre 0 momento pré e pós-intervenção. Esse resultado foi confirmado pelo tamanho do efeito pequeno do GraulPS (Tabela 8).

Respostas modulatórias não irão necessariamente persistir em intervenções realizadas durante um período relativamente longo, podendo se manifestar de uma forma mais discreta (WOLPAW \& O'KEEFE, 1984). Essa afirmação, somada ao nível de atividade dos escolares fisicamente ativos e que praticavam basquetebol há pelo menos um ano, poderia explicar a ausência de alterações significativas nas variáveis ora estudadas.

Ao analisar o amplo panorama de adaptações neuromusculares decorrentes do treinamento físico, fica claro que a IPS não é a única responsável pelas alterações de excitabilidade na via reflexa após o treinamento. Para inferir qual a via inibitória está envolvida na modulação do reflexo de estiramento, uma variedade de experimentos deve ser realizada como, por exemplo, a obtenção do grau de depressão homossináptica ou inibição recíproca, esta última tendo um efeito pós-sináptico (MEZZARANE et al., 2013). Como sugestão para futuros que avaliem o efeito do treinamento neuromuscar sobre as mesmas condições, está a realização de testes de depressão homossináptica e inibição recorrente. Isto porque o estudo de Vila- 
chã (2012) não encontrou efeito sobre o teste de Inibição Recíproca e obteve resultado simiar para relação de entrada-saída.

Faz-se necessária, portanto, a realização de mais estudos que abordem diversos mecanismos modulatórios da medula espinhal, auxiliando na compreensão das adaptações neuronais em resposta aos diversos tipos de treinamento físico.

\subsection{Aspectos metodológicos}

\subsubsection{Idade maturacional e plasticidade neuronal}

Para distinguir se as mudanças no equilíbrio são geradas pelas adaptações ao treinamento ou mudanças em nível maturacional, testes de maturação biológicas precisariam ser aplicados antes e após a intervenção. Existem testes para inferir maturação que são realizados de forma direta (Tanner- Whitehouse Mark II) (FREITAS et al., 2003) ou indireta (prancha de Tanner) (PINTO JR, de SOUSA e GAYA, 2012), e ainda que partem das inferências relacionadas às aptidões físicas, como o teste funcional acessível Eurofit. Porém, há necessidade de mais medidas de avaliação direta que sejam específicas para cada aptidão física explorada. Já as inferências relacionadas às mudanças neurofisiológicas podem partir de análises diversas, como o padrão de recrutamento e o nível de excitabilidade reflexa.

A infância e adolescência são períodos de dinâmico desenvolvimento comportamental, cognitivo e emocional. A maturação das vias corticoespinhais envolvidas nas respostas motoras ocorre de forma gradual durante o final da infância e durante a adolescência (PAUS et al. 1999). Antes de entender como o treinamento neuromuscular atua no controle motor dos escolares, é preciso conhecer as particularidades do processo de maturação para que as inferências sejam coerentes.

Segundo Paus et al. (1999), os axônios continuam a se desenvolver durante a infância e a adolescência, e estão envolvidos na função motora. A velocidade de transmissão neural não depende apenas da sinapse, mas também de propriedades estruturais como o diâmetro do axônio e a espessura isolante da bainha de mielina. Sabe-se que o processo de maturação de estruturas dos centros superiores possui um tempo diferente de maturação em comparação às estruturas mais caudais (como a medula 
espinhal) e vias periféricas. Por exemplo, o estudo de Eyre \& Ramesh (1991) analisa os componentes centrais e periféricos isoladamente: Os resultados mostram que o atraso na condução das vias motoras e somatosensorial diminui rapidamente durante os primeiros dois anos de vida e em seguida permanece constante e similar aos encontrados em adultos. Os autores ainda verificaram que esses atrasos diminuem dentro de uma faixa estreita e consistente para os membros superiores a partir de aproximadamente dois anos até a idade adulta, apesar de a estatura do indivíduo aumentar mais do que dobro e o comprimento do membro superior em cerca de $60 \%$. Considerando a idade média de 14 anos dos sujeitos analisados e na prevalência das medias de estatura pré e pós intervenção para os dois grupos no presente estudo, os resultados puderam ser analisados sem a preocupação de mudanças neurofisiológicas decorrentes da idade.

A velocidade de condução das vias descendentes aumenta até 11 anos de idade (KOH \& EYRE 1988), sugerindo a ocorrência de uma diminuição gradual do limiar de ativação dos neurônios corticais e/ou motores. Mais uma vez, como o grupo apresentou idade média de 14 anos, as velocidades de condução e a diminuição do limiar de ativação podem não estar relacionadas ao processo de maturação.

Do ponto de vista histológico, Barnea-goraly et al. (2005) encontraram aumentos no volume e densidade de substância branca desde a infância até a adolescência, como retratado anteriormente por outros autores (GIEDD et al., 1999; PAUS et al., 1999). Além das regiões pré-frontais, o crescimento apareceu nos campos envolvidos na visão, no fascículo arqueado, cápsula interna, gânglios basais, vias talâmicas e corpo caloso. O aumento observado em valores de anisotropia fracionada e densidade da matéria branca foi indicado como uma possível melhora nas habilidades motoras durante o processo desenvolvimento. Entretanto, o estudo não realizou testes funcionais motores. Há também evidências de perda de massa cinzenta nas áreas sensório-motoras durante a puberdade. Isso se propagaria até o final da adolescência ao atingir regiões corticais superiores, como o córtex préfrontal dorsolateral (GOGTAY et al.,2004) envolvido na recuperação de informações espaciais (SOWELL et al., 2001). Sowell et al. (1999) sugerem que a perda de massa cinzenta entre a adolescência e a idade adulta, seria 
consequência do aumento da mielinização em regiões periféricas do córtex que poderia melhorar o processamento cognitivo. Já as mudanças observadas no putâmen e globo pálido estariam envolvidas na função motora que provavelmente só estaria desenvolvida ao final da adolescência. O estudo atual teve como foco as vias reflexas que já alcançaram maturidade, porém podem ser influenciadas por essas mudanças em nível superior.

Hodapp et al. (2007) sugerem que há um aumento da IPS tônica das aferentes la durante a marcha com o crescimento da idade ao comparar 36 indivíduos saudáveis entre 7 e 16 anos. Porém, a análise dos dados do estudo atual não foi separada pela idade, devido a um $\mathrm{N}$ pequeno. Sugerimos a aplicação do teste para grupos maiores e idades bem definidas para que a análise ocorra a partir das idades para uma possível correlação dos resultados de IPS.

No caso dos componentes inferiores (vias periféricas motora e somatosensorial), que estão em foco no trabalho atual, a pesquisa de Eyre \& Ramesh (1991) também mostra que ocorre uma diminuição no atraso de condução das vias motoras e somatosensorial. Porém, a partir de 5 anos de idade há um aumento progressivo em proporção ao comprimento do braço. Em contraste com os centros superiores, esses atrasos de condução dos componentes periféricos aumentam gradualmente a partir da idade de 5 anos, proporcionalmente ao aumento da altura e do comprimento do membro analisado. O estudo justifica que o diâmetro das fibras motoras e somatossensoriais aumentam em proporção à altura, o que leva a constantes atrasos na condução central com o crescimento. Apesar de no presente estudo não termos verificado o comprimento do membro inferior analisado, os resultados estatísticos não mostraram diferença de estatura entre os momentos pré e pós intervenção.

Já a intensidade de estímulo necessária para atingir o limiar de disparo dos nervos periféricos motores e somatossensoriais, mostra uma diminuição até os 5 anos atingindo um platô após essa idade. A sugestão seria que os nervos periféricos atingiriam um valor máximo de velocidade de condução e de diâmetro neste período (EYRE \& RAMESH ,1991). Logo, as mudanças no limiar de disparo das fibras la podem ser relacionadas diretamente com 0 treino neuromuscular aplicado. 
Contudo, os presentes resultados mostraram alteração na inclinação (variável slope) da $\mathrm{CR}$ da onda $\mathrm{M}$. Esta mudança, provavelmente, não é atribuída à fase de maturação do sistema nervoso dos voluntários. Isso porque além dos escolares apresentarem uma idade em que a maturação neuronal periférica já foi concluída, a estatura dos sujeitos não foi alterada (EYRE \& RAMESH, 1991). Segundo Eyre \& Ramesh (1991) o aumento do comprimento do membro poderia gerar atraso na condução dos PA, o que deveria ser compensado por um aumento no diâmetro da fibra nervosa.

Alterações periféricas referentes ao músculo ou placa motora podem ter ocorrido. Um exemplo seria a hiperplasia de um grupo de fibras musculares cuja UM é de tamanho pequeno ou intermediário. Este aumento do número de fibras poderia afetar a amplitude e a excitabilidade da resposta motora direta, refletindo em uma mudança no ganho de recrutamento reflexo. Porém, nenhum teste foi feito para confirmar esta especulação.

Outro dado que apresentou diferença significativa entre os valores de significância foi o Percentual de Gordura $(p=0,030)$. Esta variável poderia afetar os resultados graças à uma possível redução da impedância, o que poderia contribuir para o aumento na excitabilidade encontrado após o treinamento, caso as entradas externas se tornem mais sensíveis pela redução de gordura. No entanto, essa resposta apresentou um tamanho de efeito bem pequeno. Assim, essa resposta apesar de ser significativa para a análise de variância, foi extraída de um $\mathrm{N}$ pequeno e possivelmente não apresentará boa reprodutibilidade para populações maiores. Possivelmente, este pode ter sido outro fator de mudança na excitabilidade das fibras eferentes para estímulos elétricos externos, graças a um aumento da permeabilidade (\% Gordura) no GC. Mais estudos precisam mensurar estas variáveis para confirmar esta hipótese.

Crone et al. (1999), mostraram que a onda Mmax pode variar ao longo do experimento, mas não é de nosso conhecimento nenhum dado da literatura que explora a variação no recrutamento da onda $M$ em dias diferentes. Para redução de um possível erro sistemático, mais de uma medida deve ser realizada para cada artefato de estímulo. Acreditamos ainda que o resultado do presente trabalho possa abrir uma nova possibilidade de pesquisa para aferir aspectos periféricos afetados pelo treinamento, que não 
se manifestam em medidas de amplitude reflexa (ou direta) pontuais. Portanto, a análise da CR da onda $\mathrm{M}$ em estudos futuros, cujo o foco seja o controle motor, pode trazer uma contribuição metodológica importante.

\subsubsection{Análise estatística}

A escolha adequada do tipo de análise estatística é fundamental para detectar diferenças entre os grupos de dados sem a presença de nenhum viés.

O aplicativo $R$ ( $R$ Core Team, 2015) que integra ferramentas de análises de dados estatístico foi escolhido por ser uma versão livre do Software $S$ que permite desenvolvimento livre e está disponível sem custos pelo projeto GNU em Licença Pública Geral (GNU GPL by Free Software Foundation). Todas as análises estatísticas, incluindo o cálculo do Delta do Cliff puderam ser executados neste programa. Porém, o aplicativo exige habilidade de programação (MACBETH, RAZUMIEJCZYK \& LEDESMA, 2011), o que além demandar algum tempo implicou na colaboração do Laboratório de Bioestatísica (LABIEST) da Universidade de Brasília para execução e interpretações corretas. A análise dos dados independentes foi feita procurando seguir todos os requisitos necessários indicados na literatura.

Segundo Romano et al., (2006) ao utilizar a distribuição t como base para a comparação de duas médias amostrais é preciso que alguns pressupostos sejam obedecidos para que a interpretação do resultado seja coerente: (1) O teste é paramétrico, assim os dados devem poder ser manipulados utilizando aritmética básica (GRAVETTER \& WALLNAU, 2004) e os intervalos e relações de medições devem ter uma distância e diferença de magnitude igual entre cada número; (2) as amostras devem ser independentes e logo cada medição não é influenciada por qualquer outra medição prévia; (3) Presume-se que a amostra é originada de uma população que apresenta distribuição normal. Mesmo o t-teste sendo robusto e podendo resistir a esta violação relativamente bem em alguns casos, especialmente quando existe um grande tamanho da amostra ou um $\mathrm{N}$ igual em cada grupo (MYERS \& WELL, 1995; PAGANO, 1995), o risco de violação é maior para $\mathrm{N}$ pequenos; (4) A homogeneidade da variância 
(homocedasticidade) deve existir para avaliar se a variável dependente afetou as médias da população e não se afetou os desvios-padrão. $O$ conhecimento de que a variância pode ser calculada elevando o desvio padrão ao quadrado, a homogeneidade de variância assume que as variâncias populacionais são também iguais (PAGANO, 1995).

A contabilização de variâncias heterogêneas é importante para concluir se houve diferença significativa entre as médias dos dois grupos sob investigação. Caso ocorra, é preciso realizar um ajuste às essas para não cometer um erro do Tipo I (rejeitar a hipótese nula quando esta é verdadeira) (ROMANO et. al, 2006). Em outras palavras, a quantidade de variação da amostra influencia os resultados, pois os desvios das amostras são incorporados no termo de erro, que é o denominador do teste $t$ (erro padrão). Assim, quanto menor forem os desvios da amostra, maior será o valor da estatística (GRAVETTER \& WALLNAU, 2004). No entanto, o presente estudo não realizou este ajuste para nenhuma das medidas, incluindo as medidas DIF50 e DIF100 cujos desvios padrões foram bem altos. Isso porque nenhum dos dados apresentou diferença significativa $(p>0,05)$ e sob a condição das amostras serem relativamente semelhantes, raramente há um problema com erro tipo I e taxa de inflação (MYERS \& WELL, 1995). Tendo em vista que o ajuste reduz o erro do tipo I, talvez os dados que apresentassem variâncias heterogenias deveriam ser analisados com outro tipo de teste.

Sabe-se também que quanto maior for o tamanho da amostra $(\mathrm{N})$, mais fácil seria de se obter um resultado estatisticamente significativo, porém a interpretação poderia ser equivocada a partir de um resultado significativo gerado pela taxa de inflação e não pelo efeito da intervenção.

Para obter uma interpretação mais precisa dos resultados do teste-t, a estatísticas de tamanho de efeito (d de Cohen), que não é afetada pelo tamanho da amostra (ROMANO et. al, 2006), foi realizada. Seguindo o requisito normalidade da distribuição, a aplicação do Teste d de Cohen apresenta a vantagem de poder ser descrita em termos de uma proporção de sujeitos do GE cujos valores esperamos que excedam o valor típico do GC para as futuras intervenções. Segundo CONBOY (2012), o valor da magnitude do efeito $d$ nos permite chegar a uma estimativa da proporção de sujeitos no GE que terá melhor cotação, em estudos futuros, do que o valor 
médio do GC. O valor desta proporção é facilmente derivado por meio de uma Tabela de valores de $z$ que fornece as proporções de área (integral) localizada abaixo de secções da curva normal padrão.

Ao comparar os valores brutos de tamanho d, sabemos distinguir facilmente qual número possui um valor maior. Para responder quão grande deve ser a diferença entre esses valores, há várias tentativas para estabelecer níveis de magnitude, como o esquema de Cohen (1988) escolhido. Porém o uso dessa formula simplificada de forma arbitrária é recomendado somente no caso de não existir nenhuma base de comparação melhor (CONBOY, 2012). É importante levar em consideração que as medidas de magnitude do efeito informam sobre o grau de divergência entre a hipótese nula e os resultados observados, ou seja o tamanho da diferença entre as comparações. Conboy (2012), sugere ainda que os pesquisadores utilizem intervalos de confiança, porem ressalva que o uso deste tipo de teste ainda está em desenvolvimento e precisa ser executado mais vezes para atingir o nível de confiança estatística necessária. Por isso, o presente trabalho apresentou essa abordagem em adição aos testes de hipótese amplamente utilizados na literatura científica.

Para medidas de distribuição normal usamos o Teste $d$ de Cohen que avalia a diferença entre as médias de cada grupo em unidades de desvio padrão para variáveis distribuídas de forma normal. No caso das variáveis não paramétricas usamos o Teste Delta de Cliff, que testa equivalência das probabilidades de escores de tamanhos diferentes entre grupos independentes e distribuição não paramétrica.

Neste tipo de análise, o valor "d" do teste de Cohen representa a diferença entre os dois grupos em unidades de desvio padrão. Assim o valor $" d=1 "$ indica que os dois grupos estão distantes em desvio padrão, detectando assim uma grande diferença. Além disso, o d de Cohen pode ser classificado segundo a sua grandeza de efeito pelo Esquema de Cohen (1988): $|d|<0.5=$ pequeno, $0.5 \leq|d| \leq 0.8=$ médio, $|d|>0.8=$ grande.

No caso do valor Delta de Cliff, o resultado representa o grau de sobreposição entre as duas distribuições de escores. $O$ valor de Delta pode variar de -1 (se todas as observações do Grupo 1 são maiores do que todas as observações em Grupo 2) para +1 (se todas as observações do Grupo 1 
são menores que todas as observações do Grupo 2), assumindo o valor zero como distribuições idênticas (ROMANO et al., 2006).

Segundo Romano et al. (2006), a principal diferença entre as avaliações paramétricos e a não paramétrico é que os índices não paramétricos só representam a medida em que os grupos são diferentes, mas não a proporção em escala dessa diferença. Entretanto, assim como o d de Cohen, o delta de Cliff também pode ser classificado segundo a sua grandeza conforme o Esquema de Romano (2006): $|\delta|<0.33=$ pequeno, $0.33 \leq|\delta| \leq 0.474=$ médio, $|\delta|>0.474$ =grande.

Logo, o tamanho do efeito responde quão grande é a diferença entre esses valores, em níveis de magnitude que comparam as variações entre os momentos e grupos de cada variável e não valores absolutos. Desta forma, quando um teste de hipótese não é significativo os resultados cujos tamanhos de efeitos são intermediários ou grandes indicam uma tendência estatística relacionada à interação entre as variações. Por esta razão, as magnitudes dos efeitos são avaliadas em módulo.

De forma geral, quando o tamanho do efeito é positivo temos: a variação do GE aumentou mais do que a do $\mathrm{GC}$; ou a variação do $\mathrm{GE}$ diminuiu menos do que a do GC (SlopeM); ou ainda a variação do GE aumentou enquanto que a do GC diminuiu (SlopeH e H@th). Já quando o tamanho do efeito é negativo temos: a variação do GE aumentou menos do que a do GC; ou a variação do GE diminuiu mais do que a do GC (\%G); ou ainda a variação do GE diminuiu enquanto que a do GC aumentou (MC).

Como os resultados obtidos para todas as variáveis paramétricas independentes foi um tamanho de efeito pequeno, foi confirmada a ausência de diferença significativa após o treinamento neuromuscular gerada pelo teste de hipótese.

No caso dos testes de medidas repetidas, além das análises de variância ANOVA e ANOVA não paramétrica, o cálculo do tamanho do efeito também foi realizado, porém as fórmulas de transformação são diferentes para os delineamentos envolvendo grupos independentes e os de medidas repetidas. Nouri (2000) apresenta as respectivas fórmulas de transformação. Durante o delineamento de medidas repetidas, a correlação entre os valores 
pré e pós é um elemento imprescindível no cálculo da magnitude de efeito obtido à base de valores estatísticos. Por esta razão, Conboy (2003) indica sempre relatar o valor da correlação entre valores de pré-teste e pós-teste, como foi feito no estudo de Romano et al. (2006).

Foi sugerido que a partir dos resultados de tamanho de efeito intermediário, que se o teste fosse repetido sobre as mesmas condições com um número amostral $(\mathrm{N})$ maior, o poder do teste cresceria e as respostas encontradas possivelmente apresentariam diferença estatisticamente significativa para os testes convencionais de hipótese, além das interações permanecerem as mesmas. Assim, os valores de $p$ maiores do que $5 \%$ para os dados que apresentaram efeito moderado estariam relacionados apenas à quantidade reduzida da amostra e o resultado confirmaria que o treinamento gerou efeito nestas variáveis.

\section{CONCLUSÃO}

O programa de treinamento neuromuscular foi capaz de induzir alterações sobre quantificadores eletrofisiológicos relacionados à excitabilidade da via reflexa. O recrutamento das unidades motoras evocadas por meio de estímulos elétricos transcutâneos em escolares praticantes de basquetebol foi alterado.

Mudanças na relação estímulo-resposta foram reveladas por meio dos parâmetros $\mathrm{H} @$ th e SlopeH extraídos da alça ascendete da curva de recrutamento do reflexo $\mathrm{H}$ no músculo $\mathrm{SO}$. Houve um aumento no ganho de recrutamento (SlopeH) sugerindo uma compressão dos limiares de ativação dos $\mathrm{MN}$, ou seja, a amplitude do reflexo $\mathrm{H}$ varia mais para um determinado intervalo de estímulos após o treinamento em comparação à situação controle. Isto pode indicar que o treinamento induziu um aumento generalizado na excitabilidade da via reflexa. As primeiras unidades motoras recrutadas parecem ter sofrido mais o efeito do treinamento, uma vez que foi observado um aumento significativo no parâmetro H@th.

Não houve alterações no grau de IPS, sugerindo que este mecanismo de controle de ganho da via reflexa não sofreu qualquer alteração decorrente do treinamento. Portanto, as alterações observadas no padrão de 
recrutamento motor não devem estar associadas a alterações no mecanismo de inibição pré-sináptica.

Mais estudos são necessários para quantificar possíveis alterações no recrutamento de axônios motores para estímulos externos. 


\section{REFERÊNCIAS}

1. AAGAARD, P., SIMONSEN, E. B., ANDERSEN, J. L., MAGNUSSON, P., \& DYHRE-POULSEN, P. (2002). Neural adaptation to resistance training: changes in evoked $\mathrm{V}$-wave and $\mathrm{H}$-reflex responses. Journal of Applied Physiology, 92(6), 2309-2318.

2. ADRIAN, E. D., \& BRONK, D. W. (1929). The discharge of impulses in motor nerve fibres: Part II. The frequency of discharge in reflex and voluntary contractions. The Journal of physiology, 67(2), i3.

3. ABBRUZZESE, M., RUBINO, V., \& SCHIEPPATI, M. (1996). Taskdependent effects evoked by foot muscle afferents on leg muscle activity in humans. Electroencephalography and Clinical Neurophysiology / Electromyography and Motor Control, 101(4), 339348.

4. ACQUESTA, F.M., PENEIREIRO, G.M., BIANCO, R., AMADIO, A.C., SERRÃO, J.C. Características dinâmicas de movimentos seleccionados do basquetebol. Rev Port Cien Desp.;7(2):174-82, 2007.

5. ADAMS, G. R., HATHER, B. M., BALDWIN, K. M., \& DUDLEY, G. A. (1993). Skeletal muscle myosin heavy chain composition and resistance training. Journal of Applied Physiology, 74(2), 911-915.

6. ALEMDAROĞLU, U. (2012). The relationship between muscle strength, anaerobic performance, agility, sprint ability and vertical jump performance in professional basketball players. Journal of human kinetics, 31, 149-158.

7. ALHAJAYA, MOHAMMED SALEM. Effects of proprioception training on knee joint position sense in male soccer athletes. Journal of Sociological Research 6.1 (2015): 104-115.

8. ALROWAYEH, H. N., SABBAHI, M. A., \& ETNYRE, B. (2005). Soleus and vastus medialis $\mathrm{H}$-reflexes: Similarities and differences while standing or lying during varied knee flexion angles. Journal of neuroscience methods, 144(2), 215-225.

9. AVELA, J.; FINNI, J.; KOMI, P.V. Excitability of the soleus reflex arc during intensive stretch-shortening cycle exercise in two power- 
trained athlete groups. European journal of applied physiology, 97(4), 486-493. 2006.

10. BACKX,F. J. G., BEIJER, H.J.M., BOL, E., ERICH, W.,B.,M. Injuries in high-risk persons and high-risk sports. Am J Sports Med. 19:124-30; 2 1991.

11. BARNEA-GORALY, N., MENON, V., ECKERT, M., TAMM, L., BAMMER, R., KARCHEMSKIY, A. \& REISS, A. L. (2005). White matter development during childhood and adolescence: a crosssectional diffusion tensor imaging study.Cerebral cortex, 15(12), 18481854.

12. BAUDRY, S., \& DUCHATEAU, J. (2012). Age-related influence of vision and proprioception on la presynaptic inhibition in soleus muscle during upright stance. The Journal of physiology, 590(21), 5541-5554.

13. BAUDRY, S., COLLIGNON, S., \& DUCHATEAU, J. (2015). Influence of age and posture on spinal and corticospinal excitability. Experimental gerontology, 69, 62-69.

14. BEAUMONT, E., \& GARDINER, P. F. (2003). Endurance training alters the biophysical properties of hindlimb motoneurons in rats. Muscle \& nerve, 27(2), 228-236

15. BECK, S., TAUBE, W., GRUBER, M., AMTAGE, F., GOLLHOFER, A. \& SCHUBERT, M. 2007. Task-specific changes in motor evoked potentia Is of lower limb muscles after different training interventions. Brain Res 1179, 51-60.

16. BEHRENS, M., MAU-MOELLER, A., WASSERMANN, F., BADER, R., \& BRUHN, S. (2015). Effect of balance training on neuromuscular function at rest and during isometric maximum voluntary contraction. European journal of applied physiology, 115(5), 10751085.

17. BONETTI, L. V., BRUM, G., R., MIOTTO, M., TADIELLO, G. S., SCHMITT, V. M., DEMARCHI, T. The use of the taping on ankle stability in basketball athletes. ConScientiae Saúde, 2012;11(3):49149. 
18. BOVE, M., TROMPETTO, C., ABBRUZZESE, G. \& SCHIEPPATI, M. 2006. The posture-related interaction between la-afferent and descending input on the spinal reflex excitability in humans. Neurosci Left 397, 301-306.

19. BRESSEL, E., YONKER, J. C., KRAS, J., \& HEATH, E. M. (2007). Comparison of static and dynamic balance in female collegiate soccer, basketball, and gymnastics athletes. Journal of athletic training, 42(1), 42.

20.BROOKE, J. D., CHENG, J., MISIASZEK, J. E., \& LAFFERTY, K. (1995). Amplitude modulation of the soleus $\mathrm{H}$ reflex in the human during active and passive stepping movements. Journal of neurophysiology, 73(1), 102-111.

21. BRUNNER, E. AND LANGER, F. (2000): Nonparametric analysis of ordered categorical data in designs with longitudinal observations and small sample sizes. Biometrical Journal, 42, 663-685.

22. BRINKWORTH, R. S., \& TÜRKER, K. S. (2003). A method for quantifying reflex responses from intra-muscular and surface electromyogram. Journal of neuroscience methods, 122(2), 179-193.

23. BURKE, R. E., JANKOWSKA, E., \& TEN BRUGGENCATE, G. (1970). A comparison of peripheral and rubrospinal synaptic input to slow and fast twitch motor units of triceps surae. The Journal of Physiology, 207(3), 709.

24. BURKE, R. E., \& RYMER, W. Z. (1976). Relative strength of synaptic input from short-latency pathways to motor units of defined type in cat medial gastrocnemius. Journal of neurophysiology, 39(3), 447-458.

25. BURKE, D., GANDEVIA, S. C., \& MCKEON, B. (1983). The afferent volleys responsible for spinal proprioceptive reflexes in man. The Journal of physiology, 339(1), 535-552..

26. BURKE, D., GANDEVIA, S.C., \& MCKEON, B. (1984). Monosynaptic and oligosynaptic contributions to human ankle jerk and $\mathrm{H}$ reflex.Journal of Neurophysiology, 52(3), 435-448.

27. BURKE, R. E. (2011). Motor units: anatomy, physiology, and functional organization. Comprehensive Physiology. 
28. CAPADAY, C., \& STEIN, R. B. (1986). Amplitude modulation of the soleus $\mathrm{H}$-reflex in the human during walking and standing. The Journal of neuroscience,6(5), 1308-1313.

29. CAPADAY, C. \& STEIN, R.B. 1987. Difference in the amplitude of the human soleus $\mathrm{H}$ reflex during walking and running. ] Physiol 392, 513522.

30. CAPADAY, C., \& STEIN, R. B. (1989). The effects of postsynaptic inhibition on the monosynaptic reflex of the cat at different levels of motoneuron pool activity. Experimental brain research, 77(3), 577-584.

31. CAPADAY, C.; CODY, F. W.; STEIN, R. B. Reciprocal inhibition of soleus motor output in humans during walking and voluntary tonic activity. Journal of Neurophysiology, 64, 607-16. 1990.

32. CAPADAY, C., LAVOIE, B. A., \& COMEAU, F. (1995). Differential effects of a flexor nerve input on the human soleus $\mathrm{H}$-reflex during standing versus walking.Canadian journal of physiology and pharmacology, 73(4), 436-449.

33. CAPADAY, C. (1997). Neurophysiological methods for studies of the motor system in freely moving human subjects. Journal of neuroscience methods,74(2), 201-218.

34. CARAFFA, A., CeRUlli, G., PROJETTI, M., AISA, G., RIZZO, A. Prevention of anterior cruciate ligament injuries in soccer. $A$ prospective controlled study of proprioceptive training. Knee Surg, Sports Traumatol, Arthroscopy. 1996 4:19-21.

35. CARP, J. S., CHEN, X. Y., SHEIKH, H., \& WOLPAW, J. R. (2001). Operant conditioning of rat $\mathrm{H}$-reflex affects motoneuron axonal conduction velocity. Experimental brain research, 136(2), 269-273.

36. CASTAGNA, C., ABT, G., MANZI, V., ANNINO, G., PADUA, E., \& D'OTTAVIO, S. (2008). Effect of recovery mode on repeated sprint ability in young basketball players. The Journal of Strength \& Conditioning Research, 22(3), 923-929.

37. CASTAGNA, C., MANZI, V., D'OTTAVIO, S. T. E. F. A. N. O., ANNINO, G., PADUA, E., \& BISHOP, D. (2007). Relation between maximal aerobic power and the ability to repeat sprints in young basketball players. The Journal of Strength \& Conditioning Research, 21(4), 1172-1176. 
38. CASTAINGTS, V., MARTIN, A., VAN HOECKE, J., \& PEROT, C. (2004). Neuromuscular efficiency of the triceps surae in induced and voluntary contractions: morning and evening evaluations. Chronobiology international, 21(4-5), 631-643.

39. CHEN, X. Y., \& WOLPAW, J. R. (2002). Probable corticospinal tract control of spinal cord plasticity in the rat. Journal of Neurophysiology, 87(2), 645-652.

40. CHEN, YUNG-SHENG, AND SHI ZHOU. "Soleus H-reflex and its relation to static postural control." Gait \& posture 33.2 (2011): 169178.

41. CHENG, T.L., FIELDS, C.,B., BRENNER, R.,A., WRIGHT, J.,L., LOMAX, T., SCHEIDT, P.,C. Sports injuries: An important cause of morbidity in urban youth. Pediatrics; 105: E32, 2000.

42. CHRISTIE, A., LeStER, S., LAPIERRE, D., \& GABRIEL, D. A. (2004). Reliability of a new measure of $\mathrm{H}$-reflex excitability. Clinical Neurophysiology, 115(1), 116-123.

43. CHRISTIE, A. D., INGLIS, J. G., BOUCHER, J. P., \& GABRIEL, D. A. (2005). Reliability of the FCR H-reflex. Journal of Clinical Neurophysiology, 22(3), 204-209.

44. CLIFF, N (1993). Dominance statistics: Ordinal analyses to answer ordinal questions. Psychological Bulletin, n. 114 , vol.3,p.494-509.

45. CIANCHETTI, C. Soleus $\mathrm{H}$ reflex and afferent discharges from antagonist muscles. An electrophysiological method of evaluation. Electroencephalography and Clinical Neurophysiology, 39, 4 425-7. 1975.

46. CONBOY, J. "Estimando a dimensão do N de uma amostra." INUAF Studia 1.2 (2000): 227-274.

47. CONBOY, JOSEPH EDWARD. Algumas medidas típicas univariadas da magnitude do efeito. Análise Psicológica, v.21, n.2, p. 145-158, 2012.

48. COHEN, J. (1988). Statistical power analysis for the behavioral sciences ( $2^{\text {nd }}$ ed.). New York: Academic Press. 
49. COUGHLAN, GARRETT, \& BRIAN CAULFIELD (2007). "A 4-week neuromuscular training program and gait patterns at the ankle joint." Journal of athletic training 42.1: 51.

50. COX, E. D., LEPHART, S. M., \& IRRGANG, J. J. (1993). Unilateral balance training of noninjured individuals and the effects on postural sway. Journal of Sport Rehabilitation, 2(2).

51. CRESSEY, E. M., WEST, C. A., TIBERIO, D. P., KRAEMER, W. J., \& MARESH, C. M. (2007). The effects of ten weeks of lower-body unstable surface training on markers of athletic performance. The Journal of Strength \& Conditioning Research, 21(2), 561-567.

52. CRONE, C., HULTBORN, H.,JESPERSEN, B., NIELSEN, J., Reciprocal la inhibition between ankle exors and extensors in man. $J$ Physiol 1987; 389: 163 \pm 85 .

53. CRONE C, HULTBORN H, MAZIERES L, MORIN C, NIELSEN J, PIERROT-DESEILLIGNY E. Sensitivity of monosynaptic test reflexes to facilitation and inhibition as a function of the test reflex size: a study in man and the cat. Experimental Brain Research. 1990; 81:35-45.

54. CRONE, C., JOHNSEN, L. L., HULTBORN, H., \& ØRSNES, G. B. (1999). Amplitude of the maximum motor response (Mmax) in human muscles typically decreases during the course of an experiment. Experimental brain research, 124(2), 265-270.

55. CUTSEM, MICHAËL, JACQUES DUCHATEAU \& KARL HAINAUT. "Changes in single motor unit behaviour contribute to the increase in contraction speed after dynamic training in humans." The Journal of physiology 513.1 (1998): 295-305.

56. DELEXTRAT, A., \& COHEN, D. (2009). Strength, power, speed, and agility of women basketball players according to playing position. The Journal of Strength \& Conditioning Research, 23(7), 1974-1981.

57. DE LUCA Cj. Eletromyography.In: Webster JG, editor. Encyclopedia of medical devices and instrumentation. New York: John Wiley \& Sons; 2006. P. 98-109.

58. DE MATTOS, E. C. T. (2009). Adaptações neurais na medula espinhal de humanos para diferentes tipos de treinamento físico (Doctoral dissertation, Universidade de São Paulo).

59. DE ROSE, G.; TADIELLO, F. F.; DE ROSE Jr. D. Lesões esportivas: 
um estudo com atletas do basquetebol brasileiro. Buenos Aires, Revista Digital № 94. 2006.

60. DELUCA CJ. The use of surface electromyography in biomechanics. Journalof Applied biomechanics. 1997; 13(2):135 63.

61. Desaulniers, P., LAVOIE, P. A., \& GARDineR, P. F. (2001). Habitual exercise enhances neuromuscular transmission efficacy of rat soleus muscle in situ. Journal of Applied Physiology, 90(3), 1041-1048.

62. DEWHURST, S., RICHES, P. E., NIMMO, M. A., \& DE VITO, G. (2005). Temperature dependence of soleus $\mathrm{H}$-reflex and $\mathrm{M}$ wave in young and older women. European journal of applied physiology, 94(56), 491-499.

63. DIENER, H. C., BOOTZ, F., DICHGANS, J., \& BRUZEK, W. (1983). Variability of postural "reflexes" in humans. Experimental brain research, 52(3), 423-428.

64. DIETZ, V., HORSTMANN, G., \& BERGER, W. (1988). Involvement of different receptors in the regulation of human posture. Neuroscience letters, 94(1), 82-87.

65.DRAGERT, K., ZEHR, E.P. Rhythmic arm cycling modulates Hoffmann reflex excitability differentially in the ankle flexor and extensor muscles. Neurosci Lett 450:325-328, 2009.

66. DUYSENS, J., TAX, A. A. M., TRIPPEL, M., \& DIETZ, V. (1992). Phase-dependent reversal of reflexly induced movements during human gait. Experimental brain research, 90(2), 404-414.

67. ERLANGER, J., \& GASSER, H. S. (1937). Electrical signs of nervous activity.

68. EARLES, D. R., KOCEJA, D. M., \& SHIVELY, C. W. (2000). Environmental changes in soleus $\mathrm{H}$-reflex excitability in young and elderly subjects. International journal of neuroscience, 105(1-4), 1-13.

69. ECCLES JC, FATT P, LANDGREN S (1956) Central pathway for direct inhibitory action of impulses in largest afferent nerve fibres to muscle. J Neurophysiol 19:75-98.

70. EILS, E., ROSENBAUM, D. A multi-station proprioceptive exercise program in patients with ankle instability. MEDICINE \& SCIENCE IN SPORTS \& EXERCISE $\AA$ Copyright $\odot 2001$ by the American College of Sports Medicine. 
71. EYRE, J. A., S. MILLER, \& V. RAMESH. Constancy of central conduction delays during development in man: investigation of motor and somatosensory pathways. The Journal of physiology 434.1 (1991): 441-452.

72. FAIST, M., V. DIETZ, \& E. PIERROT-DESEILLIGNY. "Modulation, probably presynaptic in origin, of monosynaptic la excitation during human gait."Experimental brain research 109.3 (1996): 441-449.

73. FITZPATRICK, R., BURKE, D., \& GANDEVIA, S. C. (1994). Taskdependent reflex responses and movement illusions evoked by galvanic vestibular stimulation in standing humans. The Journal of Physiology, 478(Pt 2), 363.

74. FLESHMAN, J. W., MUNSON, J. B., \& SYPERT, G. W. (1981). Homonymous projection of individual group la-fibers to physiologically characterized medial gastrocnemius motoneurons in the cat. Journal of neurophysiology, 46(6), 1339-1348.

75.FOURNIER, E.;KATZ, R.;PIERROT-DESEILLIGNY, E.. A reevaluation of the pattern of group I fibre projections in the human lower limb on using randomly alternated stimulations. Experimental Brain Research 56: 193-19. 1984

76. FREITAS, D. L., MAIA, J. A., BEUNEN, G. P., LEFEVRE, J. A., ClAESSENS, A. L., MARQUES, A. T. \& PHILIPPAERTS, R. M. (2003). Maturação esquelética e aptidão física em crianças e adolescentes madeirenses. Revista Portuguesa de Ciências do Desporto, 3(1), 61-75.

77. FRIEDMAN, W. A., SYPERT, G. W., MUNSON, J. B., \& FLESHMAN, J. W. (1981). Recurrent inhibition in type-identified motoneurons. Journal of Neurophysiology,46(6), 1349-1359.

78. FU, A.,S.,N., HUI-CHAN, W.,Y. Ankle joint proprioception and postural control in basketball players with bilateral ankle sprains. Am. J Sports Med., 33, pp; 1174-1182. 2005.

79. FUMOTO, M., KOMIYAMA, T., \& NISHIHIRA, Y. (2002). Soleus Hreflex dynamics during fast plantarflexion in humans. Journal of Electromyography and Kinesiology, 12(5), 367-374. 
80. FUNASE, K., \& MILES, T. S. (1999). Observations on the variability of the $\mathrm{H}$ reflex in human soleus. Muscle \& nerve, 22(3), 341-346.

81. GANTUS, M.,C., ASSUMPÇÃO, J.,D. Epidemiologia das lesões do sistema locomotor em atletas de basquetebol. Acta Fisiátrica. 2002;9(2):77-84.; 11.

82. GAUChARD, G.,C., JEANDEL, C., TESSIER, A., PERRIN, P.,P., Beneficial effect of proprioceptive physical activities on balance control in elderly human subjects. Neuroscience Letters, 273, pp. 81-84. 1999.

83. GIEDD, J. N., BLUMENTHAL, J., JEFFRIES, N. O., CASTELLANOS, F. X., LIU, H., ZIJDENBOS, A. \& RAPOPORT, J. L. (1999). Brain development during childhood and adolescence: a longitudinal MRI study. Nature neuroscience, 2(10), 861-863.

84. GUEDES, P. F., \& JOÃO, S. M. (2014). Postural Characterization of Adolescent Federation Basketball Players. Journal of physical activity \& health, 11(7), 1401-1407.

85. GRANACHER, U., GOLLHOFER, A. \& STRASS, D. 2006. Training induced adaptations in characteristics of postural reflexes in elderly men. Gait l'osture 24, 459-466.

86. GRAVETTER, F.J. \& WALLNAU, L.B. (2004). Statistics for the Behavioral Sciences, $6^{\text {th }}$ edition, California: Wadsworth/Thomson.

87. GREY, M. J., LADOUCEUR, M., ANDERSEN, J. B., NIELSEN, J. B., \& SINKJAER, T. (2001). Group II muscle afferents probably contribute to the medium latency soleus stretch reflex during walking in humans. The Journal of physiology,534(3), 925-933.

88. GOLDBERG, J., SULLIVAN, S. J., \& SEABORNE, D. E. (1992). The effect of two intensities of massage on $\mathrm{H}$-reflex amplitude. Physical therapy, 72(6), 449-457.

89. GOLLHOFER, A., \& RAPP, W. (1993). Recovery of stretch reflex responses following mechanical stimulation. European journal of applied physiology and occupational physiology, 66(5), 415-420. 
90. GRUBER, M., TAUBE, W., GOLLHOFER, A., BECK, S., AMTAGE, F. \& SCHUBERT, M. 2007. Training-specific adaptations of $\mathrm{H}$ - and stretch reflexes in human soleus muscle. J Mot Behav 39, 68-78.

91. GUIMARÃES, M. M., SACCO, I. C., \& JOÃO, S. M. (2007). Caracterização postural da jovem praticante de ginástica olímpica. Braz. J. Phys. Ther.(Impr.), 11(3), 213-219.

92. GUSTAFSSON, B., \& PINTER, M. J. (1985). On factors determining orderly recruitment of motor units: a role for intrinsic membrane properties. Trends in Neurosciences, 8, 431-433.

93. HAYASHI, R., TAKO, K., TOKUDA, T., \& YANAGISAWA, N. (1992). Comparison of amplitude of human soleus H-reflex during sitting and standing. Neuroscience research, 13(3), 227-233.

94. HAYASHI, R., TOKUDA, T., TAKO, K., \& YANAGISAWA, N. (1997). Impaired modulation of tonic muscle activities and H-reflexes in the soleus muscle during standing in patients with Parkinson's disease. Journal of the neurological sciences, 153(1), 61-67.

95. HAYES, K. C., WARNKING, R., SILNY, J., \& RAU, G. (1980). Multielectrode recording of Hoffmann reflexes. Electroencephalography and clinical neurophysiology, 50(1), 196-199.

96. HÄKKINEN, K., \& KOMI, P. V. (1983). Changes in neuromuscular performance in voluntary and reflex contraction during strength training in man. International journal of sports medicine, 4(4), 282-288.

97. HÄKKINEN, K., \& KOMI, P. V. (1986). Training-induced changes in neuromuscular performance under voluntary and reflex conditions. European journal of applied physiology and occupational physiology, 55(2), 147-155.

98. HEDRICK, A. (1993). SPORTS-SPECIFIC: Strength and Power Training for Basketball. Strength \& Conditioning Journal, 15(4), 31-36.

99. HEITKAMP, H.E., HORSTMANN, T., MAYER, F., WELLER, \& DICKHUTH, H.H. 2001. Gain in strength and muscular balance after balance training. Int J Sports Med 22, 285-290.

100. HENNEMAN E, MENDELL LM. Functional organization of motoneuron pool and its inputs. Handbook of Physiology The nervous 
System, Bethesda (MD): American Physiological Society; 1982. P.423-507.

101. HODAPP, M., KLISCH, C., BERGER, W., MALL, V., \& FAIST, M. (2007). Modulation of soleus $\mathrm{H}$-reflexes during gait in healthy children. Experimental brain research, 178(2), 252-260.

102. HOSEINI, N.; KOCEJA D.M.; RILEY, Z.A. The effect of operantconditioning balance training on the down-regulation of spinal $\mathrm{H}$ reflexes in a spastic patient. Neuroscience Letter, n.24;504(2):112-4. Oct, 2011.

103. HOFFER, J. A. \& STEEN ANDREASSEN. Regulation of soleus muscle stiffness in premammillary cats: intrinsic and reflex components. Journal of neurophysiology 45.2 (1981): 267-285.

104. HOFFMAN, M., \& PAYNE, V. G. (1995). The effects of proprioceptive ankle disk training on healthy subjects. Journal of Orthopaedic \& Sports Physical Therapy, 21(2), 90-93

105. HOLTERMANN, A., ROELEVELD, K., ENGSTRØM, M., \& SAND, T. (2007). Enhanced H-reflex with resistance training is related to increased rate of force development.European journal of applied physiology, 101(3), 301-312.

106. HORSLEN, B. C., MURNAGHAN, C. D., INGLIS, J. T., CHUA, R., \& CARPENTER, M. G. (2013). Effects of postural threat on spinal stretch reflexes: evidence for increased muscle spindle sensitivity? Journal of neurophysiology, 110(4), 899-906.

107. HUGON, M (1973) Metodology of the Hoffmann Reflex in man. New developments $n$ electromyography and chemical neurophysiology. J.E. Desmedt. Basel, Karger. 3m: 277-293.

108. HULTBORN, H., MEUNIER, S., PIERROT-DESEILLIGNY, E., \& SHINDO, M. (1987). Changes in presynaptic inhibition of la fibres at the onset of voluntary contraction in man. The Journal of physiology, 389(1), 757-772.

109. HULTBORN, H.; NIELSEN, J.B. Spinal control of locomotionfrom cat to man. Acta Physiologica, 189(2), 111-121. 2007. 
110. HOPKINS, J. T., \& WAGIE, N. C. (2003). Intrasession and intersession reliability of the quadriceps Hoffmann reflex. Electromyography and clinical neurophysiology, 43(2), 85-89.

111. ILES, J. F. (1986). Reciprocal inhibition during agonist and antagonist contraction. Experimental brain research, 62(1), 212-214.

112. ILES, J. F., \& PISINI, J. V. (1992). Vestibular-evoked postural reactions in man and modulation of transmission in spinal reflex pathways. The Journal of Physiology, 455(1), 407-424.

113. ILES, J.F. Evidence for cutaneous and corticospinal modulation of presynaptic inhibition of la afferents from the human lower limb. The Journal of physiology, 491(Pt.1), 197-207. 1996.

114. ISHIHARA, A., KAWANO, F., ISHIOKA, N., OISHI, H., HIGASHIBATA, A., SHIMAZU, T., \& OHIRA, Y. (2004). Effects of running exercise during recovery from hindlimb unloading on soleus muscle fibers and their spinal motoneurons in rats. Neuroscience research, 48(2), 119-127.

115. JENSEN, J. L., MARSTRAND, P. C., \& NIELSEN, J. B. (2005). Motor skill training and strength training are associated with different plastic changes in the central nervous system. Journal of applied physiology, 99(4), 1558-1568.

116. JOHANNSSON, J., JACQUES DUCHATEAU \& STÉPHANE BAUDRY. "Presynaptic inhibition of soleus la afferents does not vary with center of pressure displacements during upright standing." Neuroscience 298 (2015): 63-73.

117. JOHN, W., POWELL, K., D., BARBER, F., Injury Patterns in Selected High School Sports: A Review of the 19951997 Seasons Journal of Athletic Training 1999;34(3):277-284.

118. KANDA, K., BURKE, R. E., \& WALMSLEY, B. (1977). Differential control of fast and slow twitch motor units in the decerebrate cat. Experimental Brain Research,29(1), 57-74.

119. KANDEL ER, SHWARTZ JH, JESSEL TM, SIEGELBAUM SA, HUDSPETH AJ. Principles of neural science. 5 ed. New York: McGraw - Hill; 2013.

120. KANDEL, E.,R., SCHWARTZ, J.,H., JESSEL, T.,M., Princípios 
da neurociência. $4^{\text {a }}$ ed. São Paulo, Manole. 2003

121. KATZ, R., MEUNIER, S. \& PIERROT-DESEILLIGNY, E. 1988.

Changes in presynaptic inhibition of la fibres in man while standing. Brain 111,417-437.

122. KAWAISHI, YU \& KAZUHISA DOMEN. "The relationship between dynamic balancing ability and posture-related modulation of the soleus H-reflex." Journal of Electromyography and Kinesiology (2015).

123. KEEN, D. A., YUE, G. H., \& ENOKA, R. M. (1994). Trainingrelated enhancement in the control of motor output in elderly humans. Journal of Applied Physiology, 77(6), 2648-2658.

124. KERNELL, D. (1986). Organization and properties of spinal motoneurones and.The Oculomotor and Skeletalmotor Systems: Differences and Similarities, 64, 21.

125. KERNELL, DANIEL, \& HANS HULTBORN. (1990) Synaptic effects on recruitment gain: a mechanism of importance for the inputoutput relations of motoneurone pools?. Brain research 507.1: 176179.

126. KERR, ROBERT. (1975) Movement control and maturation in elementary-grade children.Perceptual and Motor Skills 41.1: 151-154.

127. KITANO, K.; TSURUIKE, M.; ROBERTSON, C. T.; KOCEJAL, D.M. Effects of a complex balance task on soleus H-reflex and presynaptic inhibition in humans. Electromyography and clinical neurophysiology, 49(5), 235. Jul-Aug, 2009.

128. KLEINPAUL, J. F., MANN, L., \& DOS SANTOS, S. G. (2010). Lesões e desvios posturais na prática de futebol em jogadores jovens Injuries and postural deviations in young players' soccer practice. FISIOTERAPIA PESQUISA, 236.

129. SHANGOLD, M. M., \& MIRKIN, G. (1985). The Adolescent Athlete. In Pediatric and Adolescent Obstetrics and Gynecology (pp. 313-318). Springer New York. 
130. KLIMSTRA M, ZEHR EP. A sigmpoid function is the best fit for the ascending limb of the Hoffmann reflex recruitment curve. Experimental Brain Research. 2008; 186(1):93-105.

131. KOCEJA, D. M., TRIMBLE, M. H., \& EARLES, D. R. (1993). Inhibition of the soleus H-reflex in standing man. Brain research, 629(1), 155-158.

132. KOCEJA, D. M., \& MYNARK, R. G. (2000). Comparison of heteronymous monosynaptic la facilitation in young and elderly subjects in supine and standing positions. International journal of neuroscience, 104(1), 1-15.

133. KOH, T. H., \& J. A. EYRE. "Maturation of corticospinal tracts assessed by electromagnetic stimulation of the motor cortex." Archives of disease in childhood 63.11 (1988): 1347-1352.

134. KOVACS, E. J., BIRMINGHAM, T. B., FORWELL, L., \& LITCHFIELD, R. B. (2004). Effect of training on postural control in figure skaters: a randomized controlled trial of neuromuscular versus basic off-ice training programs. Clinical journal of sport medicine, 14(4), 215-224.

135. LAGERQUIST, O., ZEHR, E. P., \& DOCHERTY, D. (2006). Increased spinal reflex excitability is not associated with neural plasticity underlying the cross-education effect. Journal of Applied Physiology, 100(1), 83-90.

136. LEPHART, S. et al.Como Restabelecer o Controle neuromuscular. In: PRENTICE, William E. Técnicas de Reabilitação em Medicina Esportiva. São Paulo:Manole, 2002, p. 88-103.

137. LLEWELLYN M, PROCHAZKA A, YANG JF (1989) Human Hreflexes are reduced in difficult beam-walking compared to stance and normal walking. J Physiol (Lond) 418: 104P

138. LLEWELLYN M, YANG JF, PROCHAZKA A. Human H-reflexes are smaller in difficult beam walking than in normal treadmill walking. Exp Brain Res. 1990; 83: 22-28. pmid:2073943 doi: 10.1007/bf00232189

139. MAGLADERY, J. W.; MCDOUGAL, D. B., JR. Electrophysiological studies of nerve and reflex activity in normal man. I. Identification of certain reflexes in the electromyogram and the conduction velocity of peripheral nerve fibers. Johns Hopkins Medicine 
Journal, 86, 265-290. 1950.

140. MACBETH, GUILLERMO, EUGENIA RAZUMIEJCZYK, AND RUBÉN DANIEL LEDESMA. "Cliff's Delta Calculator: A nonparametric effect size program for two groups of observations." Universitas Psychologica 10.2 (2011): 545-555.

141. MAURER, C., MERGNER, T., \& PETERKA, R. J. (2006). Multisensory control of human upright stance. Experimental Brain Research, 171(2), 231-250.

142. MCCREA, D. A. Can sense be made of spinal interneuron circuits? Behavioral and Brain Sciences, 15, 633-643. 1992.

143. MCKAY, GOLDIE, PAYNE, CAKES; A prospective study of injures in basketball: a total profile and comparison by gender and standard of competition, 2001.

144. MCGUINE, TIMOTHY A. \& JAMES S. KEENE. "The effect of a balance training program on the risk of ankle sprains in high school athletes." The American journal of sports medicine 34.7 (2006): 11031111.

145. Mcllroy, W. E., Bishop, D. C., Staines, W. R., Nelson, A. J., Maki, B. E., \& Brooke, J. D. (2003). Modulation of afferent inflow during the control of balancing tasks using the lower limbs. Brain research, 961(1), 73-80.

146. MEEUWISSE, W.,H., SELLMER, R., HAGEL, B.,E. Rates and risks of injury during intercollegiate basketball. Am. J Sports Med., 31, pp. 379-385. 2003.

147. MECKEL, Y., CASORLA, T., \& ELIAKIM, A. (2009). The Influence of Basketball Dribbling on Repeated Sprints. International Journal of Coaching Science, 3(2).

148. MELLO, R.; PARADA, K. Perfil de lesões dos membros inferiores em atletas de basquetebol do sexo masculino. Anais de Pesquisa da Universidade de Ribeirão Preto. São Paulo, 2002.

149. METAXAS, T. I., KOUTLIANOS, N., SENDELIDES, T., \& MANDROUKAS, A. (2009). Preseason physiological profile of soccer and basketball players in different divisions. The Journal of Strength \& Conditioning Research, 23(6), 1704-1713. 
150. MEUNIER, S. and PIERROT-DESEILLIGNY, E. Cortical control of presynaptic inhibition of la afferents in humans. Experimental Brain Research, 119, 415-426. 1998.

151. MEUNIER, S. et al.(1993). "Pattern of monosynaptic metoronymous la connections in the human limb" Experimental Brain Research 96: 534-544.

152. MEZZARANE, R.A.; ELIAS, L.A.; MAGALHÃES, F.H. ; CHAUD, V.M. ; KOHN, A.F. Experimental and simulated EMG responses in the study of the human spinal cord. In: Turker H. (Org.). Electromyography, 1ed.: Rijeka: In Tech, 1-30. 2013.

153. MEZZARANE, R.A.; KLIMSTRA, M.; LEWIS, A.; HUNDZA, S.R.; ZEHR, E.P. Interlimb coupling from the arms to legs is differentially specified for populations of motor units comprising the compound $\mathrm{H}$ reflex during "reduced" human locomotion. Experimental Brain Research, 208:157-68. 2011.

154. MEZZARANE, R.A.; KOHN, A.F.; COUTO-ROLDAN, E.; MARTINEZ, L.; FLORES, A. Absence of effects of contralateral group I muscle afferents on presynaptic inhibition of la terminals in humans and cats. Journal of Neurophysiology, 108:1176-1185. 2012.

155. MEZZARANE, R.A., et al."Enhanced D1 and D2 Inhibitions Induced by Low-Frequency Trains of Conditioning Stimuli: Differential Effects on $\mathrm{H}$-and T-Reflexes and Possible Mechanisms." PloS one 10.3 (2015): e0121496.

156. MISIASZEK, J. E. (2003). The H-reflex as a tool in neurophysiology: Its limitations and uses in understanding nervous system function. Muscle \& nerve, 28(2), 144-160.

157. MIZUNO, Y.et al.(1971). "Reciprocal group I inhibition on triceps surae motoneurons in man" Journal of neurophysiology 43:1010-1017.

158. MORITANI, T. (1979). Neural factors versus hypertrophy in the time course of muscle strength gain. American Journal of Physical Medicine \& Rehabilitation,58(3), 115-130.

159. MORITANI, T., ODDSSON, L., \& THORSTENSSON, A. (1990).

Differences in modulation of the gastrocnemius and soleus $\mathrm{H}$-reflexes 
during hopping in man. Acta physiologica scandinavica, 138(4), 575576.

160. MORITA, H.; CRONE, C.; CHRISTENHUIS, D.; PETERSEN, N. T.; NIELSEN, J. B. Modulation of presynaptic inhibition and disynaptic reciprocal la inhibition during voluntary movement in spasticity. Brain, 124, Pt 4 826-37. 2001.

161. MUNSON, J. B., SYPERT, G. W., ZENGEL, J. E., LOFTON, S. A., \& FLESHMAN, J. W. (1982). Monosynaptic projections of individual spindle group II afferents to type-identified medial gastrocnemius motoneurons in the cat. Journal of neurophysiology, 48(5), 1164-1174.

162. MYER, G.D., FORD, K.R., BRENT,].L. \& HEWETT, T.E. 2006. The effects of plyometric vs. dynamic stabilization and balance training on power, balance, and landing force in female athletes. J Strength Cond Res 20, 345-353.

163. MYERS, J.L. \& WELL, A.D. (1995). Research Design and Statistical Analysis. Hew Jersey: Lawrence Erlbaum Associates.

164. MYKLEBUST, BARBARA M. "A review of myotatic reflexes and the development of motor control and gait in infants and children: a special communication."Physical Therapy 70.3 (1990): 188-203.

165. NASHNER, L. M. (1976). Adapting reflexes controlling the human posture. Experimental Brain Research, 26(1), 59-72.

166. NARDONE, A., \& SCHIEPPATI, M. (1988). Shift of activity from slow to fast muscle during voluntary lengthening contractions of the triceps surae muscles in humans. The Journal of Physiology, 395(1), 363-381.

167. NEUROSCIENCE, Fourth Edition. Dale Purves, George J. Augustine, David Fitzpatrick, William C. Hall, Anthony-Samuel LaMantia, James O. McNamara, and Leonard E. White, Sinauer, 2008.

168. Nielsen, Crone, C. \& Hultborn, H. 1993. H-reflexes are smaller in dancers from The Royal Danish Ballet than in well-trained athletes. Eur J Appl Physiol Occup Physiol 66, 116-121. 
169. NOURI, HOSSEIN. Effect size for ANOVA designs. No. 129. Sage, 2000.

170. PAGANO, R.R. (1995). Understanding Statistics in the Behavioral Sciences, 6th edition. California: Wadsworth/Thomson.

171. PANICS, G., TALLAY, A., PAVLIK, A., \& BERKES, I. (2008). Effect of proprioception training on knee joint position sense in female team handball players. British journal of sports medicine, 42(6), 472476.

172. PANIZZA M, NILSSON J, HALLETT M. Optimal stimulus duration for the $\mathrm{H}$ reflex. Muscle \& nerve. 1989; 12: 576-579.

173. PASANEN, K., PARKKARI, J., PASANEN, M., Hannele HIILLOSKORPI, H., KANNUS, P. Neuromuscular training and the risk of leg injuries in female floorball players: cluster randomised controlled study. BMJ 2008;337:a295 doi:10.1136/bmj.a295)

174. PASTRE, C.,M., CARVALHO, G., F., MONTEIRO, H.,L., NETTO, J., Jr., PADOVANI, C.,R., GARCÍA, A.,B. Exploração de fatores de risco para lesões no atletismo de alta performance. Rev. Bras. Med. Esporte. 2007; 13(3):200-04. doi:10.1590/S151786922007000300014.

175. Paus, Tomáš, et al. "Structural maturation of neural pathways in children and adolescents: in vivo study." Science 283.5409 (1999): 1908-1911.

176. Péréon, Y., Tich, S. N. T., Fournier, E., Genet, R., \& Guihéneuc, P. (2004). Electrophysiological recording of deep tendon reflexes: normative data in children and in adults. Neurophysiologie Clinique/Clinical Neurophysiology,34(3), 131-139.

177. PIERROT-DESEILligNy, E., BERGEGO, C., KATZ, R., \& MORIN, C. (1981). Cutaneous depression of lb reflex pathways to motoneurones in man. Experimental brain research, 42(3-4), 351-361.

178. PIERROT-DESEILLIGNY, E., \& MAZEVET, D. (2000). The monosynaptic reflex: a tool to investigate motor control in humans. Interest and limits. Neurophysiologie Clinique/Clinical Neurophysiology, 30(2), 67-80. 
179. PIERROT-DESEILLIGNY, E.; BURKE, D. The circuitry of the human spinal cord: its role in motor control and movement disorders. Cambridge University Press. 2005.

180. PINTO JÚNIOR, J. A. D., DE SOUSA, M. D. S. C., GAYA, A. C. A., \& HENRIQUES ALVES, J. V. D. M. (2012). Maturação biológica e desempenho físico de jovens atletas de ginástica rítmica. Revista Brasileira de Ciência e Movimento, 20(1), 88-96.

181. PLISKY, P. J., RAUH, M. J., KAMINSKI, T. W., UNDERWOOD, F. B. Star Excursion Balance Test as a Predictor of Lower Extremity Injury in High School Basketball Players. Orthop Sports Phys Ther 2006;36(12):911-919. doi:10.2519/jospt.2006.2244.

182. PROCHAZKA A, WESTERMAN RA, ZICCONE SP (1976)

Discharges

single hindlimb afferents in the freely moving cat. $J$ Neurophysiol 39:1090-1104

183. PROCHAZKA, A., \& TREND, P. S. (1988). Instability in human forearm movements studied with feed-back-controlled muscle vibration. The Journal of physiology, 402, 421.

184. PROCHAZKA A, HULLIGER $M$, TREND P, DURMULLER $N$ (1988) Dynamic and static fusimotor set in various behavioural contexts. In: Hnik T, Soukup R, Vejsada R, Zelena J (eds) Mechanoreceptors: development, structure and function. Plenum Press, London, pp 417-430

185. PROCHAZKA, A., HULLIGER, M., ZANGGER, P., \& APPENTENG, K. (1985). 'Fusimotor set': new evidence for $\alpha$ independent control of $\mathrm{y}$-motoneurones during movement in the awake cat. Brain research, 339(1), 136-140

186. RIEMANN, B. L., TRAY, N. C., \& LEPHART, S. M. (2003). Unilateral multiaxial coordination training and ankle kinesthesia, muscle strength, and postural control. Journal of Sport Rehabilitation, 12(1), 13-30.

187. ROBINSON, K. L., MCCOMAS, A. J., \& BELANGER, A. Y. (1982). Control of soleus motoneuron excitability during muscle stretch 
in man. Journal of Neurology, Neurosurgery \& Psychiatry, 45(8), 699704.

188. ROMANO, JEANINE, et al. "Appropriate statistics for ordinal level data: Should we really be using t-test and Cohen'sd for evaluating group differences on the NSSE and other surveys." annual meeting of the Florida Association of Institutional Research. 2006.

189. ROSS, S. E., GUSKIEWICZ, K. M, GROSS, M. T., YU, I .Balance Measures for Discriminating between Functionally Unstable and Stable Ankles. MEDICINE \& SCIENCE IN SPORTS \& EXERCISE8 Copyright (C) 2009 by the American College of Sports Medicine).

190. RUDOMIN, P. and SCHMIDT, R. F. Presynaptic inhibition in the vertebrate spinal cord revisited. Experimental Brain Research, 129, 1 1-37. 1999.

191. SABBAHI, M., \& DE LUCA, C. J. (1981). Topical anesthesia: Hreflex recovery changes by desensitization of the skin. Electroencephalography and clinical neurophysiology, 52(4), 328-335.

192. SCHIEPPATI M. The Hoffmann reflex: a means of assessing spinal reflex excitability and its descending control in man. Progress in Neurobiology, 1987; 28:345 76.

193. SCHIEPPATI, M., \& NARDONE, A. (1997). Medium-latency stretch reflexes of foot and leg muscles analysed by cooling the lower limb in standing humans. The Journal of physiology, 503(3), 691-698.

194. SCHNEIDER, C., LAVOIE, B. A., \& CAPADAY, C. (2000). On the origin of the soleus $\mathrm{H}$-reflex modulation pattern during human walking and its task-dependent differences. Journal of Neurophysiology, 83(5), 2881-2890.

195. SCHUBERT, M., BECK, S., TAUBE, W., AMTAGE, F., FAIST, M., \& GRUBER, M. (2008). Balance training and ballistic strength training are associated with task-specific corticospinal adaptations. European Journal of Neuroscience, 27(8), 2007-2018.

196. SEFTON, J.M.; YARAR, C.; HICKS-LITTLE, C.A.; BERRY, J.W.; 
CORDOVA, M.L. Six weeks of balance training improves sensorimotor function in individuals with chronic ankle instability. The Journal of orthopaedic and sports physical therapy, 41(2), 81. Feb, 2011.

197. SHAFFER, SCOTT W., \& ANNE L. HARRISON. "Aging of the somatosensory system: a translational perspective." Physical therapy 87.2 (2007): 193-207.

198. SHETH, P., YU, B. LASKOWSKI, R. E., AN, K. Ankle Disk Training Influences Reaction Times of Selected Muscles in a Simulated Ankle Sprain. Journal of Sports Medicine, Vol. 25, No 4, 1997.

199. SILVA, A. S. D., ABDALLA, R. J., FISBERG, M. Incidência de lesões musculoesqueléticas em atletas de elite do basquetebol feminino. Acta Ortopédica Brasileira, 15(1), 43-46, 2007.

200. SINKJ/ER, T., ANDERSEN, J. B., NIELSEN, J. F., \& NIELSEN, J. F. (1996). Impaired stretch reflex and joint torque modulation during spastic gait in multiple sclerosis patients. Journal of neurology, 243(8), 566-574.

201. SMITH, A. C., RYMER, W. Z., \& KNIKOU, M. (2015). Locomotor training modifies soleus monosynaptic motoneuron responses in human spinal cord injury. Experimental brain research, 233(1), 89-103.

202. STEIN RB. Presynaptic inhibition in humans. Prog Neurobiol 1995;47:533-44.

203. SOLOPOVA, I. A., KAZENNIKOV, O. V., DENISKINA, N. B., LEVIK, Y. S., \& IVANENKO, Y. P. (2003). Postural instability enhances motor responses to transcranial magnetic stimulation in humans. Neuroscience letters, 337(1), 25-28.

204. SÖDERMAN, K., WERNER, S., PIETILÄ, T., ENGSTRÖM, B., \& ALFREDSON, H. (2000). Balance board training: prevention of traumatic injuries of the lower extremities in female soccer players?. Knee surgery, sports traumatology, arthroscopy,8(6), 356363.

205. SOWELL, ELIZABETH R., et al. "Improved memory functioning and frontal lobe maturation between childhood and adolescence: a 
structural MRI study."Journal of the International Neuropsychological Society 7.03 (2001): 312-322.

206. SUDA, E. Y., COELHO, A. T. Instrumentos de avaliação para limitações funcionais associadas à instabilidade crônica de tornozelo: uma revisão sistemática da literatura. Fisioter. Pesqui.,v.19,n.1,p.7985,2012 .

207. TAUBE, J.,S, MULLER, R.,U., RANCK, J.,B., JR.,. Headdirection cells recorded from the postsubiculum in freely moving rats. I. Description and quantitative analysis. J Neurosci. 10: 420-435, 1990 208. TAUBE, W., GRUBER, M., BECK, S., FAIST, M., GOLLHOFER, A. \& SCHUBERT, M. 2007A. Cortical and spinal adaptations induced by balance training: correlation between stance stability and corticospinal activation. Acta Physiol (Oxf)189, 347-358.

209. TAUBE, W.; KULLMANN, N.; LEUKEL, C.; KURZ, O.; AMTAGE,

F.; GOLLHOFER, A. Differential reflex adaptations following sensorimotor and strength training in young elite athletes. International journal of sports medicine, 28(12), 999-1005. 2007.

210. TAUBE, WOLFGANG, MARKUS GRUBER \& ALBERT GOLLHOFER. "Spinal and supraspinal adaptations associated with balance training and their functional relevance." Acta Physiologica 193.2 (2008): 101-116.

211. TOKUDA, T., TAKO, K., HAYASHI, R., \& YANAGISAWA, N. (1991). Disturbed modulation of the stretch reflex gain during standing in cerebellar ataxia.Electroencephalography and Clinical Neurophysiology/Evoked Potentials Section, 81(6), 421-426.

212. TOKUNO, C.D., CARPENTER, M.G., THORSTENSSON, A., GARLAND, S.J. \& CRESSWELL, A.G. 2007. Control of the triceps surae during the postural sway of quiet standing. Acta Physiol (Oxfj 191, 229-236.

213. TRIMBLE, M. H. (1998). Postural modulation of the segmental reflex: effect of body tilt and postural sway. International journal of neuroscience, 95(1-2), 85-100.

214. TRIMBLE, M.H. \& KOCEJA, D.M. 1998. Modulation of the triceps surae H-reflex with training. Int J Neurosci 76, 293- 303. 
215. TRIMBLE, M.H. \& KOCEJA, D.M. 2001. Effect of a reduced base of support in standing and balance training on the soleus $\mathrm{H}$ reflex. Int J Neurosci 106, 1-20.

216. TUCKER, K. J., \& TÜRKER, K. S. (2004). Muscle spindle feedback differs between the soleus and gastrocnemius in humans. Somatosensory \& motor research,21(3-4), 189-197.

217. TUCKER, K. J., TUNCER, M., \& TÜRKER, K. S. (2005). A review of the H-reflex and $\mathrm{M}$-wave in the human triceps surae. Human movement science, 24(5), 667-688.

218. VEALE, J. L. (1978). Renshaw cell activity in the human spinal cord. Studies in neurophysiology, 211-223.

219. VERHAGEN, E., BEEK, A., TWISK, J., BOUTER, L., BAHR, R., MECHELEN, W. The effect of a proprioceptive balance boardtraining program for the prevention of ankle sprains. The American Journal of Sports Medicine. Vol. 32, n. 6, 2004.

220. VILA-CHÃ, C.; FALLA, D.; CORREIA, M.V.; FARINA, D. Changes in $\mathrm{H}$ reflex and $\mathrm{V}$ wave following short-term endurance and strength training. Journal of Applied Physiology, 112(1), 54-63. 2012.

221. VOIGT, MICHAEL, FABIO CHELLI \& CARLO FRIGO. "Changes in the excitability of soleus muscle short latency stretch reflexes during human hopping after 4 weeks of hopping training." European journal of applied physiology and occupational physiology 78.6 (1998): 522-532.

222. VOSS, V. H. (1971). Tabelle der absoluten und relativen Muskelspindelzahlen der menschlichen Skelettmuskulatur. Anat Anz, 129(5), 562-572.

223. WANG, H. K., CHEN, C. H., SHIANG, T. Y., JAN, M. H., \& LIN, K. H. (2006). Risk-factor analysis of high school basketball-player ankle injuries: a prospective controlled cohort study evaluating postural sway, ankle strength, and flexibility.Archives of physical medicine and rehabilitation, 87(6), 821-825.

224. WILlEMS, T.,M., WITVROUW, E., DELBAERE, K., MAHIEU, N., DE BOURDEAUDHUIJ, I., DE CLERCQ, D,. Intrinsic risk factors for inversion ankle sprains in male subjects: a prospective study. $A m J$ 
Sports Med. Mar; 33(3):415-23, 2005.

225. WINDHORST, U. (1996). On the role of recurrent inhibitory feedback in motor control. Progress in neurobiology, 49(6), 517-587.

226. WOLPAW, J. R., \& O'KEEFE, J. A. (1984). Adaptive plasticity in the primate spinal stretch reflex: evidence for a two-phase process. The Journal of neuroscience,4(11), 2718-2724.

227. WOLPAW, J. R., \& LEE, C. L. (1989). Memory traces in primate spinal cord produced by operant conditioning of H-reflex. Journal of neurophysiology, 61(3), 563-572.

228. WOLPAW, J. R., \& TENNISSEN, A. M. (2001). Activitydependent spinal cord plasticity in health and disease. Annual review of neuroscience, 24(1), 807-843.

229. YAGGIE, A. \& CAMPBELL, B.M. 2006. Effects of balance training on selected skills. J Strength Cond Res 20, 422- 428.

230. YANG, J. F., \& WHELAN, P. J. (1993). Neural mechanisms that contribute to cyclical modulation of the soleus $\mathrm{H}$-reflex in walking in humans. Experimental brain research, 95(3), 547-556.

231. YUE, G., \& COLE, K. J. (1992). Strength increases from the motor program: comparison of training with maximal voluntary and imagined muscle contractions. Journal of neurophysiology, 67(5), 1114-1123.

232. ZHANG, SHUQI, BRAD MANOR, AND LI LI. "H-index is important for postural control for people with impaired foot sole sensation." PloS one 10.3 (2015): e0121847.

233. ZECH, A.; HÜBSCHER, M.; VOGT, L.; BANZER, W.; HÄNSEL, F.; PFEIFER, K. Balance Training for Neuromuscular Control and Performance Enhancement: A Systematic Review. Journal of Athletic Training. Vol. 45. Núm. 4.. p.392-403, 2010.

234. ZEHR, E.P. 2002. Considerations for use of the Hoffmann reflex in exercise studies. Eur J Appl Physiol86, 455-468.

235. ZEHR, E. PAUL, \& RICHARD B. STEIN. "Interaction of the Jendrassik maneuver with segmental presynaptic inhibition." Experimental brain research 124.4 (1999): 474-480. 
236. ZEHR, E. PAUL. "Training-induced adaptive plasticity in human somatosensory reflex pathways." Journal of applied physiology 101.6 (2006): 1783-1794.

237. ZEHR, E.P.; KLIMSTRA, M.; DRAGERT, K.; BARZI, Y.; BOWDEN, M.G.; JAVAN, B.; PHADKE. Enhancement of arm and leg locomotor coupling with augmented cutaneous feedback from the hand. Journal of Neurophysiology, 98: 1810-1814. 2007. 


\section{ANEXOS}

Anexo I - Termo de Assentimento Livre e Esclaredido

\section{Termo de Assentimento Livre e Esclarecido - TALE}

Você está sendo convidado (a) a participar de uma pesquisa com 0 título "Análise dos efeitos de um programa de treinamento neuromuscular sobre o equilíbrio postural e sobre a excitabilidade de reflexos de escolares praticantes e não praticantes de basquetebol" para estudar o controle dos movimentos. O responsável pela pesquisa é o Professor Rinaldo André Mezzarane. Esta pesquisa é importante, pois irá ajudar a evitar lesões durante o jogo de basquete.

Pesquisa é um conjunto de testes que serão feitos em você, se você concordar em participar. Assentimento significa que você concorda em fazer parte de um grupo de estudantes, da sua faixa de idade, para participar da pesquisa.

Por favor, peça a algum membro da equipe para explicar qualquer palavra ou informação que você não entenda. Você poderá fazer qualquer pergunta antes do início e durante os testes.

Se você concordar em participar, o pesquisador pedirá para você preencher um questionário e ficar em pé sobre um quadrado de metal localizado no chão. Você também fará movimentos de bandeja e rebote do basquete, mas sem bola. Depois você irá sentar em uma cadeira e um estímulo elétrico bem fraco será aplicado na parte de trás ou do lado do joelho com um disco de metal. O estímulo não dói, apenas dá uma sensação de coceira ou beliscão fraco. Em seguida, um estímulo mecânico fraco (leve batida) será aplicado logo acima do calcanhar com um aparelho. O estímulo mecânico também não dói. Se você se sentir incomodado ou com dor, avise o pesquisador ou qualquer pessoa da equipe. Os testes em que você vai participar têm três horas de duração no total, e serão realizados na Faculdade de Educação Física da UnB.

Quando terminar os testes, você irá participar de um treinamento de equilíbrio em sua escola durante oito semanas, junto com o treino de basquete. Existe risco de queda durante os treinos, mas o professor de 
Educação Física sempre estará por perto orientando os exercícios para que não ocorram quedas. Após os treinos, você irá voltar para a Faculdade e vai repetir os testes. Você poderá desistir de participar dos testes quando quiser, sem precisar explicar a razão.

Você não vai receber dinheiro para participar nos testes.

Os resultados obtidos dos testes serão publicados em revistas científicas, mas o seu nome não será divulgado.

Nome do Responsável:

Nome do Participante:

Pesquisador: Rinaldo André Mezzarane

Brasília, de de 


\section{Anexo II - TERMO DE CONSENTIMENTO E LIVRE ESCLARECIMENTO}

(TCLE)

\section{Termo de Consentimento Livre e Esclarecido - TCLE}

O (a) seu (sua) filho (a) está sendo convidado (a) a participar do projeto "Análise dos efeitos de um programa de treinamento neuromuscular sobre o equilíbrio postural e sobre a excitabilidade de reflexos de escolares praticantes e não praticantes de basquetebol" sob a responsabilidade do pesquisador Prof. Dr. Rinaldo André Mezzarane. O projeto consiste em realizar medidas reflexas e de oscilação postural antes e após um treinamento de equilíbrio (ou treinamento neuromuscular).

O objetivo da pesquisa é aprofundar o conhecimento do controle dos movimentos relacionados ao esporte e ajudar a evitar lesões decorrentes da prática esportiva. O treinamento de equilíbrio poderá resultar em uma melhora no controle dos movimentos com vistas à prevenção de lesões.

Todos os esclarecimentos necessários serão prestados antes e no decorrer da pesquisa e thes asseguramos que a identidade de seu(sua) filho(a) será mantida no mais rigoroso sigilo.

A participação se dará por meio do preenchimento de um questionário, análise do equilíbrio postural em pé sobre uma plataforma de força, e realização de testes de salto e aterrissagem simulando bandeja e rebote do basquete. Serão aplicados estímulos elétricos de baixa intensidade próximos ao joelho por meio de eletrodos. Estes eletrodos serão fixados na perna por meio de uma fita antialérgica. Um estímulo mecânico de baixa intensidade será aplicado no tendão de Aquiles por meio de um aparelho. Nenhum dos testes provoca desconforto ou dor e seu(sua) filho(a), que estará sendo monitorado(a) pelo pesquisador, deverá relatar em qualquer momento eventuais dores ou qualquer tipo de desconforto, podendo desistir do experimento se assim o desejar. As medidas e as intervenções são extremamente seguras. Existe risco mínimo associado a possíveis quedas durante o treinamento, contudo os participantes estarão realizando atividades supervisionadas por um professor de Educação Física que aplicará 
atividades orientadas, minimizando os riscos. Os experimentos serão realizados no Laboratório de Processamento de Sinais Biológicos e Controle Motor da Faculdade de Educação Física da UnB. O tempo estimado para a realização de todas as etapas do experimento será de aproximadamente três horas. Após os testes inicias o (a) seu(sua) filho(a) participará de um regime de treinamento de equilíbrio por oito semanas. Esses treinos serão realizados na escola de seu (sua) filho (a). Após as oito semanas o mesmo procedimento da primeira visita será repetido. As visitas serão agendadas de acordo com a disponibilidade.

O (A) Senhor (a), ou o (a) seu(sua) filho(a), podem se recusar a participar de qualquer procedimento ou responder qualquer questão que lhes tragam constrangimento, podendo desistir de participar da pesquisa em qualquer momento sem nenhum prejuízo para o(a) Senhor(a) ou para o(a) seu(sua) filho(a) e sem a necessidade de prover explicações adicionais. A participação de seu (sua) filho (a) é voluntária, isto é, não há pagamento por sua colaboração. Despesas relacionadas diretamente ao transporte para o laboratório serão cobertas pelo pesquisador responsável. Caso haja algum dano direto resultante dos procedimentos de pesquisa, o(a) Senhor(a) poderá ser indenizado(a), obedecendo-se as disposições legais vigentes no Brasil.

Os resultados da pesquisa serão divulgados na Faculdade de Educação Física da Universidade de Brasília podendo ser publicados posteriormente. Os dados e materiais utilizados na pesquisa ficarão sob a guarda do pesquisador por um período de no mínimo cinco anos, após isso serão destruídos ou mantidos na instituição.

Se o (a) Senhor (a) tiver qualquer dúvida adicional em relação à pesquisa, por favor telefone para: Prof. Dr. Rinaldo André Mezzarane ou Prof. Dr. Tiago Guedes Russomanno no telefone (61) 3107-2526, da Faculdade de Educação Física da Universidade de Brasília, no horário comercial. Este projeto foi aprovado pelo Comitê de Ética em Pesquisa da Faculdade de Ciências da Saúde da Universidade de Brasília. As dúvidas com relação à assinatura do TCLE ou os direitos do sujeito da pesquisa podem ser esclarecidas pelo telefone: (61) 3107-1947 ou do e-mail cepfs@unb.br, horário de atendimento de $10 \mathrm{hs}$ às $12 \mathrm{hs}$ e de $14 \mathrm{hs}$ às $17 \mathrm{hs}$, de segunda a 
sexta-feira. Este documento foi elaborado em duas vias, uma ficará com o pesquisador responsável e a outra com o sujeito da pesquisa.

Nome do Responsável:

Pesquisador: Rinaldo André Mezzarane

Brasília, de de 


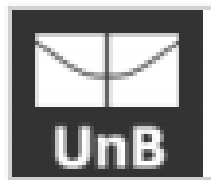

\section{FACULDADE DE CIÊNCIAS DA SAÜDE DA UNIVERSIDADE DE BRASILIA - CEP/FS-UNB}

\section{PARECER CONSUBSTANCIADO DO CEP}

\section{DADOS DO PROJETO DE PESQUISA}

Thtulo da Pesquiba: Antlise dos efeños de um programa de treinamento proprioceptivo sobre o equiltorio postural e sobre a encitabilidade de reflewes de escolares praticantes e niso praticantes de basquetebol

Pesquisader: Fonaldo Andre Mezzarane

Área Tematica:

Versalo: 2

CAAE: 339396149.0000 .0030

Instituigăo Propenente: Faculdade de Educaça Fisica - UnB

Patrocinadee Princlpal: MNISTERIO DA CIENCIA, TECNOLOCIA E BONACAO

\section{DADOS DO PARECER}

Númwe do Parseer: 788.170

Data da Relatoria: 10ro92014

Apressutaçăo do Projoto:

Exercicies proprioceptives podem evifar ou reduzir os eleitos de kesbes, como entorse por inversấo no ternousto, per meio de mehora no controk do equilibrio e aumento na efídéncia de respestas reflexas. 0 objetivo do presente projeib e avaliar os efeitos de um programa de enercicios propribceptivos no equilibrio poatural e na excitibilidade de reflewoa de escolares praficartes e nio praficantes de basquetebol. Este esbudo tem vinculo com dois projetos de mestrado. Para o estudo, a amostra sera composta de aproximadamente 60 (sessenta) escolares, de ambos os sexos, com idades entre 12 e 17 anos, dos quais 40 (quarenta) sto praticantes de basquetebel ha pelo menos um ano e 20 (vinte) naso praticantes de basquetebol. A amestra sera dinidida em tres grupos contendo 20 individuos cada, Grupo Contrele (GC) e Crupo Experimental (CE) (para es praticantes de basquetebel), e grupo de nafo praticantes (CNP). O GC e 0 GE realizarto a redina normal de treinamento, mas apenas o GE realoard a rotina junbo com os exercicios do programa de treinamento proprioceptivo. Os escolares realizarlo ea exercicios em um dia de treino normal logo apos o aquecimento inicial. Os escolares naso praticantes (ONC) nato faräo exercicioa propriocepfives. O equilbrio poshural sera avaliado por meio de uma plafaforma de força e a excitabilidade de reflexos dos extensores do tornozelo (músculo soleus - sO) sera avaliada por meio de medidas de reflexo $\mathrm{H}$ e reflexo T. Todos os participantes realzarto a

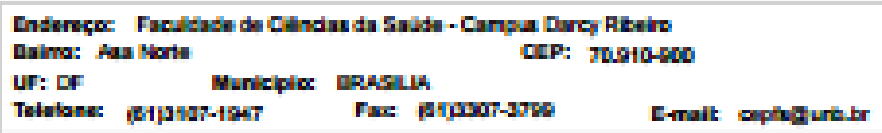




FACULDADE DE CIÊNCIAS DA
SAUUDE DA UNIVERSIDADE DE
BnB

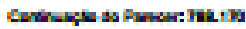

mesma scja notificada da aprovaçiso e do acomearhamento do projeto de pesquisa.

Conclusçes ou Pendlincias e Lista de Inadequaçōes:

Considerando a andise do presente projeto solicitase ao pesquisador o que se segue:

1 - Por tratar-se de estudo realizado com participantes da rode escolar do Distribo Federal, devertso os pesquiadores incluirem aquela Insthukgaso como co-participante do projeto e incluir o Termo de anukndia de insituiçato co-participante, bem como, do Diretor da Escola de Taguatinga onde sertso seiecionados os participantes do projeto. PENDENCIA ATENDIOA

Naso ha pendencias.

Protocolb en conformidade com a Resoluça 4682012 e comelementares.

Situaçlo do Parecor:

Aprovado

Nocessita Apreclaçalo da CONEP:

Naso

Consideraçedes Finais a critrio do CEP:

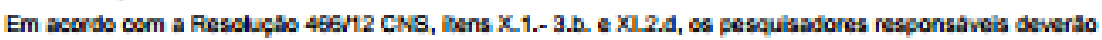
acresentar relatorios parcial semestral e final do projeto de pesquisa, contados a partir da data de acrovaçấo do protocolo de pesquisa.

BRASLIA, 11 de Seiembro de 2014

Assinade per:

Marie Togasshi

(Coordonader) 
Anexo IV - Questionário de Caracterização da Amostra

\section{QUESTIONÁRIO DE CARACTERIZACCÃO}

\section{ANAMNESE}

Nome:

Idade:

Data

de

Nascimento:

Endereço:

CEP:

Telefones:

Escolaridade:

Nome

dos

responsáveis:

\section{CARACTERÍSTICAS FÍSICAS}

Massa Corporal:

Kg Estatura: $\mathrm{m}$

Membro Dominante:

Posição em Quadra: (1) Armador (2) Ala Armador (3) Ala (4) Ala Pivô (5) Pivô

Realiza alguma outra atividade física orientada ou não além do basquetebol?

$$
\text { ( ) } \operatorname{Sim} \quad(\text { ) Não }
$$


Qual?:

Frequência semanal (horas):

\section{HISTÓRICO DO ATLETA}

Tempo

de

treinamento

(em

meses):

Frequência semanal atual (horas):

Tem algum conhecimento sobre Treinos Neuromusculares?

$$
\text { ( ) Sim ( ) Não }
$$

\section{HISTÓRICO DE LESÕES:}

Já realizou alguma cirurgia em membros inferiores. ( ) SIM ( ) NÃO

Qual?:

Nos últimos 6 meses sofreu alguma lesão de membros inferiores?

$$
\text { ( ) SIM ( ) NÃO }
$$

Qual?:

Essa lesão ocorreu: Em treino ( ) Em jogo ( ) Fora de Quadra ( )

Foi necessário afastamento das atividades relacionadas ao basquete por conta da lesão?
Por
) $\operatorname{SIM}(\quad$ ) NÃO.
quanto
tempo?:

Realizou tratamento fisioterapêutico para essa lesão? 


$$
\text { ( ) SIM ( ) NÃO }
$$

Usa órtese em treino?

$$
\text { ( ) } \operatorname{SIM}(\text { ) NÃO }
$$

Quais?:

Por

qual

motivo

usa?

Uso de órtese em jogo? ( ) SIM ( ) NÃO

Quais?:

Por

qual

motivo

usa? 
QUESTIONARIO DE AVALIAÇÃO FUNCIONAL DO TORNOZELO (AJFAT)

Nome:

1. Como você descreveria o nível de dor que você sente em seu tornozelo?

(0) muito maior em um do que no outro tornozelo

(1) um pouco maior em um do que no outro tornozelo

(2) não sinto dor nos tornozelos

(3) ligeiramente menor em um do que no outro tornozelo

(4) muito menor em um do que no outro tornozelo

2. Como você descreveria qualquer inchaço do tornozelo?

(0) muito maior em um do que no outro tornozelo

(1) um pouco maior em um do que no outro tornozelo

(2) não possuo inchaço nos tornozelos

(3) ligeiramente menor em um do que no outro tornozelo

(4) muito menor em um do que no outro tornozelo

3. Como você descreveria a capacidade de seu tornozelo ao andar em superfícies irregulares?

(0) muito maior em um do que no outro tornozelo

(1) um pouco maior em um do que no outro tornozelo

(2) igual nos dois tornozelos

(3) ligeiramente menor em um do que no outro tornozelo

(4) muito menor em um do que no outro tornozelo

4. Como você descreveria a sensação geral de estabilidade de seu tornozelo?

(0) muito menos estável em um do que no outro tornozelo 
(1) um pouco menos estável em um do que no outro tornozelo

(2) estabilidade igual nos dois tornozelos

(3) um pouco mais estável em um do que no outro tornozelo

(4) muito mais estável em um do que no outro tornozelo

5. Como você descreveria a sensação geral de força de seu tornozelo?

(0) muito menos forte em um do que no outro tornozelo

(1) um pouco menos forte em um do que no outro tornozelo

(2) igual em força entre os tornozelos

(3) ligeiramente mais forte em um do que no outro tornozelo

(4) muito mais forte em um do que no outro tornozelo

6. Como você descreveria sua capacidade nos tornozelos quando você desce escadas?

(0) muito menor em um do que no outro tornozelo

(1) ligeiramente menor em um do que no outro tornozelo

(2) igual entre os tornozelos

(3) um pouco maior em um do que no outro tornozelo

(4) muito maior em um do que no outro tornozelo

7. Como você descreveria sua capacidade nos tornozelos quando você corre?

(0) muito menor em um do que no outro tornozelo

(1) ligeiramente menor em um do que no outro tornozelo

(2) igual entre os tornozelo

(3) um pouco maior em um do que no outro tornozelo

(4) muito maior em um do que no outro tornozelo

8. Como você descreve a capacidade dos seus tornozelos para "cortar", ou mudar de direção quando você está correndo?

(0) muito menor em um do que no outro tornozelo

(1) ligeiramente menor em um do que no outro tornozelo

(2) igual entre os tornozelo 
(3) um pouco maior em um do que no outro tornozelo

(4) muito maior em um do que no outro tornozelo

9. Como você descreveria o nível global de atividade de seu tornozelo?

(0) muito menor em um do que no outro tornozelo

(1) ligeiramente menor em um do que no outro tornozelo

(2) igual entre os tornozelo

(3) um pouco maior em um do que no outro tornozelo

(4) muito maior em um do que no outro tornozelo

10. Qual situação melhor descreve sua capacidade de sentir o tornozelo começando a "pisar em falso"?

(0) muito mais tarde do que o outro tornozelo

(1) um pouco mais tarde do que o outro tornozelo

(2) ao mesmo tempo como no outro tornozelo

(3) um pouco mais cedo do que o outro tornozelo

(4) muito mais cedo do que o outro tornozelo

11. Comparando os tornozelos, qual situação melhor descreve a sua capacidade de respota do seu tornozelo quando "pisa em falso"?

(0) muito mais tarde do que o outro tornozelo

(1) um pouco mais tarde do que o outro tornozelo

(2) ao mesmo tempo nos dois tornozelos

(3) um pouco mais cedo do que o outro tornozelo

(4) muito mais cedo do que o outro tornozelo

12. Na sequência de um incidente (torcer, "pisar em falso", cair, tropeçar), qual situação melhor descreve o tempo necessário para voltar à atividade?

(0) mais de 2 dias

(1) 1 a 2 dias

(2) mais de 1 hora e menos de 1 dia

(3) 15 minutos a 1 hora 
(4) quase imediatamente 


$$
\text { Anexo VI - IPAQ VERSÃO CURTA }
$$

QUESTIONARIO INTERNACIONAL DE ATIVIDADE FISICA - IPAQ

(Versão Curta)

Nome:

Você trabalha de forma remunerada: ( ) Sim ( ) Não

Quantas horas você trabalha por dia:

Quantos anos completos você estudou:

De forma geral sua saúde está:

( ) Excelente ( ) Muito boa ( ) Boa

Para responder as questões lembre que:

- atividades físicas VIGOROSAS são aquelas que precisam de um grande esforço físico e que fazem respirar MUITO mais forte que o normal;

- atividades físicas MODERADAS são aquelas que precisam de algum esforço físico e que fazem respirar UM POUCO mais forte que o normal;

Para responder as perguntas pense somente nas atividades que você realiza por pelo menos 10 minutos contínuos de cada vez:

1a. Em quantos dias de uma semana normal, você realiza atividades VIGOROSAS por pelo menos 10 minutos contínuos, como por exemplo correr, fazer ginastica aeróbica, jogar futebol, pedalar rápido na bicicleta, jogar basquete, fazer serviços domésticos pesados em casa, no quintal ou no jardim, carregar pesos elevados ou qualquer atividade que faça você suar BASTANTE ou aumentem MUITO sua respiração ou batimentos do coração?

dias: por SEMANA ( ) Nenhum 
1b. Nos dias em que você faz essas atividades vigorosas por pelo menos 10 minutos contínuos, quanta tempo no total você gasta fazendo essas atividades por dia?

horas: Minutos:

2a. Em quantos dias de uma semana normal, você realiza atividades MODERADAS por pelo menos 10 minutos contínuos, como por exemplo, pedalar leve na bicicleta, nadar, dançar, fazer ginástica aeróbica leve, jogar vôlei recreativo, carregar pesos leves, fazer serviços domésticos na casa, no quintal ou no jardim como varrer, aspirar, cuidar do jardim, ou qualquer atividade que faça você suar leve ou aumentem moderadamente sua respiração ou batimentos do coração (POR FAVOR NAO INCLUA CAMINHADA)

horas: Minutos:

2b. Nos dias em que você faz essas atividades moderadas por pelo menos 10 minutos contínuos quanta tempo no total você gasta fazendo essas atividades por dia?

horas: Minutos:

3a. Em quantos dias de uma semana normal você caminha por pelo menos 10 minutos contínuos em casa ou no trabalho, como forma de transporte para ir de um lugar para outro, por lazer, por prazer ou como forma de exercício?

dias: por SEMANA ( ) Nenhum

3b. Nos dias em que você caminha por pelo menos 10 minutos contínuos quanta tempo no total você gasta caminhando por dia? 
horas: Minutos:

4a. Estas ultimas perguntas são em relação ao tempo que você gasta sentado ao todo no trabalho, em casa, na escola ou faculdade e durante o tempo livre. Isto inclui o tempo que você gasta sentado no escritório ou estudando, fazendo lição de casa, visitando amigos, lendo e sentado ou deitado assistindo televisão.

Quanto tempo por dia você fica sentado em um dia da semana? Horas: Minutos:

4b. Quanto tempo por dia você fica sentado no final de semana? Horas: Minutos: 
Anexo VII - Questionário adaptado do estudo de Bonetti e Coelho

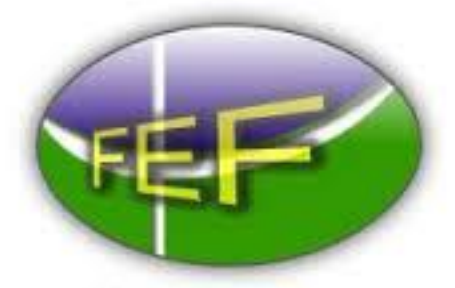

Faculdade de Educaçăo Fisica da Universidade de Brasilia

\section{Universidade de Brasília Faculdade de Educação Física}

Por favor, responda o questionário* abaixo:

1 - Dominância do membro inferior:

( ) Destro

( ) Sinistro

( ) Ambidestro

2 - Tempo de prática do basquetebol:

( ) Menos de um ano

( ) Entre um e dois anos

( ) Entre dois e quatro anos

( ) Entre quatro e cinco anos

( ) Mais de cinco anos

3 - Qual o seu conhecimento sobre treinos neuromusculares:

( ) Nunca ouvi falar

( ) Já ouvi falar, mas nunca pratiquei

( ) Já ouvi falar e já pratiquei

( ) Conheço e pratico regularmente

( ) Outro:

*Questionário adaptado do estudo de Bonetti e Coelho (2004) 